Universidade de São Paulo

Escola de Enfermagem de Ribeirão Preto

Lucilene Cardoso

"Egressos de internação psiquiátrica - um olhar sobre o paciente e seu familiar cuidador". 


\section{"Egressos de internação psiquiátrica - um olhar sobre o paciente e seu familiar cuidador".}

Lucilene Cardoso

Tese (Doutorado) apresentada ao Programa de PósGraduação em Enfermagem Psiquiátrica, Departamento de Enfermagem Psiquiátrica e Ciências Humanas da Escola de Enfermagem de Ribeirão Preto Universidade de São Paulo, para obtenção do grau de Doutora em Enfermagem Psiquiátrica.

Área de concentração (Linha de Pesquisa): Enfermagem Psiquiátrica: o doente, a doença $\mathrm{e}$ as práticas terapêuticas).

Orientadora $\operatorname{Prof}^{\mathrm{a}}$. Dra ${ }^{\mathrm{a}}$. Sueli Aparecida Frari Galera

Ribeirão Preto

2008 
Ficha Catalográfica

Autorizo a reprodução e divulgação total ou parcial deste trabalho, por qualquer meio convencional ou eletrônico para fins de estudo e pesquisa, desde que citada a fonte.

Cardoso, Lucilene.

"EGRESSOS DE INTERNAÇÃO PSIQUIÁTRICA - um olhar sobre o paciente e seu familiar cuidador"/ Lucilene Cardoso; Orientadora Prof ${ }^{a}$. Dr ${ }^{a}$. Sueli Aparecida Frari Galera. - Ribeirão Preto, 2008. 114f.

Tese (doutorado) - Programa de Pós Graduação em Enfermagem Psiquiátrica -- Departamento de Enfermagem Psiquiátrica e Ciências Humanas -- Escola de Enfermagem de Ribeirão Preto da Universidade de São Paulo.

Linha de pesquisa: Enfermagem Psiquiátrica: o doente, a doença e as práticas terapêuticas.

1- Enfermagem; 2- Pacientes psiquiátricos; 3- Familiares cuidadores; 4- Avaliação em enfermagem; 5- Sobrecarga. 
Lucilene Cardoso

\section{"EGRESSOS DE INTERNAÇÃO PSIQUIÁTRICA \\ - um olhar sobre o paciente e seu familiar cuidador".}

Tese (Doutorado) apresentada ao Programa de Pós-Graduação em Enfermagem Psiquiátrica, Departamento de Enfermagem Psiquiátrica e Ciências Humanas da Escola de Enfermagem de Ribeirão Preto - Universidade de São Paulo, para obtenção do grau de Doutora em Enfermagem Psiquiátrica.

Área de concentração (Linha de Pesquisa): Enfermagem Psiquiátrica: o doente, a doença e as práticas terapêuticas).

Orientadora Prof ${ }^{\mathrm{a}}$. Dr ${ }^{\mathrm{a}}$. Sueli Aparecida Frari Galera

Data de aprovação: / maio/ 2008.

\section{Banca examinadora}

Prof $^{a}$. Dr ${ }^{\mathrm{a}}$. Sueli Aparecida Frari Galera

Instituição: Escola de Enfermagem de Ribeirão Preto - Universidade de São Paulo.

Assinatura:

Prof. Dr.

Instituição: Escola de Enfermagem de Ribeirão Preto - Universidade de São Paulo.

Assinatura:

Prof. Dr

Instituição: Escola de Enfermagem de Ribeirão Preto - Universidade de São Paulo.

Assinatura:

Prof $^{a}$. Dr ${ }^{\mathrm{a}}$

Instituição:

Assinatura:

Prof. Dr.

Instituição:

Assinatura: 
Dedico este trabalho à minha Família e àqueles que convivem com o transtorno mental $e$ ainda carecem de uma assistência à saúde de qualidade. 


\section{AGRADECIMENTOS}

À querida orientadora Profa ${ }^{\text {a }}$ Dra . Sueli Aparecida Frari Galera por sua orientação apoio, respeito e amizade, auxiliando meu crescimento como profissional e como pessoa, nessa trajetória de vida.

À William Fernando Prado, meu amor, companheiro e amigo de todas as horas, momentos e conquistas.

À minha família que me apóia desde sempre e que me ensinou a buscar a realização de meus sonhos dedicando amor e respeito ao próximo, todo meu carinho e gratidão.

Aos amigos que tanto me apoiaram e vibraram com minhas conquistas sempre, saudade imensa.

Aos meus professores que tanto colaboraram para meu aprendizado e profissionalização ao dividirem sua experiência e sabedoria.

À todos os pacientes, familiares e cuidadores que colaboraram com esse trabalho e àqueles que não colaboraram nesse, mas muito me ensinam sobre o cuidado em saúde mental e humanidade.

À equipe do Núcleo de Saúde Mental pelo apoio, amizade e respeito compartilhado em minha trajetória acadêmica.

Às amizades conquistadas nesse caminho de vida: Ângela Márcia, Rozani, Maria Luiza, Israel, Marli, Bianca, Carol e todos que torceram por essa realização.

À Coordenação de Aperfeiçoamento de Pessoal de Nível Superior (CAPES) pela concessão da bolsa de doutorado como apoio financeiro aos meus estudos.

Aos professores da banca examinadora desse trabalho, pela disponibilidade em colaborar para meu aperfeiçoamento profissional fornecendo valiosos ensinamentos, relatos de experiências e reflexões. 
"Uma doença é o que todos que tem aquela afecção têm em comum ... enquanto que

o adoecer de cada pessoa é um processo único" ${ }_{(107)}$ 


\section{RESUMO}

CARDOSO, L. Egressos de internação psiquiátrica - um olhar sobre o paciente e seu familiar cuidador. 2008. 114f. TESE (Doutorado) - Escola de Enfermagem de Ribeirão Preto, Universidade de São Paulo, 2008.

Com internações psiquiátricas criteriosas e marcadas por períodos mais curtos de institucionalização, pacientes e familiares se tornaram cada vez mais os principais provedores de cuidados em saúde mental. Nesse contexto a cronicidade dos transtornos mentais leva estas pessoas a conviverem com o processo de internação-reinternação, e suas as atividades cotidianas se organizam em torno das possibilidades de tratamento do transtorno mental. O objetivo deste trabalho foi conhecer quem são os egressos de internação e seus cuidadores em relação à: características sócio-demográficas; adesão do paciente ao tratamento psicofarmacológico, manifestação de sintomas psicopatológicos, ocorrência de reinternação e sobrecarga dos cuidadores. Foram entrevistados 48 pacientes e 21 cuidadores. Verificou-se que os egressos de internação psiquiátrica nessa amostra são em sua maioria mulheres (62,5\%), residem com familiares $(93,8 \%)$, com casa própria $(70,8 \%)$, onde coabitam quatro pessoas $(58,4)$. A renda individual não ultrapassou um salário mínimo para $66,7 \%$ dos pacientes, observando que $54,2 \%$ possuem até o primeiro grau completo de escolaridade e apenas $14,6 \%$ deles exercem algum tipo de trabalho regularmente. A manifestação de sintomas psiquiátricos esteve presente entre os pacientes e mostrou correlação com reinternação e grau de adesão ao tratamento psicofarmacológico. Entre os egressos $70,8 \%$ foram classificados com baixo grau de adesão ao tratamento medicamentoso. O baixo grau de adesão ao tratamento medicamentoso é fator relacionado à sobrecarga familiar, porém não é seu determinante. Sabe-se que pacientes com boa adesão ao tratamento têm menos riscos à ocorrência de recaídas e reinternações, mas não estão livres de suas doenças e de todo fardo que essa acarreta em suas vidas. Todos os cuidadores dessa amostra possuíam parentesco com os pacientes e para esses o cuidado sempre trouxe algum grau de sobrecarga. Intervenções de manutenção ao tratamento, educação, ventilação e alívio de crises podem buscar atender à demanda de cuidado dessas pessoas, não se restringindo a apenas garantir adesão ao tratamento psicofarmacológico, mas também visando identificar e minimizar riscos, trabalhar carências e os conflitos sociais, emocionais e financeiros gerados pela manifestação crônica da doença mental. Pesquisas e intervenções acerca das necessidades dos pacientes egressos de internação e de seus cuidadores são importantes para uma atuação sistematizada dos profissionais inseridos em serviços de saúde mental.

Palavras-chave: Avaliação em enfermagem; Enfermagem psiquiátrica. Internação psiquiátrica; Sobrecarga Familiar; Saúde mental. 


\section{ABSTRACT \\ CARDOSO, L. Outpatients of psychiatric institucionalization - look at patients and family caregivers. 2008. 114f. THESIS - Escola de Enfermagem de Ribeirão Preto, Universidade de São Paulo, 2008.}

With severe psychiatric institutionalizations and shorter periods of institutionalization, familiar and patients had become each time more the main suppliers of cares in mental health. In this context the severity of the mental illness takes these people to coexist the process of restabilization and rehospitalization, and this daily activity if organized around the possibilities of treatment of illness. The objective of this work was to know who is the outpatients of psychiatric institucionalization and this family caregivers in relation to: demographic data characteristics; adherence to pharmacological treatment, psychiatric symptoms manifestation, rehospitalization and family burden. 48 patients and 21 family caregivers participated. The outpatients of psychiatric institucionalization in this sample are in majority women $(62,5 \%)$, inhabit with family $(93,8 \%)$, with proper house $(70,8 \%)$, where four people cohabit $(58,4)$. The individual income did not exceed a minimum wage for $66,7 \%$ of the patients, observing that $54.2 \%$ possess until the first complete degree of scholl and only $14.6 \%$ of them exert some type of work regularly. The manifestation of psychiatric symptoms was present between the patients and showed to correlation with rehospitalization and poor adherence to pharmacological treatment. Between outpatients $70.8 \%$ they had been classified with low degree of adherence to the pharmacological treatment. The low degree of adherence to the pharmacological treatment is factor related to the family burden, however it is not its determinative one. It is known that patient with good adherence to treatment they have little risks to the occurrence of fallen again and rehospitalization, but are not free of its illnesses and all pack that this causes its lives. All family caregivers of this sample have kinship with the patients and for these the care always brought some degree of overload. Interventions of maintenance to the treatment, education, ventilation and relief of crises can search to take care of to the social, emotional and financial demand of care of these people, if not restricting only to guarantee adhesion to the psychopharmacology family caregivers treatment, but also aiming at to identify and to minimize risks, to work lacks and conflicts generated by the chronic manifestation of the insanity. Research and interventions concerning the necessities of outpatients of psychiatric institucionalization and this family caregivers are important for a more efficient performance of the inserted professionals in services of mental health.

Key-words: Nursing assessment; psychiatric nursing; psychiatric institutionalizations; family burden; mental health. 


\begin{tabular}{|c|}
\hline $\begin{array}{l}\text { RESUMEN } \\
\text { CARDOSO, L. Salidas de la internación psiquiátrica - mira en el paciente y su } \\
\text { cuidador familiar. 2008. 114f. TESIS (Doutorado) - Escola de Enfermagem de } \\
\text { Ribeirão Preto, Universidade de São Paulo, 2008. }\end{array}$ \\
\hline 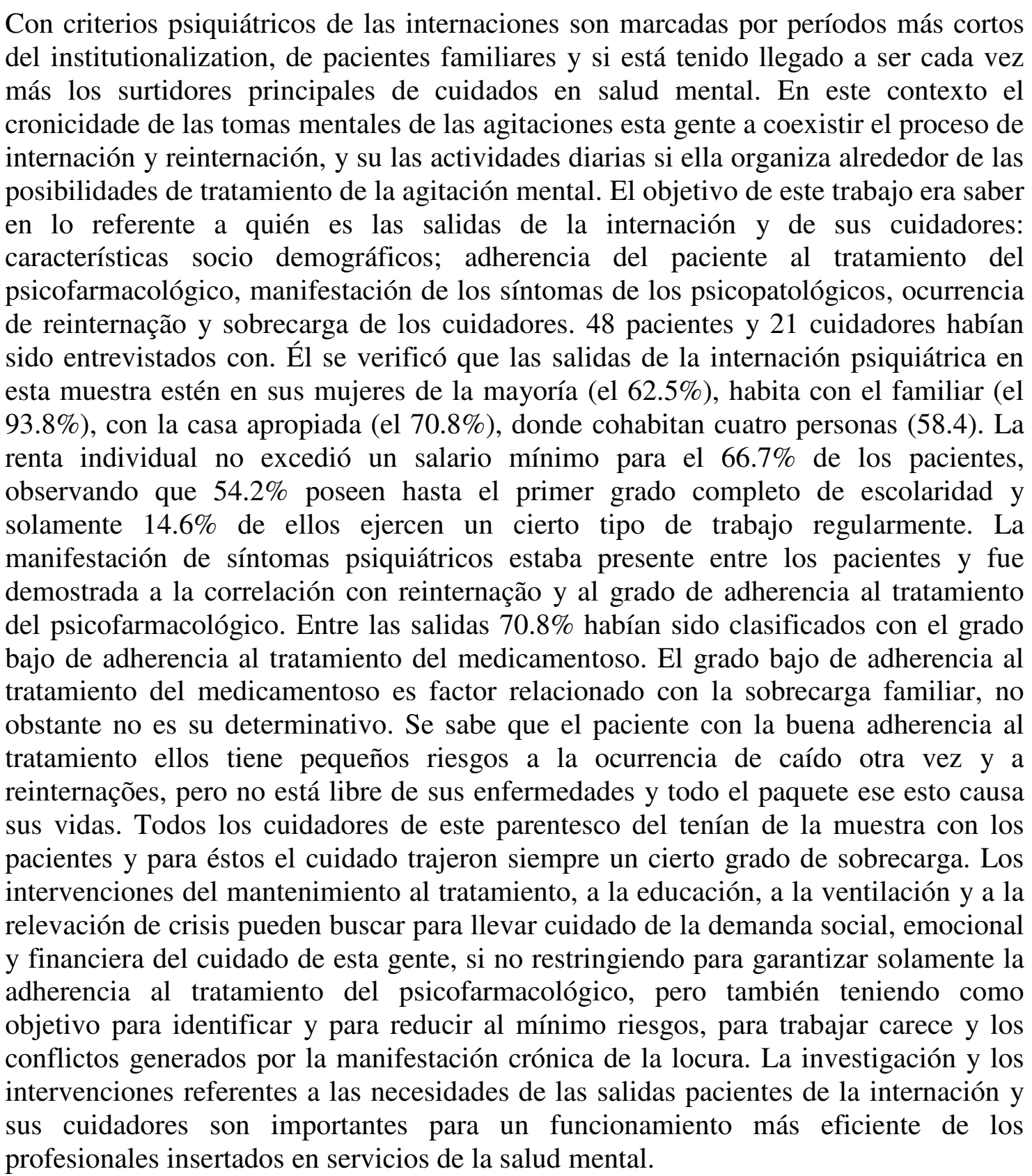 \\
\hline $\begin{array}{l}\text { Descritores: Evaluación en enfermería; Enfermería psiquiátrica; internación } \\
\text { psiquiátrica; sobrecarga de los cuidadores; Salud mental. }\end{array}$ \\
\hline
\end{tabular}


Tabela 1 - Distribuição de freqüência quanto ao sexo e idade de pacientes egressos de internação psiquiátrica.

Tabela 2 - Distribuição de frequiência quanto a características sócio-demográficas e econômicas dos pacientes egressos de internação psiquiátrica recente.

TABELA 3 - Distribuição de freqüência relativa aos diagnósticos principais e comorbidade entre pacientes egressos de internação psiquiátrica recente.

TABELA 4 - Distribuição de freqüência dos pacientes egressos de internação psiquiátrica recente em relação ao diagnostico e tempo de doença.

TABELA 5 - Conhecimento dos pacientes egressos de internação psiquiátrica recente acerca da prescrição psicofarmacológica prescrita.

Tabela 6 - Opinião dos egressos de internação psiquiátrica recente e seus cuidadores quanto à importância do tratamento psicofarmacológico na manutenção de seu tratamento.

Tabela 7 - Características sócio-demográficas e econômicas dos cuidadores de pacientes egressos de internação recente.

Tabela 8 - Distribuição de freqüência quanto às respostas dos pacientes egresso de internação psiquiátrica a BPRS (Brief Psychiatric Rating Scale-BPRS)

Tabela 9 - Distribuição de freqüência quanto ao grau de adesão ao tratamento medicamentoso e tipo de baixa adesão entre pacientes egressos de internação psiquiátrica, referentes à análise com o teste de Morisky e Green.

Tabela 10 - Distribuição da freqüência de pacientes egressos de internação psiquiátrica, referente às questões do teste de Morisky e Green.

Tabela 11 - Descrição do escore médio das subescalas e questões de cálculo da escala FBIS-BR, de acordo com as respostas dos cuidadores de egressos de internação psiquiátrica recente.

Tabela 12 - Distribuição do número de internações anteriores de pacientes egressos de internação recente.

TABELA 13 - Descrição dos comportamentos que determinaram à necessidade de internação dos pacientes egressos de internação psiquiátrica recente.

Tabela 14 - Distribuição de freqüência quanto a características sócio-demográficas, econômicas e clínicas dos pacientes egressos de internação recente que necessitaram de reinternação.

Tabela 15 - Distribuição do Coeficiente de correlação de Spearman em relação às variáveis reinternação psiquiátrica, ter um cuidador, grau de adesão ao tratamento, Teste de Morisky e Green e sobrecarga familiar e os dezoito itens da BPRS (Brief Psychiatric Rating Scale-BPRS).

Tabela 16 - Distribuição de freqüências dos pacientes egressos de internação psiquiátrica em relação a possuir um cuidador e a manifestação de retraimento emocional.

Tabela 17 - Distribuição de freqüência dos pacientes em relação ao grau de adesão ao tratamento e a manifestação dos sintomas doze e treze da BPRS (Brief Psychiatric Rating Scale-BPRS).

Tabela 18 - Distribuição de frequiência dos pacientes em relação às respostas a as perguntas 1,2 e 3 do Teste de adesão de Morisky e Green e ao item quatro da escala BPRS (Brief Psychiatric Rating Scale-BPRS) 
Tabela 19 - Distribuição de freqüência dos pacientes em relação as respostas a pergunta 1 do Teste de adesão de Morisky e Green e aos itens dez, doze e quinze da escala BPRS.

Tabela 20 - Distribuição de frequiência dos pacientes em relação às respostas a pergunta 1 do Teste de adesão de Morisky e Green e ao Escore Total da BPRS (Brief Psychiatric Rating Scale-BPRS).

Tabela 21- Distribuição de freqüência dos pacientes em relação as respostas a pergunta 2 do Teste de adesão de Morisky e Green e ao Escore Total da BPRS (Brief Psychiatric Rating Scale).

Tabela 22 - Porcentagens de respostas dos pacientes egressos de internação psiquiátrica recente aos itens que avaliam sintomas psicopatológicos na Escala BPRS (Brief Psychiatric Rating Scale-BPRS).

Tabela 23 - Porcentagens de respostas dos familiares cuidadores às questões que avaliam a sobrecarga objetiva, em cada subescala A, B e D da FBIS-BR.

Tabela 24 - Porcentagens de respostas dos familiares cuidadores às questões que avaliam a sobrecarga subjetiva, em cada subescala A, B e D da FBIS-BR. 


\section{Sumário}

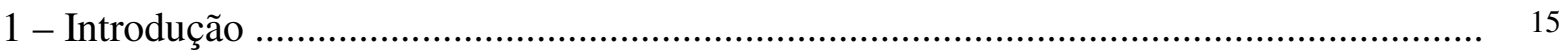

1.1 O papel da família na manutenção do Tratamento e a sobrecarga do cuidador ............. 18

1.2 A manutenção do tratamento e a adesão ................................................................

1.3 Enfermagem psiquiátrica e a manutenção do tratamento ............................................. 24

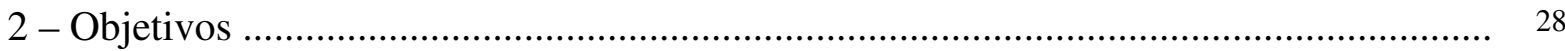

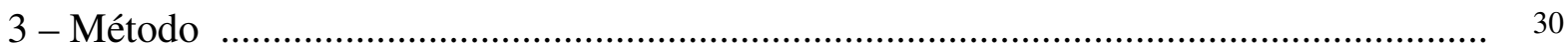

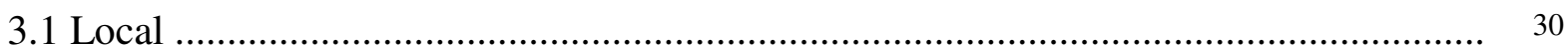

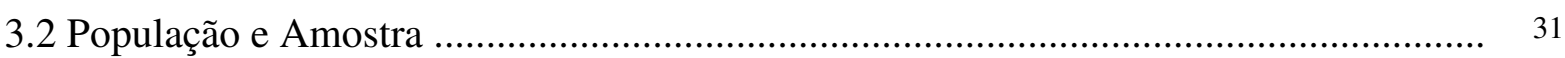

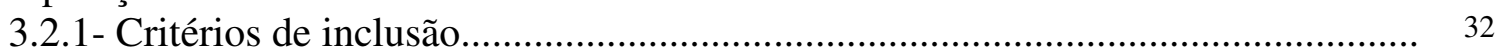

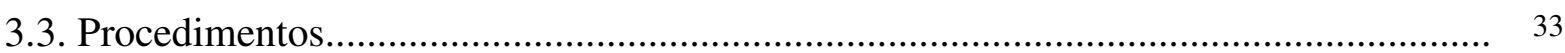

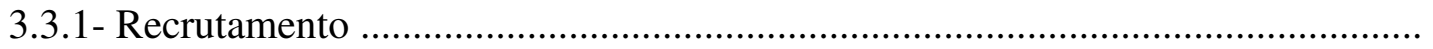

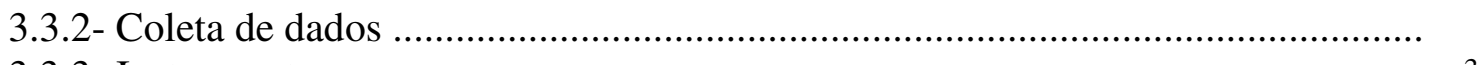

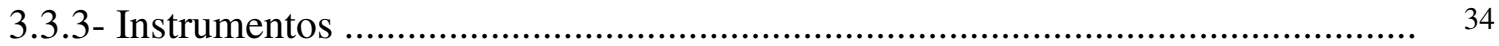

Questionário $\quad 34$

BPRS- Escala Breve de Avaliação Psiquiátrica 35

Teste de Adesão de Morisky e Green 37

FBIS-BR Escala de Sobrecarga dos Familiares de Pacientes Psiquiátricos-Versão Brasileira 39

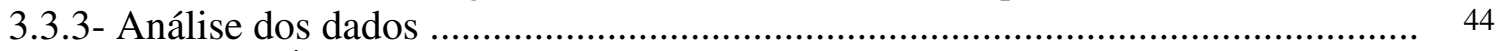

3.3.4- Questões Éticas .............................................................................. 45

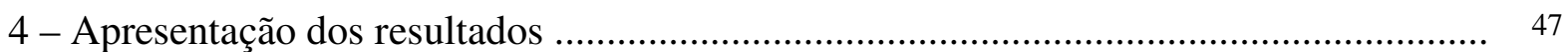

4.1 Pacientes egressos de internação psiquiátrica .......................................................... 48

4.2 Cuidadores dos pacientes egressos de internação psiquiátrica .................................. 54

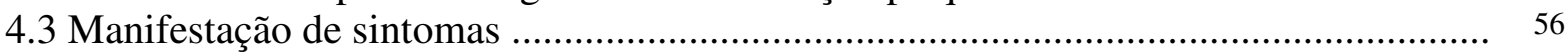

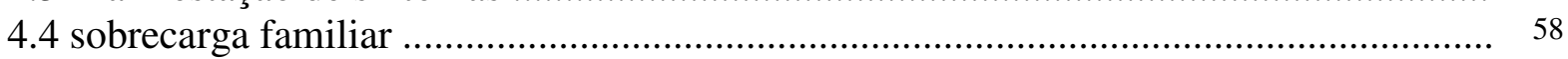

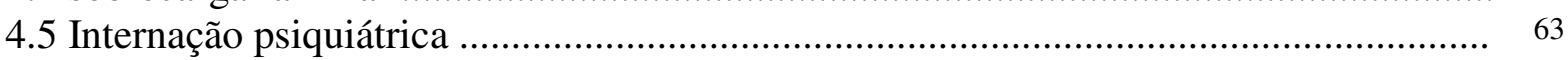

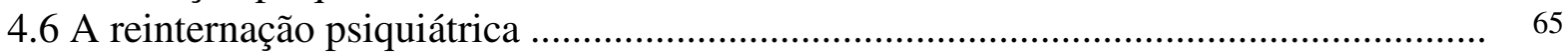

4.7 Os pacientes egressos de internação psiquiátrica e seus cuidadores (adesão ao 67 tratamento, manifestação de sintomas, sobrecarga familiar, ocorrência de reinternação)

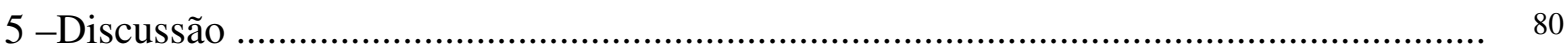

5.1 Adesão do Paciente egresso de internação psiquiátrica

5.2 Os cuidadores dos pacientes egressos de internação psiquiátrica 86

$\begin{array}{ll}5.3 \text { A sobrecarga Familiar - cuidadores } & 88\end{array}$

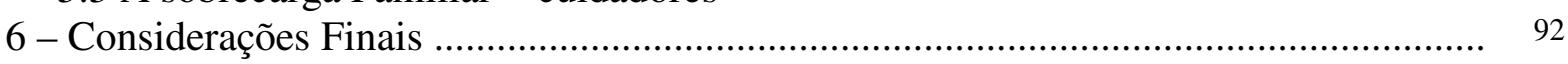

7 - Referências

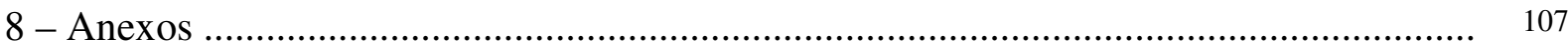


A humanidade, desde os primórdios, tem dificuldade em lidar com as diferenças e com as dissonâncias do senso e convivência comum. Na psiquiatria o tratamento da loucura por vezes foi baseado na intolerância frente aos comportamentos dos doentes mentais tendo no cárcere dos indivíduos uma opção para afugentar o diferente e “proteger” a sociedade ${ }^{(\mathbf{1})}$.

Apesar do entendimento da loucura, como a representação de sintomas de determinadas doenças mentais e da evolução do tratamento psiquiátrico, a busca por suas causas e sua cura ainda é um desafio. $\mathrm{O}$ tratamento psiquiátrico, em sua maioria, ainda é prolongado e marcado por sucessivas internações, principalmente no curso do tratamento dos transtornos mentais graves e persistentes ${ }^{(2)}$.

Segundo estimativas internacionais e do Ministério da Saúde, 3\% da população, ou seja, 5 milhões de pessoas necessitam de cuidados contínuos devido a transtornos mentais graves e persistentes, e mais $9 \%$ precisam de atendimento eventual relacionados a transtornos menos graves, totalizando $12 \%$ da população geral de um país. Portanto no Brasil, esses transtornos afetam 20 milhões de pessoas $^{(\mathbf{3})}$.

Estudos atuais têm adotado a designação de distúrbios graves e persistentes para os transtornos mentais crônicos. Esses distúrbios correspondem a uma variedade de diagnósticos, relativos a doenças determinantes de acentuado comprometimento psíquico, que duram muito tempo ao longo da vida. Estão incluídas nessa classificação as psicoses funcionais (não orgânicas) como: Esquizofrenia, Transtorno esquizotípico, Transtornos delirantes persistentes, Transtorno delirante induzido, Transtornos esquizoafetivos, Episódio maníaco, Transtorno afetivo bipolar, Episódio depressivo grave com sintomas psicóticos e Transtorno depressivo recorrente-episódio atual grave com sintomas psicóticos ${ }^{(\mathbf{4 , 5})}$. 
Estas doenças são consideradas graves, pois causam inúmeros prejuízos nas funções mentais e nas habilidades para atividades de auto cuidado e de relacionamento interpessoal. Prejudicam a qualidade de vida do portador do transtorno e de seus familiares. Ao longo do tempo esses transtornos podem alternar episódios agudos e períodos estáveis e as perdas funcionais podem ser permanentes. Geralmente necessitam de tratamento poli-medicamentoso a longo prazo. Por estas razões estes transtornos também são classificados como persistentes e necessitam de cuidados permanentes desafiando os sistemas de saúde de todo o mundo ${ }^{(\mathbf{4 , 6})}$.

É preconizado que nos momentos de estabilidade dos sintomas estes pacientes sejam incentivados a desenvolver sua cidadania e utilizem os serviços de atendimento extra-hospitalares. Quando em crise estes pacientes são atendidos em prontoatendimentos para avaliação da necessidade ou não de uma internação psiquiátrica ${ }^{(7)}$.

Nas últimas décadas, os hospitais psiquiátricos deixaram de constituir a base do sistema assistencial, cedendo terreno a uma rede de serviços extra-hospitalares de crescente complexidade. No Brasil, como em muitos outros paises, esta rede de serviços está em desenvolvimento e ainda carece da implantação de uma infra-estrutura extrahospitalar mais próxima do cotidiano de seus clientes ${ }^{(\mathbf{8 , 9})}$.

O contexto atual é notadamente marcado por um círculo que se repete nos tratamentos psiquiátricos: os curtos períodos de estabilidade mental dos pacientes são seguidos de internações também curtas, resultantes de sucessivas recaídas ${ }^{(2,10,11)}$. Fenômeno conhecido pelo termo porta giratória.

Sabe-se que em decorrência das recaídas o tempo para recuperação do paciente pode se tornar mais longo e o prognóstico desfavorável ${ }^{(\mathbf{1 2})}$. As conseqüências das recaídas variam desde a ruptura psicossocial, maior utilização de serviços de 
emergência, necessidade de internação, maior número de consultas para o controle clínico e desajustes no ambiente familiar ${ }^{(\mathbf{1 3})}$. Assim a prevenção de recaídas é um dos principais objetivos da assistência psiquiátrica comunitária, principalmente entre o grupo de portadores de transtornos mentais graves e persistentes ${ }^{(3)}$.

Assim, preconiza-se a manutenção do tratamento psiquiátrico na comunidade após a internação psiquiátrica, com a finalidade de promover uma assistência à saúde mais próxima ao cotidiano do paciente e auxiliando na reordenação de suas capacidades psicossociais e suas potencialidades no curso da doença. Como promove a continuidade do tratamento psicofarmacológico e auxilia os demais tratamentos, o tratamento comunitário possibilita também a promoção da reabilitação psicossocial, minimização de riscos e alívio do estresse familiar ${ }^{(\mathbf{1 4})}$.

A finalidade desta pesquisa é dar início à sistematização da manutenção do tratamento psiquiátrico para pacientes egressos de internações psiquiátricas de modo que seja possível ao longo do tempo avaliar o impacto da intervenção na prevenção da recaída de portadores de transtornos graves e persistentes.

A literatura apresenta evidências de que as recaídas estão relacionados à adesão do paciente ao tratamento psicofarmacológico e psicossocial, e às condições sociais e familiares do paciente ${ }^{(\mathbf{1 5}, \mathbf{1 6})}$. 


\subsection{O Papel da família na manutenção do tratamento e a sobrecarga do cuidador.}

A moralização do processo de institucionalizar o doente mental somada ao processo de desinstitucionalização psiquiátrica, tornou a internação psiquiátrica mais criteriosa, com períodos mais curtos de hospitalização. Com isso, a família e cuidadores passaram a ser cada vez mais os principais provedores de cuidados e apoio aos pacientes psiquiátricos $^{(\mathbf{1 7})}$.

Apesar do aspecto positivo da promoção dos laços familiares e sociais, essa responsabilização, muitas vezes, é marcada pela sobrecarga dos cuidadores, devido à falta de orientação e de apoio necessários para o desempenho do papel que esses assumem no dia-a-dia ${ }^{(17-19)}$.

Há inúmeras pesquisas acerca da sobrecarga sentida por familiares e cuidadores frente às doenças crônicas. A presença de um familiar com transtorno mental sempre traz algum grau de sobrecarga a seus familiares e provoca a constante necessidade de adaptações na estrutura familiar ${ }^{(\mathbf{2 0 - 2 2})}$.

Muitas vezes, o cuidado cotidiano envolve uma demanda de atenção do cuidador que limita e prejudica as demais tarefas que ele precisa desempenhar em seu loco social. A demanda de cuidado não se restringe apenas a minimizar riscos e sintomas, envolve também fatores sociais, emocionais e financeiros ${ }^{(23)}$.

Trata-se, portanto de considerar também, na assistência à saúde mental, o papel fundamental do cuidador: familiar ou não, que cuida do doente no exercício de atividades rotineiras como alimentar-se, fazer uso das medicações prescritas, 
movimentar-se, ir às consultas, salvo a realização de técnicas legalmente determinadas como de competência profissional ${ }^{(24)}$.

A família é um núcleo cotidiano de convívio social, rico em perspectivas e necessidades que também precisa ser trabalhada e assistida pelos serviços de saúde mental na promoção à saúde. Devido à natureza crônica da doença mental, a família e em especial o familiar/cuidador é submetido a constantes eventos estressores no curso destas doenças. O que pode afetar além das relações familiares a saúde do próprio familiar/cuidador ${ }^{(20,25)}$.

O papel de cuidador pode fazer as pessoas se sentirem felizes, úteis e privilegiadas por Deus. Porém, pode também fazer com que se sintam tristes por falta de reconhecimento e revoltadas pela situação imposta pela doença. A tensão cotidiana do familiar cuidador emerge, então, do convívio com o sofrimento do outro e da falta de respostas sobre como atuar diante dos comportamentos apresentados na crise $\mathrm{e}^{\mathbf{( 2 6 )}}$.

É função da equipe de saúde incluir o familiar na promoção do cuidado esclarecendo a manifestação da doença, particularidades do tratamento, importância da aliança terapêutica e da adesão ao tratamento, dividindo os encargos da manutenção e minimizando fatores estressores que ela acarreta ${ }^{(27)}$.

A inclusão dos cuidados com o doente mental crônico no cotidiano da família sempre traz algum grau de sobrecarga os familiares ${ }^{(\mathbf{2 0 , 2 2})}$. As maiores dificuldades relatadas por cuidadores são relativas a condições financeiras, sobrecarga física e teimosia do doente ${ }^{(\mathbf{2 8})}$. É de grande importância para a promoção da saúde que a sobrecarga sentida pelos familiares/cuidadores destes pacientes psiquiátricos possa ser identificada e trabalhada. 
Hoenig e Hamilton definiram pela primeira vez o termo sobrecarga familiar como uma experiência de "fardo a carregar" vivenciada por familiares de doentes mentais ${ }^{(29)}$. Essa experiência pode ser descrita por mudanças negativas no cotidiano familiar resultado do adoecimento e curso da doença mental com a implementação de hábitos e responsabilidades que afetam toda a dinâmica familiar. Estas mudanças, muitas vezes, requerem adaptações que podem afetar as necessidades desses familiares, causar acúmulo de responsabilidades e até adiamento de planos pessoais ${ }^{(\mathbf{2 0 , 2 9 )}}$.

A sobrecarga familiar pode ser definida, como sendo o estresse emocional e econômico a que as famílias se submetem, quando um parente recebe alta de um hospital psiquiátrico e retorna ao seu lar, principalmente quando laços familiares foram rompidos pelo padrão de cronicidade, no caso dos pacientes que permanecem por longos períodos em instituições psiquiátricas ${ }^{(30)}$.

A palavra burden, na língua inglesa, é freqüentemente usada para descrever os aspectos negativos associados aos cuidados de indivíduos doentes e equivale aos termos fardo, impacto, sobrecarga e interferência. As conseqüências adversas para as famílias de pessoas portadoras de transtornos mentais têm sido sistematicamente documentadas em estudos sobre sobrecarga familiar ${ }^{(\mathbf{2 9 , 3 1 - 3 4 )}}$ e parecem apontar para o fato de que todas as áreas do funcionamento familiar são afetadas pela presença da doença mental. É importante notar que a sobrecarga familiar é um fenômeno facilmente perceptível e que persiste mesmo quando o paciente responde positivamente a tratamentos inovadores e efetivos.

A sobrecarga familiar possui duas vertentes, a sobrecarga objetiva e a sobrecarga subjetiva. A sobrecarga objetiva está relacionada às conseqüências negativas da presença de um portador de transtorno mental na família, tais como: acúmulo de tarefas, aumento de custos financeiros, limitação das atividades cotidianas, fragilização dos 
relacionamentos entre os familiares, manifestação de comportamentos de risco, entre $\operatorname{outros}^{(\mathbf{2 0 , 3 5 , 3 6 )}}$

A sobrecarga subjetiva diz respeito à percepção pessoal do familiar sobre a experiência de conviver com o doente, seus sentimentos quanto à responsabilidade e preocupações que envolvem o cuidado a saúde desses. Nessa vertente a falta de autonomia do doente mental é vista como um aspecto negativo que gera tensão e preocupação afetando o familiar emocionalmente ${ }^{(36,37)}$. A sobrecarga subjetiva está relacionada a sentimentos de desamparo, tristeza, culpa ${ }^{(17)}$.

Podem ser fatores relacionados a níveis mais elevados de sobrecarga: falta de suporte social, baixo nível de funcionamento dos pacientes, baixa escolaridade dos pacientes e familiares, estratégias ineficientes de enfrentamento ${ }^{(\mathbf{2 5})}$.

A sobrecarga sentida pelos familiares desses pacientes precisa ser identificada e aliviada pela equipe de saúde. A realização de intervenções eficazes junto às famílias dos pacientes psiquiátricos constitui um dos componentes do tratamento comunitário, contribui para a reabilitação psicossocial e auxilia a manutenção do tratamento desses pacientes ${ }^{(17)}$.

As famílias, ao serem consideradas o alicerce do tratamento, têm maior proximidade para monitorar as manifestações da doença e a eficácia da terapêutica. Mais ativos na manutenção deste cuidado, os familiares de doentes mentais convivem negativamente com a imprevisibilidade comportamental do doente e com os custos dessa dedicação. Este contexto os torna mais suscetíveis ao stress, ansiedade, depressão e raiva ${ }^{(38)}$. O que promove grandes variações na emoção expressa e sobrecarga nestas famílias. 
Os comportamentos familiares negativos que podem se desencadear frente a tais variações, são: críticas freqüentes, hostilidade e intrusão. Estes comportamentos podem ser melhor interpretados se considerados uma resposta normal a intensa sobrecarga de se conviver com o doente mental. Mais do que sintomas de uma psicopatologia familiar estes comportamentos podem evidenciar necessidades dessa clientela. A presença de interações familiares carregadas negativamente evidencia a importância de uma relação colaborativa entre os serviços de saúde mental, pacientes e familiares para melhorar manutenção destes tratamentos ${ }^{(39-41)}$.

\subsection{A manutenção do tratamento e a adesão.}

Sabe-se que o cuidado em saúde mental continua em transformação e em constante construção de novas formas de assistência ${ }^{(\mathbf{4 2})}$. Apesar de as políticas nacionais de saúde preconizarem a internação psiquiátrica apenas para casos em que os recursos comunitários foram esgotados, há um grande número de internações entre esses pacientes. O que pode evidenciar a insuficiência dos serviços e rede de apoio na promoção de práticas capazes de promover a reabilitação e a permanência do doente mental no contexto onde ele vive e adoeceu ${ }^{(\mathbf{4 3})}$.

A manutenção do tratamento psiquiátrico comunitário é um elemento fundamental na vida dos doentes mentais crônicos. De modo geral, o tratamento psiquiátrico envolve o tratamento psicofarmacológico e psicossocial com a finalidade de prevenir as recaídas e promover uma melhor qualidade de vida ao doente e seu grupo.

O tratamento psicofarmacológico possibilita controle dos sintomas e melhor manejo assistencial na promoção da saúde mental dessa clientela. Pesquisas recentes 
com pacientes com diagnóstico de esquizofrenia sugerem que o risco de recaída gira em torno de 3.5 a $10 \%$ ao mês, aproximadamente ${ }^{(\mathbf{4 4 , 4 5 )}}$ e indicam a não adesão ao tratamento psicofarmacológico como a principal razão para ocorrência de recaída em pacientes não hospitalizados ${ }^{(\mathbf{4 6 , 4 7 )}}$.

A adesão do paciente ao tratamento medicamentoso prescrito é um comportamento desejável no tratamento das doenças crônicas. No tratamento dos transtornos mentais a não adesão à medicação é observada em cerca de $50 \%$ das pessoas e é responsável por inúmeros $\operatorname{prejuízos~}^{(\mathbf{4 8 , 4 9 )}}$.

A permanência dos sintomas frente a pobre adesão dificulta abordagens terapêuticas, psicossociais, interação entre equipe de saúde e paciente, além de prejudicar a reintegração social do paciente $^{(\mathbf{5 0})}$. Os fatores que podem influenciar a adesão estão relacionados às condições sócio-demográficas, ao esquema terapêutico, à natureza da doença, ao relacionamento paciente-profissionais de saúde, entre outros $(15,16)$

A abordagem psicossocial do tratamento psiquiátrico se caracteriza pela atuação de diversos profissionais e pode ser descrita pelas seguintes atuações: visitas domiciliárias, consulta psicológica, terapia ocupacional, desenvolvimento de habilidades, medicação assistida, programas de reabilitação, psicoterapia individual, educação familiar, grupos de auto-ajuda, acompanhamento terapêutico, entre outros ${ }^{(\mathbf{1 4})}$. O tratamento psicossocial tem por objetivo ajudar pacientes e familiares a lidar com as dificuldades cotidianas e organizar a vida do paciente.

Apesar de inúmeras modalidades terapêuticas disponíveis na atualidade, quer seja psicofarmacológica (com novos e potentes antidepressivos, ansiolíticos, estabilizadores do humor e antipsicóticos) ou psicossociais (com técnicas psicoterapicas 
bastante eficazes), muitos pacientes não apresentam resposta satisfatória ao tratamento, mostrando-se resistentes e até mesmo refratários aos tratamentos convencionais. O que contribui para a ocorrência das recaídas e cronicidade dos diversos transtornos mentais.

Considerando que a adesão ao tratamento medicamentoso é elemento importante na prevenção de recaídas e que a enfermagem tem entre suas responsabilidades a administração de medicamentos e a observação de seus efeitos, este aspecto deve fazer parte do processo de avaliação sistemática de pacientes egressos de internação psiquiátrica.

\subsection{Enfermagem psiquiátrica e a manutenção do tratamento.}

De modo geral, o papel do enfermeiro em seu campo profissional é multideterminado e depende muito de sua formação acadêmica, suas características pessoais e características sociais, que muitas vezes ainda sofrem a influência das políticas de saúde ${ }^{(\mathbf{5 1})}$. Trata-se de uma profissão marcada pelo constante compromisso ético, humanos e profissionais, influenciada pela renovação dos saberes e evolução da ciência.

Não diferente, a enfermagem psiquiátrica também possui este perfil e ainda é marcada pela mudança de paradigma do cuidar em saúde mental: do cuidado centrado no hospital para o cuidado centrado na comunidade. Essa mudança tem implicações para o aprimoramento ético profissional e para o refinamento de suas competências frente aos avanços técnico-científicos.

A enfermagem psiquiátrica se afastou da histórica prática de um cuidado hospitalar caracterizado pela contenção do comportamento dos pacientes para uma 
prática mais humanizada e adequada às necessidades de sua clientela centrada na comunidade. Tal como a psiquiatria, a enfermagem em saúde mental busca a transformação e adequação de sua prática ao cuidado reabilitador e humanizador instituído pelo movimento da Reforma Psiquiátrica.

De acordo com a OMS, a missão do enfermeiro na sociedade é autônoma e tem como cerne ajudar indivíduos, famílias e grupos a determinar e alcançar seu potencial físico, mental e social de acordo com seu contexto.

"Isto exige que os enfermeiros aprendam e assegurem funções relacionadas com a promoção e manutenção da saúde, a prevenção da doença, o planejamento e a prestação de cuidados curativos e de readaptação. Os cuidados de enfermagem englobam aspectos físicos, mentais e sociais da vida na medida em que eles afetam a saúde, a doença, a deficiência e a morte. Os enfermeiros permitem a participação ativa do indivíduo, da sua família e amigos, do grupo social e da comunidade, de forma adequada em todos os aspectos dos cuidados de saúde, e encorajam assim a independência e a autodeterminação. Os enfermeiros trabalham também como parceiros dos membros das outras profissões implicadas na prestação dos serviços de saúde.” (52)

Com a ampliação de suas responsabilidades a enfermagem psiquiátrica realiza também tarefas como: orientação e manutenção do tratamento medicamentoso, desenvolvimento do relacionamento interpessoal, entendimento e atuação na dinâmica 
familiar, desenvolvimento de intervenções terapêuticas e educacionais, intervenção em crises, consultas de enfermagem (oferta de apoio, colaboração para determinação de limites, ajuda na expressão de pensamentos e sentimentos, estabelecimento de uma comunicação terapêutica, suporte pra identificação e resolução de problemas), grupoterapia, visitas domiciliárias e acompanhamento terapêutico ${ }^{(\mathbf{5 3 , 5 4})}$.

A prática em enfermagem, caracteristicamente interativa e sistemática durante o cuidado, é marcada pelo desenvolvimento de relações interpessoais necessárias à resolução de problemas. São estas características que tornam possível a manutenção da integridade de seus clientes, respeitada sua autonomia e liberdade. Ao desenvolver o relacionamento interpessoal na manutenção do tratamento psiquiátrico, o enfermeiro possibilita e estimula a promoção da relação do paciente com seu corpo, seu circulo social, sua família e suas capacidades atuais.

A saúde não deve ser vista apenas como resultado de processos de intervenção na doença, mas também de intervenções que oferecem ao individuo e coletividade meios para promover a manutenção ou recuperação de seu estado de saúde dentro de seu contexto e cotidiano ${ }^{(\mathbf{5 5})}$. Assim, entendemos que a manutenção do tratamento psiquiátrico na comunidade é uma função da enfermagem e um campo que precisar ser estudado, compreendido e assistido constantemente. 
Objetivos 29

\section{Objetivo geral}

Explorar o contexto cotidiano do egresso de internação psiquiátrica considerando pacientes e seus cuidadores na manutenção do tratamento psicofarmacológico em um serviço ambulatorial de saúde mental.

\section{Objetivos específicos:}

Conhecer quem são os egressos de internação e seus cuidadores em um serviço de saúde mental em relação à:

- Características sócio-demográficas;

- Adesão do paciente ao tratamento psicofarmacológico;

- Manifestação de sintomas psicopatológicos;

- Ocorrência de reinternação;

- Sobrecarga dos cuidadores. 
No período entre 17 de dezembro de 2007 e 17 de abril de 2008 efetuou-se um estudo de natureza quantitativa com abordagem exploratória e descritiva, acerca de todos os pacientes de um serviço público de assistência à saúde mental que se encontravam na condição de egressos de internação psiquiátrica recente e seus cuidadores.

Trata-se de um estudo que investigou as principais características de pessoas com uma doença mental que necessitaram de internação psiquiátrica sendo assim classificadas como egressas de internação após sua alta. Sabe-se que as doenças mentais atingem cerca de $3 \%$ da população e que em muitos casos a internação psiquiátrica torna-se necessária para conter uma crise ${ }^{(3)}$.

Optou-se por um estudo exploratório descritivo por entender que esse possibilita conhecer, interpretar e descrever uma dada realidade, suas implicações e fenômenos $\operatorname{associados}^{(56)}$ sendo que o problema a ser estudado é o que determina o método a ser utilizado $^{(57)}$. Através de instrumentos descritivos e escalas específicas os sujeitos da amostra tiveram seus dados coletados e categorizados para fundamentar as análises estatísticas.

\subsection{LOCAL}

O local escolhido para a realização desse estudo foi o Núcleo de Saúde Mental (NSM) na cidade de Ribeirão Preto - interior do estado de São Paulo. Respeitando o princípio básico da regionalização preconizado pelo Sistema Único de Saúde brasileiro (SUS), que determina que a rede de serviços do SUS deve ser organizada de forma hierarquizada e regionalizada para que a população de uma área delimitada possa ser 
melhor conhecida e assistida, o NSM é uma unidade pública de atendimento ambulatorial vinculada ao Centro de Saúde Escola "Joel Domingos Machado" da Faculdade de Medicina de Ribeirão Preto - Universidade de São Paulo - USP - Brasil (CSE-FMRP-USP). O serviço oferece assistência em saúde mental gratuita, realizada por uma equipe composta de médicos psiquiatras, enfermeiros, técnicos de enfermagem, psicóloga, fonoaudióloga, escriturário e auxiliar de serviços gerais.

Através de um atendimento ambulatorial especializado em Psiquiatria e Psicologia Clínica para pessoas a partir de 18 anos, residentes no Distrito Oeste da cidade, mediante guia de referência das Unidades de Saúde de segunda a sexta-feira das $7 \mathrm{~h}$ às 17 horas, o serviço oferece: atendimento médico-psiquiátrico; atendimento de enfermagem (consultas); acompanhamento psicológico; atendimento de fonoaudiologia; grupos terapêuticos.

$\checkmark \quad \mathrm{Na}$ rotina do serviço, a todos os pacientes egressos de internação psiquiátrica é agendada uma consulta médica no serviço, nas duas primeiras semanas pós-alta hospitalar, para restabelecimento do seguimento pela equipe. O Núcleo de Saúde Mental (NSM) é a unidade de referência para a assistência à saúde mental de todas as pessoas cadastradas e residentes na área de abrangência do CSE-FMRP-USP.

\subsection{POPULAÇÃO e AMOSTRA}

A população desse estudo é representada pelo universo de todos os pacientes e seu cuidadores, residentes na região Oeste de Ribeirão Preto, matriculados no referido serviço de saúde mental.

A amostra foi composta por todos os pacientes do Núcleo de Saúde Mental (NSM) que estavam na condição de egresso de internação psiquiátrica recente, no 
período de coleta de dados compreendido entre 17 de dezembro de 2007 e 17 de abril de 2008.

\subsubsection{Critérios de inclusão}

- PACIENTES: ambos os sexos; com idade superior a 18 anos; residentes em Ribeirão Preto; matriculados no referido serviço de saúde mental; egressos de internação psiquiátrica recente - hospitalizados por no mínimo 48 hs; concordantes em participar da pesquisa.

- CUIDADOR: de ambos os sexos; com idade superior a 18 anos; responsável pela supervisão e administração do tratamento medicamentoso do paciente; que acompanhe freqüentemente a manutenção do tratamento destes pacientes segundo relato do paciente e do cuidador; independente de seu grau de parentesco com o paciente; concordantes em participar da pesquisa.

A definição de cuidador adotada nesse estudo foi baseada na Política Nacional de Saúde, que diz que:

"Cuidador é a pessoa, membro ou não da família, que, com ou sem remuneração, cuida do ... doente ou dependente no exercício das suas atividades diárias, tais como alimentação, higiene pessoal, medicação de rotina, acompanhamento aos serviços de saúde e demais serviços requeridos no cotidiano - como a ida a bancos ou farmácias, excluídas as técnicas ou procedimentos identificados com profissões legalmente estabelecidas, particularmente na área da enfermagem"(24). 


\subsection{PROCEDIMENTOS}

3.3.1 Recrutamento: Foi realizado na pós-consulta de enfermagem, quando o paciente egresso de internação psiquiátrica (e seu cuidador) compareceu(ram) ao serviço para a primeira consulta médica após a alta. $\mathrm{Na}$ falta à consulta, foi realizado contato telefônico e agendamento de uma nova data para consulta e convite para participar da pesquisa.

3.3.2 Coleta dos dados: A coleta foi realizada individualmente (com o paciente, depois com seu cuidador) no período entre 17 de dezembro de 2007 e 17 de abril de 2008 (4 meses) em um único encontro. Nessa ocasião após concordância quanto ao termo de consentimento livre e esclarecido, foram aplicados os instrumentos:

- Aos pacientes (anexo1): um questionário de dados sócio-demográficos e clínicos; o Teste de Adesão ao Tratamento de Morisky e Green; Escala Breve de Avaliação Psiquiátrica - BPRS.

- Ao principal cuidador(Anexo 2): Questionário de dados sócio-demográficos; Escala de Avaliação da Sobrecarga dos familiares - FBIS-BR.

Ao final de cada encontro foi oferecido um momento para que paciente e/ou familiar pudessem expressar dúvidas e pedir esclarecimentos. 


\subsection{INSTRUMENTOS}

\section{Questionário sócio-demográfico e clínico (anexo 1 e anexo 2)}

O questionário é um conjunto de questões pré-elaborado, sistemática e seqüencialmente disposto em itens que contextualizam o tema da pesquisa. Neste trabalho de pesquisa, o uso do questionário possibilitou a abordagem das características dos sujeitos da amostra de maneira eficiente e rápida.

Trata-se de um questionário, elaborado pela pesquisadora, que contemplou as seguintes variáveis: Sexo; Idade(data de nascimento); Escolaridade do paciente; Situação conjugal do paciente; Número de filhos; Situação ocupacional do paciente; Renda pessoal do paciente; Com quem mora, Condições de moradia; Número de pessoas que coabitam; Renda familiar; Diagnóstico(s) psiquiátrico(s); Conhecimento do paciente sobre sua doença; Tempo de manifestação do transtorno psiquiátrico; Crença quanto ao tratamento psicofarmacológico; Conhecimento do nome do medicamentos prescritos; Prescrição; Internações anteriores (quantidade); Data última internação psiquiátrica, Local da última internação; motivo da internação, Duração da última internação psiquiátrica; intervalo entre alta e consulta no serviço; utilização de serviço de emergência; eventos cotidianos (Óbito familiar; Diagnóstico de doença grave na família; Acidente pessoal; Consulta em outro serviço/emergência; Tentativa de suicídio; Falta à consulta médica agendada; Procura por consultas eventuais no serviço; Problemas como tratamento medicamentoso (psiquiátrico); Mudou de residência; Teve alteração drástica na rotina( aposentou, novo emprego, gravidez, ...); Perdeu emprego; Grave Problema financeiro na família; Brigas familiares; Brigas 
conjugais (ruptura, término, discussão); Briga com terceiros (amigos , outras pessoas); Sofreu algum tipo de violência urbana (furto, assalto, enchente, agressão física, vendaval,.....); Opinião do paciente quanto a importância do tratamento com remédios.

Aos cuidadores: Vínculo do cuidador com o paciente; sexo do cuidador; Idade cuidador; Escolaridade cuidador; Estado civil do cuidador; Número filhos; Trabalho do cuidador; Opinião do Cuidador quanto à importância do tratamento com remédios.

Observações:

- O diagnóstico dos pacientes considerado foi o mais recente registrado tanto na guia de referência elaborada na alta hospitalar quanto no prontuário do serviço, de acordo com o CID 10 (International Classification of Diseases and Related Health Problems-ICD10) ${ }^{(4)}$.

- O tempo de doença considerado foi o de doença diagnosticada em um serviço de saúde, segundo relato dos sujeitos.

- O número de internações anteriores considerado foi o compatível com o relato dos sujeitos e registro no prontuário dos mesmos. 


\section{Escala Breve de Avaliação Psiquiátrica (Brief Psychiatric Rating Scale-BPRS):}

A escala BPRS escolhida para este estudo (Anexo 1) é uma escala traduzida e validada para o português e baseou-se na escala produzida por Bech et al. (58,59). Tratase de uma escala confiável, amplamente utilizada em produções científicas e possibilitou a verificação da manifestação dos sintomas psiquiátricos pelos pacientes poucos dias após a alta hospitalar.

A BPRS é uma escala para avaliar a presença e o nível de gravidade de sintomas psicóticos, dentre outros sintomas. É composta por 18 itens ou sintomas: preocupações somáticas, ansiedade psíquica, retraimento emocional, desorganização conceitual (incoerência), autodepreciação e sentimento de culpa, ansiedade somática, distúrbios motores específicos, auto-estima exagerada, humor deprimido, hostilidade, desconfiança, alucinações, retardo psicomotor, falta de cooperação, conteúdo de pensamento incomum, afeto embotado ou inapropriado, agitação psicomotora, desorientação e confusão.

Cada item psicopatológico da BPRS possui 5 níveis de severidade com escores que variam de 0 a 4 . Sendo que, 0 (zero) significa ausência ou não observação do sintoma e 4 (quatro) corresponde ao nível de maior gravidade ou comprometimento para o referido sintoma. Os valores intermediários correspondem, por sua vez, a níveis intermediários de gravidade. Não há para essa escala um ponto de corte estabelecido, a indicação de comprometimento é feita considerando a caso a caso a pontuação obtida.

Um sujeito com uma pontuação total 4, por exemplo, pode ter recebido pontuação um em quatro diferentes itens ou sintomas, o que significaria leve grau de manifestação em cada um deles ou também poderia ter pontuado 4 pontos em um único 
item, o que significaria o mais grave grau de manifestação desse sintoma, provavelmente necessitando de uma intervenção breve.

Nesse trabalho consideramos a BPRS em cada sintoma (item psicopatológico) e também o escore total das respostas dos pacientes. Consideramos ainda porcentagem de respostas aos dois últimos níveis de gravidade para cada item. Assim todos os valores foram considerados e avaliados quanto a alterações mentais compatíveis com distúrbios de natureza psiquiátrica. Quanto maior o escore total final, maior a manifestação de sintomas psiquiátricos no sujeito avaliado, independente do nível.

Utilizamos também a Entrevista Clínica Estruturada para Escala Breve de Avaliação Psiquiátrica (SIG-BPRS), anexo 3, para auxiliar a aplicação da escala BPRS $)^{(\mathbf{6 0})}$. Trata-se de um roteiro de entrevista composto por três partes:

- contato inicial (perguntas que fundamentam respostas aos itens orientação, preocupação somática, orientação, triagem, orientação, preocupação somática);

- entrevista (perguntas que fundamentam respostas aos itens orientação, ansiedade psíquica, sentimentos de culpa, humor deprimido, desconfiança, auto-estima exagerada, conteúdo incomum do pensamento, preocupação somática, alucinações);

- encerramento (agradecimento do entrevistador e momento oferecido ao entrevistado para esclarecer eventuais dúvidas).

\section{Teste de adesão ao tratamento medicamentoso - Morisky-Green}

Utilizamos o teste de Morisky-Green ${ }^{(\mathbf{6 1 , 6 2})}$ para identificar o grau de adesão ao tratamento psicofarmacológico. Trata-se de um teste para avaliar o comportamento do 
paciente em relação ao uso habitual do medicamento, amplamente utilizado no meio científico $^{(\mathbf{6 3 , 6 6 )}}$ traduzido e aplicado no Brasil ${ }^{(\mathbf{6 7}, \mathbf{6 8})}$.

O Teste de Morisky-Green é composto por quatro perguntas que permitem classificar os sujeitos da amostra pelo grau e pelo tipo de adesão ao tratamento medicamentoso, conforme descrito no quadro que segue:

\begin{tabular}{|l|c|c|}
\hline \multicolumn{1}{|c|}{ TESTE MORINSK E GREEN } & \multicolumn{2}{c|}{ Baixo grau de adesão } \\
\cline { 2 - 3 } & Não Intencional & Intencional \\
\hline 1- Você alguma vez esquece de tomar seu remédio? & Sim & - \\
\hline 2- Você, às vezes, é descuidado com os horários de tomar seu remédio? & Sim & - \\
\hline 3- Quando você se sente bem, alguma vez, deixa de tomar seu remédio? & - & Sim \\
\hline 4- Quando você se sente mal, com o remédio, você às vezes deixa de tomar ele? & - & Sim \\
\hline
\end{tabular}

O paciente é classificado no grupo de alto grau de adesão, quando as respostas a todas as perguntas são negativas.

Porém, quando pelo menos uma das respostas é afirmativa, o paciente é classificado no grupo de baixo grau de adesão.

Esta avaliação permite, também, discriminar se o comportamento de baixo grau de adesão é do tipo intencional ou não intencional, sendo, também, possível caracterizar pacientes portadores de ambos os tipos de comportamento de baixa adesão. Se houver uma resposta sim em qualquer uma das duas primeiras respostas o tipo de adesão é não intencional, se a resposta sim estiver em qualquer uma das duas é últimas é intencional.

Assim, no presente estudo os sujeitos da amostra foram classificados pelo grau e pelo tipo de adesão ao tratamento, como segue: 
- Sujeito com alto grau de adesão, quando as respostas a todas as perguntas são negativas;

- Sujeito com baixo grau de adesão, quando pelo menos uma das respostas é afirmativa;

\section{Escala de Avaliação da Sobrecarga dos familiares FBIS-BR:}

A escala original de língua inglesa - FBIS/SF - é uma escala multifatorial que avalia a sobrecarga familiar, a partir de cinco subescalas, correspondentes a cinco dimensões da vida do familiar que se referem aos trinta dias anteriores à data da entrevista. Nesse trabalho utilizamos a versão brasileira (traduzida e validada) da escala $^{(17)}$.

A escala FBIS-BR (Escala de Sobrecarga dos Familiares de Pacientes Psiquiátricos-Versão Brasileira) visa avaliar a sobrecarga dos familiares cuidadores de pacientes psiquiátricos. Ela avalia tanto a sobrecarga objetiva quanto subjetiva (ver conceitos abaixo), a partir de escores independentes. Além disso, diversas dimensões da vida do familiar são avaliadas separadamente a partir desta escala, de modo que o avaliador pode conhecer as áreas de maior ou menor sobrecarga sentida pelo familiar, no seu papel de cuidador ${ }^{(69)}$.

A escala FBIS-BR possui 70 questões, dentre as quais 45 se referem ao grau de sobrecarga (sendo 21 itens de sobrecarga objetiva e 24 itens de sobrecarga subjetiva). 
Dos itens que compõem a escala quatro não podem ser utilizados no cálculo dos escores de sobrecarga por terem apresentado valores baixos de fidedignidade $(r<0,20$ item-total), no estudo de validação. São eles os de número 6 e 8 da sub-escala $B$ objetiva e os itens 6 e 8 da sub-escala $B$ subjetiva. Estes itens se referem à ajuda que o familiar prestou ao paciente ao ter que lidar com comportamentos problemáticos relacionados ao abuso de álcool e de drogas. É provável que a baixa frequiência deste tipo de problema na amostra do estudo de validação tenha contribuído para este resultado. No entanto, são itens importantes para aprofundar o conhecimento dos pesquisadores. Por isso, conforme sugestão dos autores do trabalho de validação, todos os itens foram mantidos nas aplicações da escala embora não tenham sido utilizados para contabilizar os escores da sobrecarga.

A escala totaliza, portanto, 41 itens quantitativos que devem ser incluídos nos cálculos dos escores de sobrecarga, sendo 19 de sobrecarga objetiva e 22 de sobrecarga subjetiva. O tempo de aplicação do instrumento dura aproximadamente 40 minutos.

A escala FBI-BR avalia o grau de sobrecarga dos familiares em cinco dimensões da vida dos familiares, que consistem nas seguintes sub-escalas: A) Assistência na vida cotidiana do paciente; B) Supervisão aos comportamentos problemáticos do paciente; C) Gastos financeiros do familiar com o paciente; D) Impacto nas rotinas diárias da família; E) Preocupações do familiar com o paciente.

A sobrecarga objetiva é avaliada por meio da freqüência em que o familiar prestou assistência ao paciente nas tarefas cotidianas (sub-escala A), teve que lidar e supervisionar os seus comportamentos problemáticos (sub-escala B) e sofreu alterações em sua vida profissional e social (sub-escala D) como resultado do seu papel de cuidador. Esta freqüência é avaliada em uma escala de 5 pontos, onde: 1= nenhuma vez; 
$2=$ menos que uma vez por semana; $3=$ uma ou duas vezes por semana; $4=$ de três a seis vezes por semana; $5=$ todos os dias.

A sobrecarga subjetiva é avaliada pelo grau de incômodo sentido pelo familiar ao prestar assistência cotidiana ao paciente (sub-escala A) e ao lidar com seus comportamentos problemáticos (sub-escala B), assim como pelo sentimento do familiar de estar carregando um peso financeiro (uma questão da sub-escala C) e pela freqüência de suas preocupações com o paciente (sub-escala E). Para a avaliação do grau de incômodo, as opções de resposta são: $1=$ nem um pouco; $2=$ muito pouco; $3=$ um pouco; 4 = muito.

A primeira sub-escala (A) avalia as sobrecargas objetiva e subjetiva do familiar. Possui nove questões que avaliam a freqüência da assistência prestada pelo familiar ao paciente (sobrecarga objetiva) e nove questões que avaliam o grau de incômodo sentido ao prestar essa assistência (sobrecarga subjetiva).

A segunda sub-escala (B) avalia também as sobrecargas objetiva e subjetiva do familiar. É composta por oito questões que medem a freqüência com que o familiar teve que supervisionar os comportamentos problemáticos do paciente (sobrecarga objetiva) e oito questões que avaliam grau de incômodo sentido pelo familiar ao lidar com esses comportamentos (sobrecarga subjetiva).

A terceira sub-escala (C) avalia a dimensão financeira, referente aos gastos com o paciente. É composta por cinco questões que, entretanto, não são utilizadas nos cálculos dos escores de sobrecarga, uma vez se refere a valores em dinheiro e não escores de avaliação. Por esse motivo essa subescala não foi considerada nesse estudo.

A quarta sub-escala (D) avalia apenas a sobrecarga objetiva. Possui quatro questões que medem a freqüência das alterações ocorridas na rotina familiar nos últimos 
30 dias. Estas quatro questões são utilizadas no cálculo da sobrecarga desta sub-escala. Além destas questões, duas outras questões adicionais (que não entram no cálculo dos escores de sobrecarga) avaliam as mudanças permanentes ocorridas na vida do familiar, resultantes do papel de cuidador. Uma avalia, de forma global, em que grau o cuidador teve mudanças permanentes na sua vida social e ocupacional e a outra requer que o familiar indique se teve ou não mudanças permanentes em 6 aspectos da sua vida.

A quinta sub-escala (E) avalia apenas a sobrecarga subjetiva. É constituída por sete questões que avaliam a frequiência das preocupações do familiar com o paciente, com relação ao seu futuro, à sua segurança física, às suas relações sociais, etc.

Para análise dos dados referentes à sobrecarga, analisou-se a porcentagem de respostas aos itens da FBIS-BR e a variância de postos, pelo teste não paramétrico de Friedman, para identificar os itens que acarretaram maior sobrecarga aos familiares.

Para cálculo dos escores globais de cada tipo de sobrecarga utilizou-se o seguinte procedimento:

\section{Cálculo dos escores de sobrecarga objetiva:}

- sub-escala A = calcular a média dos escores obtidos nas questões A1a, A2a, A3a, A4a, A5a, A6a, A7a, A8a, A9a, que avaliam a frequiência de ajuda que o familiar forneceu ao paciente.

- sub-escala B = calcular a média dos escores obtidos nas questões B1a, B2a, B3a, B4a, B5a, B7a, que avaliam a freqüência de supervisões do familiar aos comportamentos problemáticos dos pacientes.

- sub-escala D = calcular a média dos escores obtidos nas questões D1a, D1b, D1c, D1d, que avaliam as perturbações na vida do familiar. 
- escore global de sobrecarga objetiva = calcular a média dos escores obtidos em todas as questões citadas acima.

\section{Cálculo dos escores de sobrecarga subjetiva:}

- sub-escala $\mathrm{A}$ = calcular a média dos escores obtidos nas questões A1b, A2b, A3b,A4b, A5b, A6b, A7b, A8b, A9b, que avaliam o grau de incômodo do familiar ao dar assistência ao paciente nas tarefas cotidianas.

- sub-escala B = calcular a média dos escores obtidos nas questões B1b, B2b, B3b, B4b, B5b, B7b, que avaliam o grau de incômodo do familiar ao lidar com os comportamentos problemáticos do paciente.

- sub-escala $\mathrm{E}=$ Calcular a média dos escores obtidos em todas as questões desta subescala (E1, E2, E3, E4, E5, E6, E7), que avaliam a freqüência de preocupações do familiar com o paciente.

- escore global de sobrecarga subjetiva = calcular a média dos escores obtidos em todas as questões citadas acima.

\section{Itens que não contabilizam no cálculo dos escores e não foram considerados nesse} estudo:

1. A sub-escala C não se aplica a cálculos de escores, uma vez que trata de valores em dinheiro das despesas do paciente e da contribuição do paciente. $\mathrm{O}$ item final referente à frequiência com que o familiar considerou que eram pesados os gastos que ele teve com o paciente também.

2. Os itens que avaliam as mudanças permanentes ocorridas na vida do familiar (dentro da sub-escala D) não entram no cálculo dos escores desta sub-escala, uma vez que todos 
os escores que são incluídos nos cálculos de sobrecarga envolvem questões que se referem apenas aos últimos 30 dias.

3. Os itens 6 e 8 da sub-escala $B$, que não atingiram o critério mínimo de correlação item-total. 


\subsubsection{ANÁLISE DOS DADOS}

Utilizamos a estatística descritiva ao considerar os dados referentes à identificação dos pacientes egressos de internação psiquiátrica e seu cuidadores. Foram obtidas as frequiências e medidas de tendência central.

Os dados relativos ao Teste de Morisky e Green, foram analisados através das porcentagens de respostas obtidas em cada uma das quatro perguntas que compõem o teste. Os resultados obtidos nas escalas BPRS e FBIS BR foram classificados por escores, descritos por media de freqüência das respostas a cada item.

Os dados relativos aos dezoito itens da escala BPRS foram ainda submetidos à análise bivariada, comparando a manifestação de sintomas psiquiátricos a outras variáveis que também se destacam na manutenção dos tratamentos psiquiátricos: ocorrência de reinternação; possuir um cuidador; adesão do paciente ao tratamento psicofarmacológico (Teste de Morisky e Green); sobrecarga dos familiares cuidadores. Assim foram verificadas as possíveis associações entre a manifestação de sintomas psiquiátricos sob outros aspectos. Foi considerado o Teste de Spearman. Em todas as situações, o limite de significância estatística foi fixado em $\mathrm{P}<0,05$. Nas várias análises, utilizou-se o Programa SPSS versão 10.0. 


\subsubsection{ASPECTOS ÉTICOS}

Esta pesquisa foi aprovada pelo Comitê de Ética em Pesquisa do Centro de Saúde Escola "Joel Domingos Machado" da Faculdade de Medicina de Ribeirão Preto Universidade de São Paulo - USP -(protocolo n ${ }^{\circ} 254$ /CEP/CSE-FAMRPUSP).(Anexo5)

Todos os sujeitos da amostra receberam esclarecimento quanto ao objetivo do estudo e procedimentos que foram realizados na pesquisa e assinaram o Termo de Consentimento Livre e Esclarecido (TCLE anexo 4). Todos os direitos quanto ao sigilo, confidencialidade, livre arbítrio e segurança foram e são garantidos aos sujeitos da que participaram dessa pesquisa. A participação dos pacientes foi voluntária. 


\section{1 - Pacientes egressos de internação}

No período entre dezembro de 2007 e abril de 2008, cinqüenta e quatro pessoas com transtornos mentais receberam alta de internação psiquiátrica sendo agendada a primeira consulta médica no serviço de saúde comunitário, após a alta hospitalar. Isso representou uma média de treze internações ao mês, isentos os casos em que o mesmo paciente necessitou de nova internação dentro desse período.

Seis pacientes foram excluídos do estudo: dois se recusaram em participar após esclarecimento livre e esclarecido; um foi transferido para outro serviço especializado no tratamento de dependência química, não se concretizando a consulta médica; uma teve a alta hospitalar suspensa e sua consulta foi adiada; dois faltaram à consulta e o cadastro desatualizado no sistema de informação da rede pública de serviços impossibilitou a busca ativa desses.

Portanto, foram incluídos na amostra quarenta e oito pacientes egressos de internação psiquiátrica recente que aceitaram participar da pesquisa, sendo que 21 deles possuíam um cuidador por eles responsável na ocasião desta pesquisa.

Tabela 1 - Distribuição de freqüência quanto ao sexo e
idade de pacientes egressos de internação psiquiátrica.
\begin{tabular}{|l|c|c|c|}
\hline IDADE & SEXO & TOTAL \\
& Masculino & Feminino & \\
\hline De 18 a 20anos & 0 & 1 & $\mathbf{1}$ \\
\hline De 21 a 30 anos & 6 & 11 & $\mathbf{1 7}$ \\
\hline De 31 a 40 anos & 3 & 8 & $\mathbf{1 1}$ \\
\hline De 41 a 50 anos & 5 & 3 & $\mathbf{8}$ \\
\hline De 51 a 70 anos & 3 & 6 & $\mathbf{9}$ \\
\hline De 71a 75 anos & 1 & 1 & $\mathbf{2}$ \\
\hline Total & $\mathbf{1 8}$ & $\mathbf{3 0}$ & $\mathbf{4 8}$ \\
\hline Ribeirão Preto-SP, 2008.
\end{tabular}

Ribeirão Preto-SP, 2008. 
Entre o grupo de pacientes, trinta eram do sexo feminino e dezoito do sexo masculino com idade média de trinta e nove anos, a qual variou de dezoito a setenta e cinco anos. Conforme descrito na Tabela 1.

As características demográficas, sociais e econômicas dos pacientes da amostra estão apresentadas na Tabela 2. O estado civil destes sujeitos esteve equilibrado. Entre os pacientes da amostra 39,6\% eram solteiros e 37,5\% casados. Pacientes que já haviam sido casados ou amasiados e estavam na condição de separados ou divorciados representaram $16,7 \%$ da amostra e $6,3 \%$ eram viúvos(as).

Tabela 2 - Distribuição de freqüência quanto a características sóciodemográficas e econômicas dos pacientes egressos de internação psiquiátrica recente.

\begin{tabular}{|c|c|c|c|}
\hline Características & $\mathrm{n}(\%)$ & Características & $\mathrm{n}(\%)$ \\
\hline $\begin{array}{l}\text { Idade (anos completos) } \\
\text { Idade média } 39 \text { anos } \\
\text { Mediana } 34 \text { anos } \\
\text { Variação: } 18-75\end{array}$ & $24(50,0)$ & $\begin{array}{l}\text { Renda Pessoal (paciente)* } \\
\text { Não tem } \\
\text { Um salário mínimo } \\
\text { Dois salários } \\
\text { Três salários } \\
\text { Quatro ou mais salários mínimos }\end{array}$ & $\begin{array}{r}15(31,2) \\
18(37,5) \\
9(18,8) \\
1(2,1) \\
5(10,4)\end{array}$ \\
\hline $\begin{array}{l}\text { Estado civil } \\
\text { Solteiro (a) } \\
\text { Casado/Amasiado (a) } \\
\text { Divorciado/Separado (a) } \\
\text { Viúvo (a) }\end{array}$ & $\begin{array}{r}19(39,6) \\
18(37,5) \\
8(16,7) \\
3(6,3) \\
\end{array}$ & $\begin{array}{l}\text { Com quem reside } \\
\text { Mora sozinho } \\
\text { Reside com Familiares } \\
\text { Reside com amigos }\end{array}$ & $\begin{array}{r}2(4,2) \\
45(93,8) \\
1(2,1)\end{array}$ \\
\hline $\begin{array}{l}\text { Filhos } \\
\text { Nenhum } \\
\text { Um } \\
\text { Dois } \\
\text { Três ou mais } \\
\end{array}$ & $\begin{array}{r}20(41,7) \\
8(16,7) \\
7(14,6) \\
13(27,0) \\
\end{array}$ & $\begin{array}{l}\text { Condição de Moradia } \\
\text { Própria } \\
\text { Alugada } \\
\text { Outra (morador de rua) }\end{array}$ & $\begin{array}{r}34(70,8) \\
13(27,1) \\
1(2,1)\end{array}$ \\
\hline $\begin{array}{l}\text { Escolaridade } \\
\text { Analfabeto } \\
\text { Primeiro grau incompleto } \\
\text { Primeiro grau completo } \\
\text { Segundo grau incompleto } \\
\text { Segundo grau completo } \\
\text { Terceiro grau completo } \\
\end{array}$ & $\begin{array}{r}2(4,2) \\
17(35,4) \\
7(14,6) \\
9(18,8) \\
10(20,8) \\
3(6,3) \\
\end{array}$ & $\begin{array}{l}\text { Número de pessoas na casa } \\
\text { Até duas pessoas } \\
\text { Três ou quatro pessoas } \\
\text { Cinco ou seis pessoas } \\
\text { Sete ou oito pessoas }\end{array}$ & $\begin{array}{r}12(25,2) \\
28(58,4) \\
4(8,2) \\
4(8,2)\end{array}$ \\
\hline $\begin{array}{l}\text { Ocupação } \\
\text { Nunca Trabalhou } \\
\text { Desempregado } \\
\text { Faz trabalhos eventuais "bicos" } \\
\text { Trabalho regular informal } \\
\text { Trabalho regular registrado } \\
\text { Afastado } \\
\text { Aposentado }\end{array}$ & $\begin{array}{r}3(6,3) \\
12(25,0) \\
3(6,3) \\
2(4,2) \\
5(10,4) \\
4(8,3) \\
19(39,6)\end{array}$ & $\begin{array}{l}\text { Renda familiar* } \\
\text { Não tem } \\
\text { Dois salários } \\
\text { Três salários } \\
\text { Quatro ou mais salários mínimos }\end{array}$ & $\begin{array}{r}1(2,1) \\
12((25,0) \\
21(43,7) \\
14(29,2)\end{array}$ \\
\hline
\end{tabular}


Quanto ao número de filhos, 41,7\% deles não tinham nenhum filho e $27,0 \%$ possuíam três filhos ou mais. Pacientes com um ou dois filhos somaram 31,3\% da amostra sendo divididos como: sujeitos com apenas um filho $16,7 \%$ e com dois filhos $14,6 \%$.

Dezessete pacientes tinham como escolaridade o primeiro grau incompleto (35.4\% da amostra) e sete $(14,6 \%)$ o primeiro grau completo. Dez $(20,8 \%)$ pacientes apresentavam o segundo grau completo e nove $(18,8 \%)$ o segundo grau incompleto. Apenas dois pacientes nunca puderam estudar e três conseguiram concluir o ensino superior (terceiro grau completo). Destaca-se que a maioria dos pacientes $(54,2 \%)$ teve apenas o primeiro grau de escolaridade ou menos.

Poucos pacientes relataram exercer alguma atividade laboral. A maior parte deles $(39,6 \%)$ tem a aposentadoria como recurso de obtenção de renda. Do restante, $6,3 \%$ pacientes nunca trabalharam e não tem renda própria, $25 \%$ estavam desempregados, 6,3\% fazem trabalhos eventuais para obter dinheiro para pequenas compras, $4,2 \%$ trabalhavam regularmente não registrados e $10,4 \%$ estavam desempregados. Quatro pacientes estavam afastados de seu trabalho em decorrência de sua doença psiquiátrica.

Verificamos que $31,2 \%$ dos pacientes da amostra negaram ter alguma fonte de renda, $37,5 \%$ relataram um salário mínimo (380,00 reais, na época) e 18,8\% dos pacientes relataram renda de dois salários mínimos. Observamos que entre os pacientes egressos de internação psiquiátrica recente, $87,5 \%$ possuíam dois ou menos salários mínimos como renda pessoal. Apenas um paciente declarou renda de três salários mínimos e cinco declaram ter quatro salários ou mais como renda pessoal. 
A grande maioria dos pacientes $(93,8 \%)$ reside com seus familiares, um deles mora com amigos e dois pacientes relataram residirem sozinhos. Em 78,8\% dos casos, os pacientes egressos de internação vivem em casas próprias onde coabitam 3,5 pessoas em média. Do restante, $27,1 \%$ pagam aluguel e um paciente refere morar em seu carro sendo classificado como "morador de rua".

A renda familiar foi acima de três salários mínimos para 72,9\% dos pacientes. $\mathrm{O}$ paciente que afirmou ser morador de rua negou renda familiar e doze pacientes relatam renda familiar mensal de dois salários mínimos.

A Tabela 3 apresenta a distribuição dos pacientes em relação a seus diagnósticos distribuídos por tipo e classe diagnóstica. Entre os sujeitos que tiveram apenas um diagnóstico registrado foram prevalentes os diagnósticos classificados no grupo da Esquizofrenia e Transtornos Esquizotípicos, em 33,3\% da amostra. Nesse grupo, se destacou o diagnóstico de Esquizofrenia em dez sujeitos o que corresponde a $20,8 \%$ da amostra.

Os Transtornos de Humor (afetivos) agruparam diagnósticos de 29,2\% dos pacientes da amostra. Entre os quatorze sujeitos classificados nesse grupo diagnóstico, houve destaque para o diagnóstico de Episódio depressivo moderado em seis pacientes $(12,5 \%)$ e para o Transtorno afetivo bipolar em quatro pacientes $(8,3 \%)$.

Três pacientes tinham diagnóstico de transtorno de personalidade e um diagnóstico de Transtorno doloroso somatoforme persistente.

Entre todos os pacientes dessa amostra, 29,2\% apresentaram comorbidade psiquiátrica. Verificamos que doze tinham dois diagnósticos $(25,0 \%)$ e dois tinham três diagnósticos $(4,2 \%)$. Não houve pacientes com mais de três diagnósticos psiquiátricos registrados. 
TABELA 3 - Distribuição de freqüência relativa aos diagnósticos principais e comorbidade entre pacientes egressos de internação psiquiátrica recente.

\begin{tabular}{|c|c|c|c|c|}
\hline $\begin{array}{l}\text { Número de } \\
\text { diagnósticos }\end{array}$ & Descrição dos diagnósticos & $n(\%)$ & $\begin{array}{l}\text { N por classe } \\
\text { diagnóstica }\end{array}$ & $\%$ \\
\hline \multirow[t]{4}{*}{$\begin{array}{l}\text { Um } \\
\text { Diagnóstico }\end{array}$} & $\begin{array}{l}\text { Esquizofrenia, transtornos esquizotípicos e transtornos delirantes } \\
\text { F20.0 - Esquizofrenia } \\
\text { F20.9 - Esquizofrenia não especificada } \\
\text { F23.1 - Transtorno psicótico agudo polimorfo, com sintomas esquizofrênicos } \\
\text { F23.9 - Transtorno psicótico agudo e transitório não especificado } \\
\text { F25.0 - Transtornos esquizoafetivos }\end{array}$ & $\begin{array}{r}10(20,8) \\
1(2,1) \\
1(2,1) \\
1(2,1) \\
3(6,3)\end{array}$ & 16 & 33,3 \\
\hline & $\begin{array}{l}\text { Transtornos de humor (afetivos) } \\
\text { F31.0 - Transtorno Afetivo Bipolar } \\
\text { F31.1 - Transtorno afetivo bipolar, episódio atual maníaco sem sintomas psicóticos } \\
\text { F31.6 - Transtorno afetivo bipolar, episódio atual misto } \\
\text { F32.1 - Episódio depressivo moderado } \\
\text { F32.2 - Episódio depressivo grave sem sintomas psicóticos } \\
\text { F33.1 - Transtorno depressivo recorrente, episódio atual moderado }\end{array}$ & $\begin{array}{r}4(8,3) \\
1(2,1) \\
1(2,1) \\
6(12,5) \\
1(2,1) \\
1(2,1)\end{array}$ & 14 & 29,2 \\
\hline & $\begin{array}{l}\text { Transtornos neuróticos, relacionados a stress e transtornos somatoformes } \\
\text { F45.4 - Transtorno doloroso somatoforme persistente }\end{array}$ & $1(2,1)$ & 1 & 2,1 \\
\hline & $\begin{array}{l}\text { Transtornos da personalidade e do comportamento do adulto } \\
\text { F60.3 - Personalidade com instabilidade emocional }\end{array}$ & $3(8,3)$ & 3 & 6,2 \\
\hline $\begin{array}{l}\text { Dois } \\
\text { diagnósticos }\end{array}$ & $\begin{array}{l}\text { F02.4 e F60.3 - Demência na doença do vírus da imunodeficiência humana [HIV] + } \\
\text { Personalidade com instabilidade emocional } \\
\text { F10.2 e F32.1- Síndrome de dependência (substância psicoativa ) + Episódio depressivo } \\
\text { moderado } \\
\text { F10.7 e F25.9 - Transtorno psicótico residual ou de instalação tardia (álcool) + Transtorno } \\
\text { esquizoafetivo não especificado } \\
\text { F19.2 e F20.0 - Transtornos mentais e comportamentais devidos ao uso de múltiplas } \\
\text { drogas e ao uso de outras substâncias psicoativas + Esquizofrenia } \\
\text { F60.3 e F21.0 - Personalidade com instabilidade emocional + Transtorno esquizotípico } \\
\text { F60.3 e F } 31.5 \text { - Personalidade com instabilidade emocional + Transtorno afetivo bipolar, } \\
\text { episódio atual depressivo grave com sintomas psicóticos } \\
\text { F60.3 e F32.0 - Personalidade com instabilidade emocional + Episódio depressivo leve } \\
\text { F60.9 + F } 41.0 \text { E - Transtorno não especificado da personalidade + Ansiedade } \\
\text { generalizada } \\
\text { F60.3 e Z2915 Personalidade com instabilidade emocional + História pessoal de auto- } \\
\text { agressão. } \\
\text { F20.0 e F32.1 - Esquizofrenia + Episódio depressivo moderado } \\
\text { F20.1 e F71 - Esquizofrenia hebefrênica + Retardo mental moderado } \\
\text { F32.0 e } 50.1 \text { - Episódio depressivo leve + Anorexia nervosa atípica }\end{array}$ & $\begin{array}{l}1(2,1) \\
1(2,1) \\
1(2,1) \\
1(2,1) \\
1(2,1) \\
1(2,1) \\
1(2,1) \\
1(2,1) \\
1(2,1) \\
1(2,1) \\
1(2,1) \\
1(2,1)\end{array}$ & 12 & 25,0 \\
\hline \multirow[t]{3}{*}{$\begin{array}{l}\text { Três } \\
\text { diagnósticos }\end{array}$} & $\begin{array}{l}\text { F10.2 e F20.0 e F31.0 - Transtornos mentais e comportamentais devidos ao uso de álcool } \\
\text { - síndrome de dependência + Esquizofrenia + Transtorno Afetivo Bipolar }\end{array}$ & $1(2,1)$ & 1 & 2,1 \\
\hline & $\begin{array}{l}\text { F19.2 e F31.2 e F60.3 - Transtornos mentais e comportamentais devidos ao uso de } \\
\text { múltiplas drogas e ao uso de outras substâncias psicoativas + Esquizofrenia + } \\
\text { Personalidade com instabilidade emocional }\end{array}$ & $1(2,1)$ & 1 & 2,1 \\
\hline & TOTAL & $48(100,0)$ & 48 & 100,0 \\
\hline
\end{tabular}

Os números entre parênteses correspondem às porcentagens ( $\mathrm{N}=48$, sendo $\mathrm{N}=$ número absoluto dos pacientes pesquisados). Ribeirão Preto-SP, 2008. 
Entre aqueles que tinham dois diagnósticos, se observam três casos em que um dos diagnósticos de doença mental esteve associado ao uso de drogas (substâncias psicoativas, álcool e múltiplas drogas). Em outros cinco casos houve a associação do diagnóstico de transtorno de personalidade a outros transtornos conforme descrito na Tabela 3. Houve um diagnóstico de Personalidade com instabilidade emocional associado à Demência na doença do vírus HIV. Apenas dois pacientes apresentavam registro de três diagnósticos. Em ambos os casos havia: um diagnóstico ligado ao uso de drogas e um diagnóstico de esquizofrenia, em associação com outro diagnóstico psiquiátrico (a citar: Transtorno afetivo bipolar e Personalidade com instabilidade emocional).

O tempo de doença diagnosticada foi verificado em anos completos e está descrito na Tabela 4 comparado ao tipo de diagnóstico. Esse tempo de doença variou de menos de um ano a vinte anos completos. O tempo médio de doença foi igual a 4,4 anos.

TABELA 4 - Distribuição de freqüência dos pacientes egressos de internação psiquiátrica recente em relação ao diagnostico e tempo de doença.

\begin{tabular}{|c|c|c|c|c|c|c|c|c|}
\hline & \multicolumn{7}{|c|}{ DIAGNÓSTICOS } & \multirow[t]{2}{*}{ Total } \\
\hline TEMPO* & $\begin{array}{c}\text { Esquizofrenia e } \\
\text { transtornos } \\
\text { esquizotípicos }\end{array}$ & $\begin{array}{l}\text { Transtorno } \\
\text { humor TAB }\end{array}$ & $\begin{array}{c}\text { Transtorno } \\
\text { Humor } \\
\text { depressivos } \\
\end{array}$ & $\begin{array}{c}\text { Transtorno } \\
\text { doloroso } \\
\text { somatoforme } \\
\end{array}$ & $\begin{array}{c}\text { Personalidade } \\
\text { com } \\
\text { instabilidade }\end{array}$ & $\begin{array}{c}\text { Dois } \\
\text { diagnósticos }\end{array}$ & $\begin{array}{c}\text { Três } \\
\text { diagnósticos }\end{array}$ & \\
\hline 0 & 5 & 3 & 5 & 1 & 1 & 4 & 1 & $20(41,6)$ \\
\hline 2 & 0 & 0 & 0 & 0 & 0 & 2 & 0 & $2(4,2)$ \\
\hline 3 & 1 & 1 & 0 & 0 & 0 & 0 & 0 & $2(4,2)$ \\
\hline 4 & 1 & 0 & 0 & 0 & 0 & 2 & 0 & $3(6,2)$ \\
\hline 5 & 0 & 0 & 1 & 0 & 1 & 0 & 1 & $3(6,2)$ \\
\hline 6 & 3 & 0 & 0 & 0 & 0 & 2 & 0 & $5(10,4)$ \\
\hline 7 & 1 & 0 & 1 & 0 & 0 & 0 & 0 & $2(4,2)$ \\
\hline 8 & 2 & 1 & 0 & 0 & 0 & 1 & 0 & $4(8,3)$ \\
\hline 9 & 0 & 0 & 0 & 0 & 0 & 1 & 0 & $1(2,1)$ \\
\hline 10 & 1 & 0 & 0 & 0 & 1 & 0 & 0 & $2(4,2)$ \\
\hline 13 & 1 & 0 & 0 & 0 & 0 & 0 & 0 & $1(2,1)$ \\
\hline 17 & 0 & 0 & 1 & 0 & 0 & 0 & 0 & $1(2,1)$ \\
\hline 19 & 0 & 1 & 0 & 0 & 0 & 0 & 0 & $1(2,1)$ \\
\hline 20 & 1 & 0 & 0 & 0 & 0 & 0 & 0 & $1(2,1)$ \\
\hline TOTAL & $16(33,3)$ & $6(12,5)$ & $8(16,7)$ & $1(2,1)$ & $3(6,2)$ & $12(25,0)$ & $2(4,2)$ & $48(100,0)$ \\
\hline
\end{tabular}

$*$ mediana $=3,5$ anos, tempo de doença diagnosticada em anos completos. Os números entre parênteses correspondem às porcentagens ( $\mathrm{N}=48$, numero absoluto de pacientes entrevistados). Ribeirão Preto-SP, 2008. 
Observa-se que para 50\% o tempo de doença psiquiátrica diagnosticada foi de aproximadamente 3,5 anos. Destaca-se que 20 pacientes $(41,6 \%)$ tinham menos de um ano de doença, 10 pacientes $(20,8 \%)$ tinham de um a cinco, 29,2\% tinham de seis a dez anos e apenas $8,4 \%$ deles tinham de onze a vinte anos de doença diagnosticada.

O conhecimento dos pacientes sobre o nome da doença mental que os acometia e que por ela estavam em seguimento no serviço de saúde mental não era conhecido por $56 \%$ dos egressos. Assim, apenas vinte e um pacientes souberam dizer o nome da doença mental que lhe fora diagnosticada.

Em relação ao conhecimento quanto ao tratamento psicofarmacológico a eles prescrito, a maioria deles não sabia ou sabia parcialmente o nome e prescrição de todos os remédios a eles prescritos. Entre esses pacientes apenas 43,8\% souberam dizer corretamente nomes e dosagens dos medicamentos que estavam utilizando, conforme apresentado na Tabela 5. Não souberam dizer o nome de nenhum medicamento que estavam utilizando em seu tratamento $25 \%$ dos pacientes e 31,2 sabiam dizer apenas alguns nomes e dosagens.

\section{TABELA 5 - Conhecimento dos pacientes egressos de internação psiquiátrica recente acerca da prescrição psicofarmacológica prescrita.}

\begin{tabular}{|c|c|c|}
\hline Conhecimento quanto à prescrição & Freqüiência & Porcentagem \\
\hline Nenhum & 12 & 25,0 \\
\hline Parcial & 15 & 31,2 \\
\hline Total & 21 & 43,8 \\
\hline TOTAL & 48 & 100,0 \\
\hline
\end{tabular}

Os números entre parênteses correspondem às porcentagens $(\mathrm{N}=48$, sendo $\mathrm{N}=$ número absoluto dos pacientes pesquisados). Ribeirão Preto-SP, 2008. 
Embora não soubessem ou soubessem parcialmente dizer o nome dos medicamentos prescritos, quando questionados acerca da importância da manutenção do tratamento psicofarmacológico, $81,2 \%$ dos pacientes consideraram que o tratamento através de medicamentos é importante (Tabela 6).

Apenas vinte e um pacientes afirmaram ter uma pessoa que os auxilia na manutenção de seu tratamento, embora a maioria deles $(93,8 \%)$ morassem com familiares. Verificou-se assim, que a maioria $(56,25 \%)$ dos pacientes não tinha um cuidador.

Tabela 6 - Opinião dos egressos de internação psiquiátrica recente e seus cuidadores quanto à importância do tratamento psicofarmacológico na manutenção de seu tratamento.

\begin{tabular}{|c|c|c|c|}
\hline \multirow[t]{2}{*}{ Sujeitos } & \multicolumn{2}{|c|}{ Opinião sobre o tratamento psicofarmacológico } & $\mathbf{N}$ \\
\hline & Acham importante(\%) & Não acham importante (\%) & \\
\hline Egressos de internação psiquiátrica recente & $39(81,2)$ & $9(18,8)$ & 48 \\
\hline $\begin{array}{l}\text { Cuidadores dos egressos de internação psiquiátrica } \\
\text { recente }\end{array}$ & $21(100,0)$ & 0 & 21 \\
\hline
\end{tabular}

Entre os vinte e um cuidadores entrevistados foi unânime a opinião de que o tratamento medicamentoso no tratamento dos doentes mentais e de seus entes é importante, conforme apresentado na tabela que segue:

\section{2 - Cuidadores dos pacientes egressos de internação psiquiátrica}

Somente vinte e um pacientes afirmaram ter no seu convívio alguém que os ajudasse na manutenção de seu tratamento (cuidador). O principal diagnóstico entre os 
pacientes que tinham um cuidador foi o de esquizofrenia (52,4\%). A Tabela 7 apresenta detalhadamente as características sócio demográficas dos cuidadores desses pacientes.

A maioria dos cuidadores eram mulheres (76,2\%); casados, possuíam filhos e estudaram até o primeiro grau completo. Quatro cuidadores $(19,0 \%)$ tinham segundo grau incompleto e apenas um o segundo grau completo. Um cuidador possuía curso superior.

\section{Tabela 7 - Características sócio-demográficas e econômicas dos cuidadores de pacientes egressos de internação recente.}

\begin{tabular}{|l|r|l|r|}
\hline Características & $\mathrm{n}(\%)$ & Características & $\mathrm{n}(\%)$ \\
\hline Idade (anos completos) & & Estado civil & $1(4,8)$ \\
Medianedia 46,6 anos & & Solteiro (a) & $13(61,9)$ \\
Variação: 22-62 & $11(52,4)$ & Casado/Amasiado (a) & $3(14,3)$ \\
& & Divorciado/Separado (a) & $4(19,0)$ \\
\hline Sexo & & Viúvo (a) & \\
Feminino & & Filhos & $1(4,8)$ \\
Masculino & $16(76,2)$ & Nenhum & $7(33,3)$ \\
\hline Vínculo familiar com o paciente & $5(23,8)$ & Um & $7(33,3)$ \\
Mãe & & Dois & $6(28,6)$ \\
Irmão(ã) & $8(38,0)$ & Três ou mais & \\
Esposo(a) & $6(28,6)$ & & \\
Filho(a) & $5(23,8)$ & & \\
Sobrinho & $1(4,8)$ & & \\
\cline { 1 - 2 } Escolaridade & $1(4,8)$ & & $3(14,4)$ \\
Primeiro grau incompleto & & Ocupação & $6(28,6)$ \\
Primeiro grau completo & $4(19,0)$ & Desempregado & $4(19,0)$ \\
Segundo grau incompleto & $11(52,4)$ & Faz trabalhos eventuais “bicos” & $4(19,0)$ \\
Segundo grau completo & $4(19,0)$ & Trabalho regular informal & $4(19,0)$ \\
\hline Terceiro grau completo & $1(4,8)$ & Trabalho regular registrado & \\
\hline
\end{tabular}

Os números entre parênteses correspondem às porcentagens de cuidadores $(\mathrm{N}=21$, sendo $\mathrm{N}=$ número total de cuidadores dos pacientes egressos pesquisados). Ribeirão Preto-SP, 2008.

A idade média foi 46,6 anos e variou de vinte e dois anos a sessenta e dois. O grau de parentesco do cuidador com o paciente foi assim distribuído: mães em $38 \%$ dos casos, irmãos em $28,6 \%$, esposos (as) em $23,8 \%$. Houve um cuidador que era filho do paciente e um que era sobrinho.

Eram casados ou amasiados 61,9\% dos cuidadores, 19,0\% eram viúvos(as). Separados ou divorciados representaram $14,3 \%$ da amostra e solteiros $(4,8 \%)$. Quanto 
ao número de filhos 33,3 \% possuíam um filho e 33,3\% possuíam dois filhos. Pacientes com três filhos ou mais somaram $28,6 \%$ da amostra. Apenas um cuidador não tinha filhos.

A principal fonte de renda entre os cuidadores foi o trabalho eventual $(28,6 \%)$. A outra parte da amostra teve distribuição regular dos cuidadores sendo que quatro $(19,0 \%)$ tinham trabalho regular informal (sem registro em carteira), quatro trabalho regular registrado e quatro eram aposentados. Havia três cuidadores desempregados.

\subsection{Manifestação dos sintomas psiquiátricos}

A manifestação de sintomas foi verificada através da aplicação da escala BPRS (Brief Psychiatric Rating Scale-BPRS). A Tabela 8 apresenta a distribuição da frequiência dos pacientes em relação ao nível de gravidade dos sintomas em suas respostas aos dezoito itens da escala BPRS. Cada item psicopatológico da BPRS possui cinco níveis de gravidade com escores que variam de 0 a 4 . $\mathrm{O}$ valor zero significa ausência ou não observação do sintoma e (quatro) corresponde ao nível de maior gravidade ou comprometimento para o referido sintoma.

Os níveis de maior gravidade quanto à manifestação de sintomas (três e quatro) foram os que obtiveram menor freqüência de respostas. Consequentemente, as maiores frequiências de respostas foram identificadas nos dois menores níveis (zero e um).

As respostas dos pacientes egressos de internação psiquiátrica recente quando inquiridos sobre sintomas psiquiátricos foram predominantemente classificadas na ausência de sintomas, nível zero. O que não significa necessariamente que esses pacientes apresentavam pouco comprometimento geral em relação a suas doenças. 
Quando considerado o escore global da escala, o paciente com menor pontuação quanto à manifestação de sintomas psiquiátricos obteve 2 pontos, enquanto o que mais manifestava sintomas psiquiátricos no momento da entrevista obteve 35 pontos. Em média os pacientes egressos de internação psiquiátrica recente tiveram escore de 13 pontos na BPRS.

Tabela 8 - Distribuição de freqüiência quanto às respostas dos pacientes egresso de internação psiquiátrica a BPRS (Brief Psychiatric Rating Scale-BPRS)

\begin{tabular}{|c|c|c|c|c|c|}
\hline Itens da Escala BPRS & $0^{\mathrm{a}}$ & $1^{a}$ & $2^{a}$ & $3^{a}$ & $4^{a}$ \\
\hline 1- Preocupações somáticas & $21(43,8)$ & $16(33,3)$ & $8(16,7)$ & $1(2,1)$ & $2(4,2)$ \\
\hline 2- Ansiedade psíquica & $8(16,7)$ & $19(39,6)$ & $15(31,3)$ & $5(10,4)$ & $1(2,1)$ \\
\hline 3- Retraimento emocional & $14(29,2)$ & $19(39,6)$ & $12(25,0)$ & $2(4,2)$ & $1(2,1)$ \\
\hline 4- Desorganização conceitual (incoerência) & $34(70,8)$ & $11(22,9)$ & $2(4,2)$ & $1(2,1)$ & 0 \\
\hline 5- Autodepreciação e sentimento de culpa & $20(41,7)$ & $15(31,3)$ & $12(25,0)$ & $1(2,1)$ & 0 \\
\hline 6- Ansiedade somática & $18(37,5)$ & $17(35,4)$ & $11(22,9)$ & $1(2,1)$ & $1(2,1)$ \\
\hline 7- Distúrbios motores específicos & $39(81,3)$ & $4(8,3)$ & $2(2,1)$ & $1(2,1)$ & $3(6,3)$ \\
\hline 8- Auto-estima exagerada & $41(85,4)$ & $4(8,3)$ & $3(6,3)$ & 0 & 0 \\
\hline 9- Humor deprimido & $18(37,5)$ & $13(27,1)$ & $9(18,8)$ & $6(12,5)$ & $2(4,2)$ \\
\hline 10- Hostilidade & $13(27,1)$ & $18(37,5)$ & $12(25,0)$ & $5(10,4)$ & 0 \\
\hline 11- Desconfiança & $19(39,6)$ & $20(41,7)$ & $8(16,7)$ & $1(2,1)$ & 0 \\
\hline 12- Alucinações & $34(70,8)$ & $6(12,5)$ & $6(12,5)$ & $1(2,1)$ & $1(2,1)$ \\
\hline 13- Retardo psicomotor & $40(83,3)$ & $7(14,6)$ & $1(2,1)$ & 0 & 0 \\
\hline 14- Falta de cooperação & $23(47,9)$ & $16(33,3)$ & $8(16,7)$ & $1(2,1)$ & 0 \\
\hline 15- Conteúdo de pensamento incomum & $39(81,3)$ & $3(6,3)$ & $4(8,3)$ & 0 & $2(4,2)$ \\
\hline 16- Afeto embotado ou inapropriado & $21(43,8)$ & $12(25,0)$ & $11(22,9)$ & $4(8,3)$ & 0 \\
\hline 17- Agitação psicomotora & $38(79,2)$ & $4(8,3)$ & $3(6,3)$ & $2(4,2)$ & $1(2,1)$ \\
\hline 18- Desorientação e confusão & $37(77,1)$ & $8(16,7)$ & $1(2,1)$ & $2(4,2)$ & 0 \\
\hline Média por níveis de gravidade & 26,5 & 11,8 & $\mathbf{7 , 1}$ & 1,9 & 0,8 \\
\hline
\end{tabular}

\footnotetext{
${ }^{\text {a }} \mathrm{O}$ valor zero significa ausência ou não observação do sintoma e (quatro) corresponde ao nível de maior gravidade ou comprometimento para o referido sintoma. Os números entre parênteses correspondem às porcentagens, sendo $\mathrm{N}=48$, número absoluto dos pacientes pesquisados). Ribeirão Preto-SP, 2008.
}

Nos seguintes itens psicopatológicos, não foi encontrada manifestação do sintoma em seu grau de maior gravidade (nível quatro): desorganização conceitual, autodepreciação e sentimento de culpa, auto-estima exagerada, hostilidade $e$ desconfiança, retardo psicomotor, falta de cooperação, afeto embotado ou inapropriado, desorientação e confusão. 


\subsection{A adesão ao tratamento}

Observou-se que trinta e quatro $(70,8 \%)$ pacientes foram classificados como com baixo grau de adesão ao tratamento psicofarmacológico através da aplicação do teste de Morisky e Green, conforme descrito na Tabela 9.

Em relação ao tipo de baixa adesão ao tratamento que esses pacientes apresentaram, 40,7\% da amostra foi classificada com baixa adesão ao tratamento por comportamento misto: intencional e não intencional. $\mathrm{O}$ baixo grau de adesão por comportamento intencional foi prevalente em nove $(18,7 \%)$ pacientes e o baixo grau de adesão por comportamento não intencional em cinco (10,4\%) deles.

Tabela 9 - Distribuição de freqüência quanto ao grau de adesão ao tratamento medicamentoso e tipo de baixa adesão entre pacientes egressos de internação psiquiátrica, referentes à análise com o teste de Morisky e Green.

\begin{tabular}{|l|c|c|}
\hline \multicolumn{1}{|c|}{ Grau de adesão e Tipo de baixa adesão } & Freqüência & Porcentagem \\
\hline Alto grau adesão & 14 & 29,2 \\
\hline Baixo grau de adesão - intencional & 9 & 18,7 \\
\hline Baixo grau de adesão - não intencional & 5 & 10,4 \\
\hline Baixo grau de adesão com ambos os tipos de comportamento & 20 & 40,7 \\
\hline & 48 & 100,0 \\
\hline
\end{tabular}

$\mathrm{N}=48$, número total de pacientes egressos de internação psiquiátrica. Ribeirão Preto, 2008.

A análise individual das questões que constituem o teste utilizado está descrita na Tabela 10. Nas duas primeiras questões do teste: você alguma vez esquece de tomar seu remédio? e você, às vezes, é descuidado com os horários de tomar seu remédio? predominaram as respostas afirmativas. Enquanto que nas duas últimas quando você se sente bem, alguma vez, deixa de tomar seu remédio? e quando você se sente mal, com o remédio, você às vezes deixa de tomar ele? predominaram as respostas negativas. 
Tabela 10 - Distribuição da freqüência de pacientes egressos de internação psiquiátrica, referente às questões do teste de Morisky e Green.

\begin{tabular}{|l|c|c|}
\hline \multicolumn{1}{|c|}{ Grau de adesão e Tipo de baixa adesão } & SIM & Não \\
\hline \multicolumn{1}{|c|}{$\mathrm{n}(\%)$} & $\mathrm{n}(\%)$ \\
\hline 1- Você alguma vez esquece de tomar seu remédio? & $27(56,3)$ & $21(43,7)$ \\
\hline 2- Você, às vezes, é descuidado com os horários de tomar seu remédio? & $28(58,3)$ & $20(41,7)$ \\
\hline 3- Quando você se sente bem, alguma vez, deixa de tomar seu remédio? & $23(47,9)$ & $25(52,1)$ \\
\hline 4- Quando você se sente mal, com o remédio, vocês vezes deixa de tomar ele? & $19(39,6)$ & $29(60,4)$ \\
\hline
\end{tabular}

Verificamos que a questão dois foi a que teve o maior número de pacientes com resposta afirmativa. Ou seja, vinte e oito pacientes $(58,3 \%)$ afirmaram alguma vez ter esquecido de tomar sua medicação.

$\mathrm{Na}$ questão um 56,3\% dos pacientes afirmaram "esquecer de tomar seu remédio". Na questão dois 58,3\% dos pacientes afirmaram ser “descuidado com os horários de tomar seu remédio".

Deixar de tomar o medicamento por se sentir mal foi a questão mais negada do teste, $60,4 \%$ dos pacientes disseram que mesmo ao se sentir mal não abandonaram o tratamento (Tabela 10). A suspensão do uso da medicação por se sentir bem foi negada por $52,1 \%$ dos entrevistados.

\subsection{Sobrecarga familiar}

A sobrecarga familiar foi verificada entre os vinte e um cuidadores identificados nessa amostra e resultou na constatação de que o cuidado aos pacientes egressos de internação psiquiátrica recente trouxe algum grau de sobrecarga em todos os casos. A sobrecarga familiar total foi de 3,03 em média. Como a FBIS-BR não possui ponto de 
corte estabelecido, a indicação de sobrecarga elevada é feita considerando a porcentagem de respostas aos dois últimos pontos das escalas Likert para cada subescala ${ }^{(69)}$.

A sobrecarga objetiva que se refere às conseqüências negativas, concretas e observáveis, resultantes do papel de cuidador foi predominante maior. Em média, sobrecarga objetiva global entre os cuidadores foi de 2 , 41, sendo a maior sobrecarga observada igual a 3,68 e a menor igual a 1.

A sobrecarga subjetiva global que se refere ao grau em que os familiares percebem os comportamentos ou a dependência dos pacientes como fonte de preocupação (incômodo) teve nessa amostra de cuidadores escore médio de 1,67. A maior sobrecarga subjetiva global registrada foi de 2,59 e a menor 0,91. Na Tabela 11 são apresentados os escores médios das subescalas e questões de cálculo da escala FBIS-BR, de acordo com as respostas dos cuidadores de egressos de internação psiquiátrica recente.

Verifica-se que a sub-escala E- Preocupações do familiar com o paciente concentrou os dois maiores escores médios de sobrecarga total entre as subescalas. Esta subescala é utilizada no cálculo da sobrecarga subjetiva.

Os maiores escores médios referem-se ao item E1b-Preocupações com a segurança física do paciente $(4,09)$ e item E7b- Preocupação com o futuro do paciente.

O terceiro maior escore médio foi registrado na subescala A-Assistência na vida cotidiana do paciente, no item A5a- Preparo da alimentação $(3,90)$. Este item é utilizado para cálculo da sobrecarga objetiva. 
Tabela 11 - Descrição do escore médio das subescalas e questões de cálculo da escala FBIS$B R$, de acordo com as respostas dos cuidadores de egressos de internação psiquiátrica recente.

\begin{tabular}{|c|c|c|c|}
\hline Sub-escalas e questões & Objetiva (a) & Subjetiva (b) & Total \\
\hline Sub-escala A: Assistência ao paciente na vida cotidiana & 2,78 & 0,95 & 3,73 \\
\hline A1 - Higiene e cuidados pessoais & 1,71 & 0,57 & 2,28 \\
\hline A2 - Administração dos medicamentos & 3,19 & 1,23 & 4,43 \\
\hline A3 - Cuidado e limpeza do quarto e roupas & 2,29 & 0,37 & 2,66 \\
\hline A4 - Compras diversas & 2,76 & 0,62 & 3,38 \\
\hline A5 - Preparo da alimentação & 3,90 & 1,28 & 5,18 \\
\hline A6 - Transporte & 3,05 & 1,37 & 4,43 \\
\hline A7 - Administração do dinheiro & 3,29 & 0,95 & 4,23 \\
\hline A8 - Atividades e ocupação do tempo & 2,67 & 1,28 & 3,95 \\
\hline A9 - Freqüência às consultas médicas e atividades de tratamento & 2,14 & 0,90 & 3,04 \\
\hline Sub-escala B: Supervisão dos comportamentos problemáticos & $\mathbf{1 , 8 2}$ & $\mathbf{0 , 9 2}$ & 2,75 \\
\hline B1 - Comportamentos problemáticos & 2,57 & 1,67 & 4,24 \\
\hline B2 - Demanda excessiva de atenção & 1,86 & 0,70 & 2,57 \\
\hline B3 - Perturbações durante a noite & 1,90 & 1 & 2,9 \\
\hline B4 - Agressividades verbal e física & 1,38 & 0,70 & 2,09 \\
\hline B5 - Tentativa ou ameaça de suicídio & 2 & 1,33 & 3,33 \\
\hline B6 - Bebidas alcoólicas* & 1,19 & 0,18 & 1,38 \\
\hline B7 - Excesso de alimentos, cigarros e líquidos. & 1,19 & 0,18 & 1,38 \\
\hline B8 - Abuso de drogas* & 1,05 & 0 & 1,04 \\
\hline Sub-escala D: Impacto na rotina & 2,45 & & 2,45 \\
\hline D1a - Faltas, atrasos ou cancelamento de compromissos. & 2,38 & - & 2,38 \\
\hline D1b - Alteração nas atividades sociais e de lazer & 2,57 & - & 2,57 \\
\hline D1c - Perturbação nos serviços ou rotina da casa & 2,76 & - & 2,76 \\
\hline D1d - Alteração nos cuidados e atenção aos outros membros da família & 2,10 & - & 2,10 \\
\hline Sub-escala E: Preocupações com o paciente & & $\mathbf{3 , 2 1}$ & 3,21 \\
\hline E1 - Segurança física do paciente & - & 4,09 & 4,09 \\
\hline E2 - Adequação do tratamento médico fornecido ao paciente & - & 2,28 & 2,26 \\
\hline E3 - Vida social do paciente & - & 3,48 & 3,48 \\
\hline E4 - Saúde física do paciente & - & 3,33 & 3,33 \\
\hline E5 - Condições de moradia para o paciente & - & 1,66 & 1,67 \\
\hline E6 - Sobrevivência financeira do paciente na ausência do cuidador & - & 3,09 & 3,09 \\
\hline E7 - Futuro do paciente & - & 4,57 & 4,57 \\
\hline Escore global de sobrecarga familiar & 2,4 & 1,6 & $\mathbf{3 , 0 3}$ \\
\hline
\end{tabular}

Na sub-escala A- Assistência na vida cotidiana do paciente, o escore médio foi de 2,78 para a sobrecarga objetiva e de 0,95 para a sobrecarga subjetiva. A questão que obteve maior escore médio na sobrecarga objetiva foi o preparo da alimentação, com escore de 3,90. Na sobrecarga subjetiva, o maior escore esteve relacionado à questão de transporte com escore médio de 1,37. 
$\mathrm{Na}$ sobrecarga objetiva, com maiores escores, seguiram as questões: administração do dinheiro $(3,29)$ e a administração dos medicamentos $(3,19)$. $\mathrm{Na}$ subjetiva, seguiram as questões: preparo da alimentação e atividades e ocupação de tempo ambas com escore médio de 1,28 e administração dos medicamentos com escore 1,24 .

Para a subescala B- Supervisão aos comportamentos problemáticos do paciente, a questão com maior escore foi a questão B1 que se refere a comportamentos problemáticos. Na sobrecarga objetiva o escore dessa questão foi 2,57 e na subjetiva 1,67. Outras questões de destaque foram para sobrecarga objetiva: tentativa ou ameaça de suicídio (escore 2) e perturbações durante a noite (1,90); para a sobrecarga subjetiva comportamentos problemáticos $(1,67)$ e tentativa ou ameaça de suicídio $(1,33)$.

O impacto do cuidado ao doente mental nas rotinas diárias da família que é avaliado na subescala D da FBIS-BR para cálculo da sobrecarga objetiva, indicou um escore médio de 3,33 na questão: mudanças mais ou menos permanentes na rotina, no trabalho e na vida social. A questão perturbação nos serviços ou rotina da casa obteve escore médio de 2,76 e a questão alteração nas atividades sociais e de lazer escore 2,57 .

A preocupação com o futuro do paciente e com a segurança física do paciente fazem parte da sub-escala E-Preocupações do familiar com o paciente e se destacaram como as questões com os maiores escores registrados. Com escore médio de 4,57 a preocupação com o futuro do paciente foi a que obteve o maior escore médio dentro da escala, seguida pela questão relativa à preocupação do cuidador em relação a segurança 
física do paciente, com escore 4,09. Preocupações com as condições de moradia para o paciente foi a questão que obteve menor escore médio nessa subescala.

\subsection{A internação Psiquiátrica}

Entre os egressos de internação psiquiátrica observamos que $62,5 \%$ deles já tinham sido internados ao menos uma vez antes da internação mais recente. A quantidade de internações anteriores variou de uma a treze, conforme descrito na Tabela12 que segue.

Tabela 12 - Distribuição do número de internações anteriores de pacientes egressos de internação recente.

\begin{tabular}{|c|c|c|c|}
\hline Internação antes & $\mathrm{n}(\%)$ & Número de internações & $\mathrm{n}(\%)$ \\
\hline Não & $18(37,5)$ & 0 & $18(37,5)$ \\
\hline Sim & $30(62,5)$ & $\begin{array}{c}1 \\
2 \\
3 \\
4 \\
5 \\
6 \\
9 \\
10 \\
11 \\
12 \\
13 \\
\end{array}$ & $\begin{array}{l}9(18,8) \\
3(6,3) \\
1(2,1) \\
3(6,3) \\
4(8,3) \\
1(2,1) \\
1(2,1) \\
5(10,4) \\
1(2,1) \\
1(2,1) \\
1(2,1) \\
\end{array}$ \\
\hline Total & $48(100,0)$ & 151 & $48(100,0)$ \\
\hline
\end{tabular}

A internação recente foi a primeira internação psiquiátrica de suas vidas para 37,5\% dos pacientes da amostra. Entre os egressos cinco já haviam sido internados dez vezes antes da internação recente e nove já tinham sido internados uma vez. A média de internação foi de 3,14 . 
As informações acerca dos comportamentos que motivaram a internação recente foram coletadas através da guia de referência preenchida aos pacientes na ocasião da alta hospitalar, as quais são entregues no serviço de saúde mental na ocasião da consulta médica. Estes comportamentos estão descritos na Tabela 13 que segue.

TABELA 13 - Descrição dos comportamentos que determinaram
à necessidade de internação dos pacientes egressos de internação
psiquiátrica recente.
\begin{tabular}{|l|c|c|}
\hline Motivos de internação registrados guia referência & Frequiência & Porcentagem \\
\hline Acatisia (efeito colateral medicação) & 1 & 2,1 \\
\hline Uso ou abuso de álcool e comportamento agressivo & 1 & 2,1 \\
\hline Agressividade, irritabiliadede, agitação psicomotora & 12 & 25,0 \\
\hline Ideação suicida ou tentativa de suicídio & 17 & 35,4 \\
\hline Delírios somatoformes resistentes & 2 & 4,2 \\
\hline Sintomas psicóticos (delírios, alucinações, mania). & 14 & 29,1 \\
\hline Hipersexualidade & 1 & 2,1 \\
\hline Total & $\mathbf{4 8}$ & $\mathbf{1 0 0 , 0}$ \\
\hline
\end{tabular}
Os números entre parênteses correspondem às porcentagens (N=48, sendo N = número absoluto dos
pacientes pesquisados). Ribeirão Preto-SP, 2008.

O alto risco à vida e saúde de si ou de outros embasou a indicação da maior parte das internações observadas neste trabalho. Observou-se que a ideação suicida com, ou sem, tentativa de suicídio ocasionou a internação de $35,4 \%$ dos sujeitos da amostra. A manifestação de sintomas psicóticos motivou a internação de 29,1\% dos egressos e comportamentos agressivos ocasionaram a internação de outros $25 \%$.

Um paciente foi internado por ter apresentado acatisia, efeito adverso pelo uso de um medicamento antipsicótico (Haloperidol). Em decorrência do uso de bebida alcoólica um paciente teve grande alteração de humor que resultou em sua internação por comportamento agressivo. Houve uma internação por comportamento hipersexualizado.

Em média, estes pacientes permaneceram internados 27 dias. O menor período de internação foi de dois dias e a internação de maior duração foi de 160 dias. Apenas 
oito pacientes afirmaram ter procurado um serviço emergencial de saúde no mês que antecedeu a internação mais recente.

\subsection{A reinternação psiquiátrica}

Dos quarenta e oito sujeitos entrevistados em quatro meses, seis (12,5\%) tiveram reinternação no período de coleta dos dados, sendo quatro homens e duas mulheres. As principais características desses pacientes estão descritas na Tabela 14.

A idade média desses pacientes foi de 32 anos, $50 \%$ deles eram solteiros, não possuíam filhos, eram aposentado e tinham renda individual de um salário mínimo. Tinham apenas o primeiro grau incompleto como escolaridade, 66,7\% deles. Apenas um possuía vinculo empregatício e estava afastado do emprego.

Cinco pacientes residiam com familiares em casa própria. Um era morador de rua e afirmava residir em seu carro. A renda familiar não ultrapassou dois salários mínimos.

Nenhum deles sabia dizer o nome de sua doença. Em média os pacientes que necessitaram de internação no período tinham 8,3 anos de doença diagnosticada. Três pacientes tinham o diagnóstico de esquizofrenia, um paciente diagnóstico de transtorno Afetivo Bipolar, um deles tinha dois diagnósticos (Personalidade com instabilidade emocional e Episódio depressivo leve) e um três diagnósticos (transtornos mentais e comportamentais devidos ao uso de álcool - síndrome de dependência junto à esquizofrenia e Transtorno Afetivo Bipolar). 
Todos os pacientes que tiveram reinternação no período apresentavam baixo grau de adesão ao tratamento psicofarmacológico e nenhum deles sabia dizer o nome de todos os medicamentos que estava em tratamento. Desses, um paciente foi classificado com baixo grau de adesão do tipo intencional, um com baixo grau de adesão do tipo não intencional e quatro classificados com baixo grau de adesão do tipo misto.

Quatro pacientes tinham um cuidador responsável por seu cuidado, sendo que nesses cuidadores a sobrecarga subjetiva foi de 1,65 em média e a sobrecarga objetiva de 2,35 . 
Tabela 14 - Distribuição de freqüência quanto a características sócio-demográficas, econômicas e clínicas dos pacientes egressos de internação recente que necessitaram de reinternação.

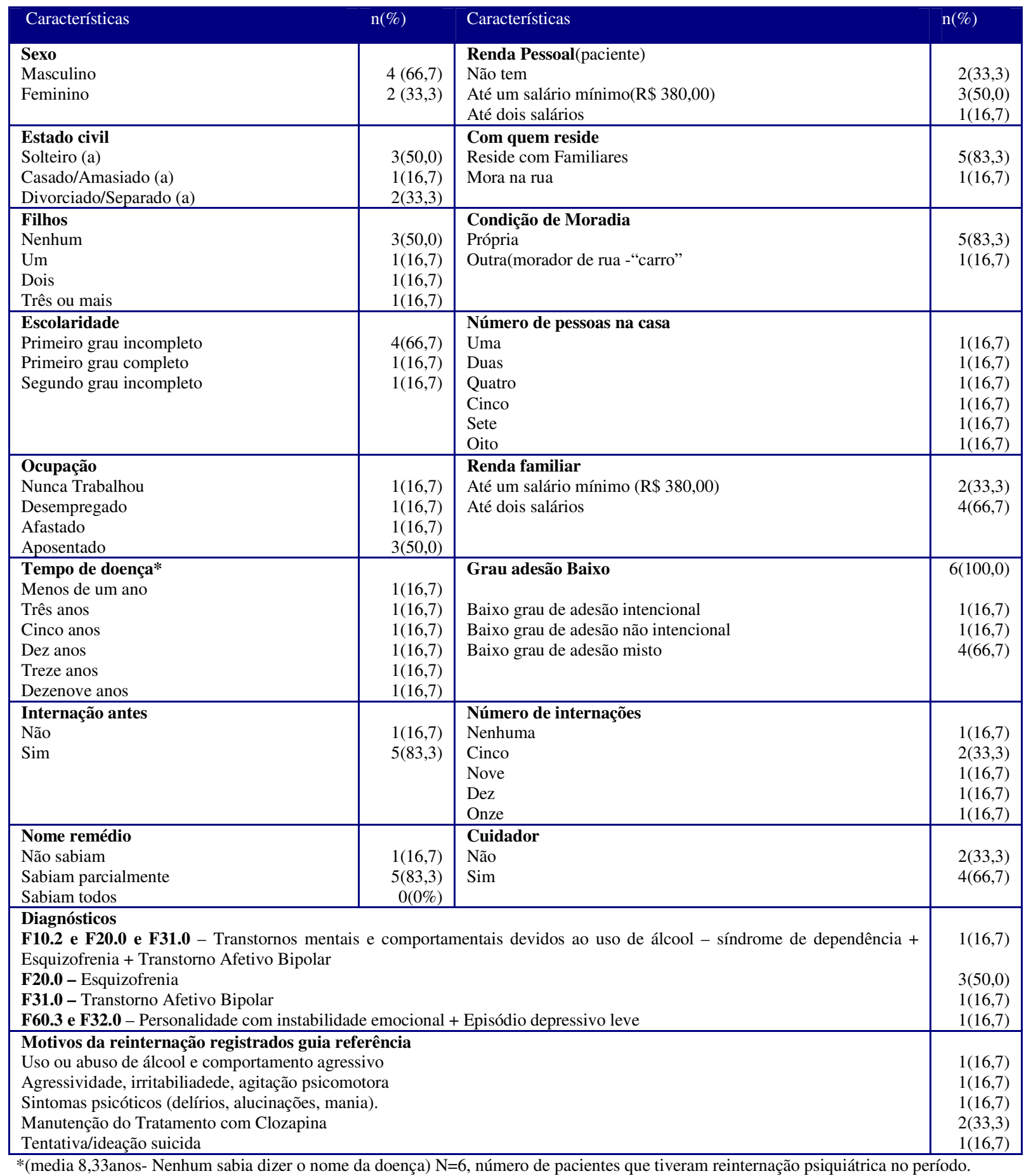




\subsection{Os pacientes egressos de internação, seus cuidadores e a manutenção do} tratamento psicofarmacológico (a adesão ao tratamento, a manifestação de sintoma, sobrecarga familiar e a ocorrência de reinternação)

Para melhor conhecer quem são pacientes egressos de internação psiquiátrica e seus cuidadores considerando também alguns aspectos cotidianos relacionados à manutenção de seu tratamento, verificamos além das variáveis sócio demográficas e econômicas, o grau de adesão ao tratamento psicofarmacológico (Teste de Morisky e Green), a manifestação de sintomas psiquiátricos (Escala BPRS) e a sobrecarga familiar (Escala FBIS-BR). Os resultados referentes à análise correlacional desses dados são descritos a seguir.

A manifestação de sintomas psiquiátricos verificada pela aplicação da BPRS (Brief Psychiatric Rating Scale-BPRS) apresentou relação com diversas variáveis conforme apresentado na Tabela 15.

Os itens 1- Preocupações somáticas, 8- Autoestima exagerada, 11Desconfiança, 13- Retardo psicomotor e 16- Afeto embotado ou inapropriado não apresentaram correlação significativa com nenhuma das demais variáveis.

Relacionados à ocorrência de reinternação se destacaram oito itens relativos a sintomas psicopatológicos e o escore total da BPRS: 4-Desorganização conceitual (incoerência) $(\mathrm{p}<0,05) ; 6-$ Ansiedade somática $(\mathrm{p}<0,05) ; 10$ - Hostilidade $(\mathrm{p}<0,01), 12$ Alucinações $(\mathrm{p}<0,01) ; 14-$ Falta de cooperação $(\mathrm{p}<0,01) ; 15$ - Conteúdo de pensamento incomum $(\mathrm{p}<0,05) ;$ 17- Agitação psicomotora $(\mathrm{p}<0,05) ; 18$ - Desorientação $e$ confusão( $\mathrm{p}<0,01) ;$ BPRS escore total $(\mathrm{p}<0,01)$. 
Nota-se que essa correlação faz sentido se observados os principais motivos de internação e reinternação. Descritos na Tabela 13, os motivos de internação: ideação suicida ou tentativa de suicídio $(34,4 \%)$, manifestação de Sintomas psicóticos como delírios, alucinações, mania $(29,1 \%)$ e manifestação de agressividade, irritabilidade, agitação psicomotora $(25,0 \%)$ foram destacados como os mais prevalentes. Entre os pacientes que reinternaram, a manifestação de agressividade, irritabilidade, agitação psicomotora motivou a reinternação de $50 \%$ dos pacientes e a manifestação de sintomas psicóticos a de $33,3 \%$ deles.

Tabela 15 - Distribuição do Coeficiente de correlação de Spearman em relação às variáveis reinternação psiquiátrica, ter um cuidador, grau de adesão ao tratamento, Teste de Morisky e Green e sobrecarga familiar e os dezoito itens da BPRS (Brief Psychiatric Rating Scale-BPRS).

\begin{tabular}{|c|c|c|c|c|c|c|c|c|c|}
\hline \multirow[t]{2}{*}{ Itens da Escala BPRS } & \multirow[t]{2}{*}{ Reinternação } & \multirow{2}{*}{$\begin{array}{c}\text { Ter } \\
\text { cuidador }\end{array}$} & \multirow{2}{*}{$\begin{array}{c}\text { Grau Adesão } \\
\text { ao } \\
\text { tratamento }\end{array}$} & \multicolumn{4}{|c|}{ Tese Morisky adesão ${ }^{1}$} & \multicolumn{2}{|c|}{ Sobrecarga } \\
\hline & & & & $\begin{array}{c}\text { Esquecimento }^{\mathrm{a}} \\
1\end{array}$ & $\begin{array}{l}\text { Descuido } \\
\text { horário }^{a} 2\end{array}$ & $\begin{array}{l}\text { Deixar por } \\
\text { bem }^{\text {a }} 3\end{array}$ & $\begin{array}{c}\text { Deixar } \\
\text { por mal }^{\text {a }} 4\end{array}$ & Subjetiva & Objetiva \\
\hline $\begin{array}{l}\text { 1- Preocupações } \\
\text { somáticas }\end{array}$ & $-0,066$ & 0,172 & $-0,046$ & 0,228 & 0,246 & 0,026 & 0,025 & $-0,141$ & $-0,206$ \\
\hline 2- Ansiedade psíquica & 0,268 & 0,268 & $-0,152$ & 0,110 & 0,145 & $-0,032$ & $-0,146$ & $-0,284$ & $-0,290$ \\
\hline $\begin{array}{l}\text { 3- Retraimento } \\
\text { emocional }\end{array}$ & $-0,024$ & $0,334^{*}$ & $-0,262$ & $-0,254$ & 0,124 & 0,145 & $-0,154$ & $-0,271$ & $-0,135$ \\
\hline $\begin{array}{l}\text { 4-Desorganização } \\
\text { conceitual } \\
\text { (incoerência) }\end{array}$ & $0,357^{*}$ & 0,090 & $-0,314^{*}$ & $0,398^{* *}$ & $0,351^{* *}$ & $0,407^{* *}$ & 0,263 & $-0,099$ & $-0,086$ \\
\hline $\begin{array}{l}\text { 5- Autodepreciação e } \\
\text { sentimento de culpa }\end{array}$ & 0,063 & $-0,153$ & 0,055 & $-0,055$ & $-0,057$ & $-0,321^{*}$ & $-0,259$ & 0,209 & 0,230 \\
\hline $\begin{array}{ll}6- & \text { Ansiedade } \\
\text { somática } & \end{array}$ & $0,291^{*}$ & 0,157 & $-0,147$ & 0,202 & 0,268 & 0,061 & 0,052 & $-0,174$ & $-0,206$ \\
\hline $\begin{array}{l}\text { 7- Distúrbios motores } \\
\text { específicos }\end{array}$ & 0,124 & 0,022 & $-0,202$ & 0,205 & $0,307^{*}$ & 0,173 & 0,160 & $-0,007$ & $-0,045$ \\
\hline $\begin{array}{l}\text { 8- Auto-estima } \\
\text { exagerada }\end{array}$ & 0,037 & $-0,012$ & 0,138 & 0,245 & 0,264 & $-0,157$ & 0,023 & 0,036 & 0,045 \\
\hline 9- Humor deprimido & $-0,140$ & $-0,104$ & 0,090 & $-0,027$ & $-0,003$ & $-0,305^{*}$ & $-0,399^{* *}$ & 0,115 & 0,094 \\
\hline 10- Hostilidade & $0,422^{\star *}$ & 0,011 & $-0,156$ & $0,310^{*}$ & $0,305^{*}$ & 0,022 & $-0,053$ & $-0,043$ & $-0,011$ \\
\hline 11- Desconfiança & 0,284 & $-0,015$ & $-0,037$ & 0,238 & 0,256 & $-0,187$ & $-0,109$ & 0,007 & 0,026 \\
\hline 12- Alucinações & $0,417^{* *}$ & 0,216 & $-0,298^{*}$ & $0,382^{* *}$ & $0,358^{*}$ & 0,175 & 0,056 & $-0,202$ & $-0,178$ \\
\hline $\begin{array}{ll}13- & \text { Retardo } \\
\text { psicomotor } & \end{array}$ & $-0,004$ & 0,176 & $-0,166$ & 0,173 & 0,045 & 0,137 & 0,007 & $-0,188$ & $-0,149$ \\
\hline $\begin{array}{ll}14- & \text { Falta } \\
\text { cooperação }\end{array}$ & $0,370^{* *}$ & 0,139 & $-0,283$ & 0,271 & 0,269 & 0,735 & 0,224 & $-0,137$ & $-0,133$ \\
\hline $\begin{array}{l}\text { 15- Conteúdo de } \\
\text { pensamento incomum }\end{array}$ & $0,307^{*}$ & 0,216 & $-0,187$ & $0,312^{*}$ & $0,294^{*}$ & 0,188 & 0,273 & $-0,243$ & $-0,256$ \\
\hline $\begin{array}{l}\text { 16- Afeto embotado } \\
\text { ou inapropriado }\end{array}$ & $-0,041$ & 0,249 & $-0,111$ & 0,238 & 0,105 & 0,072 & 0,165 & $-0,200$ & $-0,229$ \\
\hline $\begin{array}{l}\text { 17- Agitação } \\
\text { psicomotora }\end{array}$ & $0,321^{*}$ & 0,081 & $-0,229$ & 0,269 & $0,340^{*}$ & $0,337^{*}$ & $0,325^{*}$ & $-0,113$ & $-0,141$ \\
\hline $\begin{array}{l}\text { 18- Desorientação e } \\
\text { confusão }\end{array}$ & $0,419^{* *}$ & 0,130 & $-0,144$ & 0,105 & 0,083 & $0,287^{*}$ & 0,197 & $-0,100$ & $-0,188$ \\
\hline BPRS Total & $0,394^{* *}$ & 0,264 & $-0,217$ & $0,315^{*}$ & $0,298^{*}$ & 0,100 & 0,040 & $-0,264$ & $-0,235$ \\
\hline
\end{tabular}

*Correlação estatisticamente significativa $\mathrm{p}<0,05$; ** Correlação estatisticamente significativa p<0,01. ${ }^{a}$ Tese Morisky e Green questões: 1 - Você alguma vez esquece de tomar seu remédio?; 2- Você, às vezes, é descuidado com os horários de tomar seu remédio?; 3- Quando você se sente bem, alguma vez, deixa de tomar seu remédio?; 4- Quando você se sente mal, com o remédio, você às vezes deixa de tomar ele? (N=48, sendo $\mathrm{N}=$ número absoluto dos pacientes pesquisados). Ribeirão Preto-SP, 2008. 
O item 3- Retraimento emocional demonstrou correlação estatisticamente significativa com a questão de ter ou não um cuidador $(\mathrm{p}<0,05)$. A Tabela 16 apresenta a distribuição dos pacientes em relação a essas duas variáveis.

Tabela 16 - Distribuição de freqüências dos pacientes egressos de internação psiquiátrica em relação a possuir um cuidador e a manifestação de retraimento emocional.

\begin{tabular}{|c|c|c|c|c|}
\hline \multirow{2}{*}{$\begin{array}{c}\text { BPRS (Brief Psychiatric Rating } \\
\text { Scale-BPRS) }\end{array}$} & \multirow{2}{*}{$\begin{array}{l}\text { Nível de } \\
\text { gravidade }\end{array}$} & \multicolumn{2}{|c|}{ Paciente com cuidador } & \multirow[t]{2}{*}{ Total } \\
\hline & & Não & Sim & \\
\hline Item 3- Retraimento emocional & 0 & $12(44,4)$ & $2(9,5)$ & $14(29,2)$ \\
\hline & 1 & $9(33,4)$ & $10(47,6)$ & $19(39,6)$ \\
\hline & 2 & $4(14,8)$ & $8(38,1)$ & $12(25,0)$ \\
\hline & 3 & $2(7,4)$ & 0 & $2(4,2)$ \\
\hline & 4 & 0 & $1(4,8)$ & $1(2,1)$ \\
\hline Total & & 27 & 21 & 48 \\
\hline
\end{tabular}

Os números entre parênteses correspondem às porcentagens ( $n=27$, número total de pacientes egressos de internação psiquiátrica sem um cuidador; $n=21$, número total de pacientes com cuidadores dos pacientes egressos pesquisados; $N=48$, número total de pacientes egressos de internação psiquiátrica ). Ribeirão Preto-SP, 2008.

A maioria dos pacientes que tinham um cuidador pontuou no nível um e dois de gravidade nesse sintoma e um deles manifestou o maior grau de gravidade no item. Entre aqueles que não tinham um cuidador $44,4 \%$ não manifestaram retraimento emocional e $33,3 \%$ pontuaram no grau um de gravidade. Nenhum dos pacientes que não possuíam cuidador manifestou o maior grau de gravidade nesse item.

O grau de adesão ao tratamento esteve correlacionado com o item 4Desorganização conceitual (incoerência) $(\mathrm{p}<0,05)$ e com o item 12-Alucinações $(\mathrm{p}<0,05)$.

Na Tabela 17 está apresentada a distribuição de freqüência dos pacientes entre essas três variáveis. Observa-se que pacientes que tinham baixo grau de adesão foram os que mais manifestaram os dois sintomas. 
Tabela 17 - Distribuição de freqüência dos pacientes em relação ao grau de adesão ao tratamento e a manifestação dos sintomas doze e treze da BPRS (Brief Psychiatric Rating Scale-BPRS).

\begin{tabular}{|c|c|c|c|c|c|c|}
\hline \multirow[t]{2}{*}{ GRAU de adesão } & \multicolumn{5}{|c|}{ BPRS12-Alucinações } & \multirow[t]{2}{*}{ Total } \\
\hline & 0 & 1 & 2 & 3 & 4 & \\
\hline Baixo & 21 & 6 & 5 & 1 & 1 & 34 \\
\hline Alto & 13 & 0 & 1 & 0 & 0 & 14 \\
\hline Total & 34 & 6 & 6 & 1 & 1 & 48 \\
\hline & BPRS4- & gan & COI & (i) & & \\
\hline Baixo & 21 & 10 & 2 & 1 & 0 & 34 \\
\hline Alto & 13 & 1 & 0 & 0 & 0 & 14 \\
\hline Total & 34 & 11 & 2 & 1 & 0 & 48 \\
\hline
\end{tabular}

( $\mathrm{N}=48$, sendo $\mathrm{N}$ = número absoluto dos pacientes pesquisados). Ribeirão Preto-SP, 2008.

O sintoma 4-Desorganização conceitual (incoerência) também esteve correlacionado com as três primeiras perguntas do Teste de Morisky e Green $(\mathrm{p}<0,01)$ : 1-Você alguma vez esquece de tomar seu remédio?; 2-Você, às vezes, é descuidado com os horários de tomar seu remédio?; 3-Quando você se sente bem, alguma vez, deixa de tomar seu remédio?. A Tabela 19 apresenta essa relação:

Tabela 18 - Distribuição de frequiência dos pacientes em relação às respostas a as perguntas 1,2 e 3 do Teste de adesão de Morisky e Green e ao item quatro da escala BPRS (Brief Psychiatric Rating Scale-BPRS)

\begin{tabular}{|c|c|c|c|c|c|c|}
\hline & & \multicolumn{4}{|c|}{$\begin{array}{l}\text { BPRS4-Desorganização } \\
\text { conceitual (incoerência) }\end{array}$} & \multirow[t]{2}{*}{ Total } \\
\hline & & $\mathbf{0}$ & 1 & 2 & 3 & \\
\hline \multirow[t]{2}{*}{ 1-Você alguma vez esquece de tomar seu remédio? } & não & 19 & 2 & & & 21 \\
\hline & sim & 15 & 9 & 2 & 1 & 27 \\
\hline \multirow[t]{3}{*}{ Total } & & 34 & 11 & 2 & 1 & 48 \\
\hline & & \multicolumn{4}{|c|}{$\begin{array}{l}\text { BPRS4-Desorganização } \\
\text { conceitual (incoerência }\end{array}$} & Total \\
\hline & & $\mathbf{0}$ & 1 & 2 & 3 & \\
\hline \multirow[t]{2}{*}{ 2-Você, às vezes, é descuidado com os horários de tomar seu remédio? } & não & 19 & 1 & & & 20 \\
\hline & $\operatorname{sim}$ & 15 & 10 & 2 & 1 & 28 \\
\hline \multirow[t]{3}{*}{ Total } & & 34 & 11 & 2 & 1 & 48 \\
\hline & & \multicolumn{4}{|c|}{$\begin{array}{l}\text { BPRS4-Desorganização } \\
\text { conceitual (incoerência }\end{array}$} & Total \\
\hline & & $\mathbf{0}$ & 1 & 2 & 3 & \\
\hline \multirow[t]{2}{*}{ 3-Quando você se sente bem, alguma vez, deixa de tomar seu remédio? } & não & 22 & 3 & & & 25 \\
\hline & sim & 12 & 8 & 2 & 1 & 23 \\
\hline Total & & 34 & 11 & 2 & 1 & 48 \\
\hline
\end{tabular}


( $\mathrm{N}=48$, sendo $\mathrm{N}=$ número absoluto dos pacientes pesquisados). Ribeirão Preto-SP, 2008.

Verifica-se que os pacientes que afirmaram ter os três tipos de comportamento relacionados à baixa adesão ao tratamento psicofarmacológico foram aqueles que mais manifestavam a desorganização conceitual.

A questão um do teste de adesão esteve correlacionada com o item quatro com descrito anteriormente e com os itens: 10- Hostilidade $(\mathrm{p}<0,05)$, 12-Alucinações $(\mathrm{p}<0,01), 15-$ Conteúdo de pensamento incomum $(\mathrm{p}<0,05)$ e como Escore total da BPSR $(\mathrm{p}<0,05)$, conforme descrito nas Tabelas 19 e 20 que seguem.

Tabela 19 - Distribuição de frequiência dos pacientes em relação as respostas a pergunta 1 do Teste de adesão de Morisky e Green e aos itens dez, doze e quinze da escala BPRS.

\begin{tabular}{|c|c|c|c|c|c|c|c|}
\hline & & \multicolumn{5}{|c|}{ BPRS10 Hostilidade } & \multirow{2}{*}{ Total } \\
\hline & & 0 & 1 & 2 & 3 & 4 & \\
\hline \multirow[t]{2}{*}{ MORISKY1 Você alguma vez esquece de tomar seu remédio? } & não & 8 & 9 & 3 & 1 & 0 & 21 \\
\hline & $\operatorname{sim}$ & 5 & 9 & 9 & 4 & 0 & 27 \\
\hline \multirow[t]{3}{*}{ Total } & & 13 & 18 & 12 & 5 & 0 & 48 \\
\hline & & \multicolumn{5}{|c|}{ BPRS12 Alucinações } & Total \\
\hline & & 0 & 1 & 2 & 3 & 4 & \\
\hline \multirow[t]{2}{*}{ MORISKY1 } & não & 19 & 1 & 1 & 0 & 0 & 21 \\
\hline & $\operatorname{sim}$ & 15 & 5 & 5 & 1 & 1 & 27 \\
\hline \multirow[t]{3}{*}{ Total } & & 34 & 6 & 6 & 1 & 1 & 48 \\
\hline & & \multicolumn{5}{|c|}{$\begin{array}{l}\text { BPRS15 Conteúdo de } \\
\text { pensamento incomum }\end{array}$} & Total \\
\hline & & 0 & 1 & 2 & 3 & 4 & \\
\hline \multirow[t]{2}{*}{ MORISKY1 } & não & 20 & & 1 & 0 & 0 & 21 \\
\hline & $\operatorname{sim}$ & 19 & 3 & 3 & 0 & 2 & 27 \\
\hline Total & & 39 & 3 & 4 & $\mathbf{0}$ & 2 & 48 \\
\hline
\end{tabular}

Em relação ao item 10- Hostilidade, dos vinte e sete pacientes que responderam se esquecer de tomar seu remédio $13(48 \%)$ manifestavam os graus três e quatro do sintoma, indicando que esses tinham maior grau de gravidade quanto à hostilidade (Tabela 19). Em relação aos itens 12-Alucinações e 15-Conteúdo de pensamento incomum a relação é semelhante. 
Na Tabela 20, verifica-se que todos os cinco pacientes que obtiveram os maiores escores Totais na Escala BPRS responderam se esquecer de tomar seus medicamentos. Os pacientes que responderam não a essa pergunta tiveram escore total abaixo de 20.

Tabela 20 - Distribuição de freqüiência dos pacientes em relação às respostas a pergunta 1 do Teste de adesão de Morisky e Green e ao Escore Total da BPRS (Brief Psychiatric Rating Scale-BPRS).

\begin{tabular}{|r|c|c|c|}
\hline BPRS Escore total** & MORISKY 1 Você alguma vez esquece de tomar seu remédio? & Total \\
\cline { 2 - 4 } & não & sim & \\
\hline $\mathbf{2 ~ a ~ 1 0}$ & 10 & 11 & $\mathbf{2 1}$ \\
\hline $\mathbf{1 1}$ a 20 & 11 & 3 & $\mathbf{2 2}$ \\
\hline $\mathbf{2 1}$ a 30 & 0 & 2 & $\mathbf{3}$ \\
\hline 31 a 35 & 0 & $\mathbf{2 7}$ & $\mathbf{4 8}$ \\
\hline Total & $\mathbf{2 1}$ & &
\end{tabular}

( $\mathrm{N}=48$, sendo $\mathrm{N}$ = número absoluto dos pacientes pesquisados). Ribeirão Preto-SP, 2008.

A questão dois do Teste Morisky e Green, Você, às vezes, é descuidado com os horários de tomar seu remédio?, demonstrou correlação foi estatisticamente significativa em relação ao item 7- Distúrbios motores específicos $(\mathrm{p}<0,05), 10$ Hostilidade $(\mathrm{p}<0,05), 12$ - Alucinações $(\mathrm{p}<0,05), 15$ - Conteúdo de pensamento incomum $(\mathrm{p}<0,05), 17-$ Agitação psicomotora $(\mathrm{p}<0,05)$ e com o Escore total da BPRS $(\mathrm{p}<0,05)$.

Tabela 21- Distribuição de freqüência dos pacientes em relação as respostas a pergunta 2 do Teste de adesão de Morisky e Green e ao Escore Total da BPRS (Brief Psychiatric Rating Scale).

\begin{tabular}{|c|c|c|c|}
\hline \multirow[t]{2}{*}{ BPRS Escore total* } & \multicolumn{2}{|c|}{$\begin{array}{l}\text { Você, às vezes, é descuidado com os } \\
\text { horários de tomar seu remédio? }\end{array}$} & \multirow[t]{2}{*}{ Total } \\
\hline & não & $\operatorname{sim}$ & \\
\hline 2 a 10 & 10 & 11 & 21 \\
\hline 11 a 20 & 11 & 12 & 23 \\
\hline 21 a 30 & 0 & 3 & 3 \\
\hline 31 a 35 & 0 & 2 & 2 \\
\hline Total & 21 & 27 & 48 \\
\hline
\end{tabular}


Na Tabela 21, verifica-se que todos os cinco pacientes que obtiveram os maiores escores Totais na Escala BPRS responderam também ser descuidados com o horário de tomar seus medicamentos. Os pacientes que responderam não a essa pergunta tiveram escore total abaixo de 20.

Na Tabela 22, são apresentadas as freqüências dos pacientes egressos de internação psiquiátrica recente em relação a suas pontuações nos dezoito itens da escala BPRS e a variância de postos avaliada pelo Teste não paramétrico de Friedman, para identificar os itens que concentraram maior gravidade na manifestação dos sintomas psicopatológicos.

Tabela 22 - Porcentagens de respostas dos pacientes egressos de internação psiquiátrica recente aos itens que avaliam sintomas psicopatológicos na Escala BPRS (Brief Psychiatric Rating Scale-BPRS).

\begin{tabular}{|c|c|c|c|c|c|c|}
\hline Itens da Escala BPRS & $0^{\mathrm{a}}$ & $1^{\mathrm{a}}$ & $2^{a}$ & $3^{a}$ & $4^{\mathrm{a}}$ & $\begin{array}{l}\text { Média de } \\
\text { postos }\end{array}$ \\
\hline 1- Preocupações somáticas & $21(43,8)$ & $16(33,3)$ & $8(16,7)$ & $1(2,1)$ & $2(4,2)$ & 10,23 \\
\hline 2- Ansiedade psíquica & $8(16,7)$ & $19(39,6)$ & $15(31,3)$ & $5(10,4)$ & $1(2,1)$ & $13,42^{\text {** }}$ \\
\hline 3- Retraimento emocional & $14(29,2)$ & $19(39,6)$ & $12(25,0)$ & $2(4,2)$ & $1(2,1)$ & $11,85^{\text {***}}$ \\
\hline 4-Desorganização conceitual (incoerência) & $34(70,8)$ & $11(22,9)$ & $2(4,2)$ & $1(2,1)$ & 0 & 7,68 \\
\hline 5- Autodepreciação e sentimento de culpa & $20(41,7)$ & $15(31,3)$ & $12(25,0)$ & $1(2,1)$ & 0 & 10,66 \\
\hline 6- Ansiedade somática & $18(37,5)$ & $17(35,4)$ & $11(22,9)$ & $1(2,1)$ & $1(2,1)$ & 11,18 \\
\hline 7- Distúrbios motores específicos & $39(81,3)$ & $4(8,3)$ & $2(2,1)$ & $1(2,1)$ & $3(6,3)$ & 7,11 \\
\hline 8- Auto-estima exagerada & $41(85,4)$ & $4(8,3)$ & $3(6,3)$ & 0 & 0 & 6,80 \\
\hline 9- Humor deprimido & $18(37,5)$ & $13(27,1)$ & $9(18,8)$ & $6(12,5)$ & $2(4,2)$ & 11,55 \\
\hline 10- Hostilidade & $13(27,1)$ & $18(37,5)$ & $12(25,0)$ & $5(10,4)$ & 0 & $12,47^{\star \star \star}$ \\
\hline 11- Desconfiança & $19(39,6)$ & $20(41,7)$ & $8(16,7)$ & $1(2,1)$ & 0 & 10,49 \\
\hline 12- Alucinações & $34(70,8)$ & $6(12,5)$ & $6(12,5)$ & $1(2,1)$ & $1(2,1)$ & 8,08 \\
\hline 13- Retardo psicomotor & $40(83,3)$ & $7(14,6)$ & $1(2,1)$ & 0 & 0 & 6,58 \\
\hline 14- Falta de cooperação & $23(47,9)$ & $16(33,3)$ & $8(16,7)$ & $1(2,1)$ & 0 & 9,76 \\
\hline 15- Conteúdo de pensamento incomum & $39(81,3)$ & $3(6,3)$ & $4(8,3)$ & 0 & $2(4,2)$ & 7,24 \\
\hline 16- Afeto embotado ou inapropriado & $21(43,8)$ & $12(25,0)$ & $11(22,9)$ & $4(8,3)$ & 0 & 10,86 \\
\hline 17- Agitação psicomotora & $38(79,2)$ & $4(8,3)$ & $3(6,3)$ & $2(4,2)$ & $1(2,1)$ & 7,68 \\
\hline 18- Desorientação e confusão & $37(77,1)$ & $8(16,7)$ & $1(2,1)$ & $2(4,2)$ & 0 & 7,35 \\
\hline
\end{tabular}

*** p <,000 ; ${ }^{a} \mathrm{O}$ valor zero significa ausência ou não observação do sintoma e (quatro) corresponde ao nível de maior gravidade ou comprometimento para o referido sintoma.Os números entre parênteses correspondem às porcentagens de pacientes que pontuaram nos diferentes níveis de gravidade. $\mathrm{N}=48$, número absoluto dos pacientes pesquisados). Ribeirão Preto-SP, 2008. 
Ao analisar a manifestação dos sintomas psicopatológicos, observou-se que a manifestação de alguma gravidade, mesmo que em baixo grau (níveis 1 e 2), foi estatisticamente significativa em alguns itens. A ansiedade psíquica $(13,42)$ foi o sintoma que mais apresentou grau de gravidade entre os egressos (c2=183,712; $\mathrm{p}<0,000)$.

O Teste de Friedman também indicou a hostilidade $(12,47)$ e o retraimento emocional $(11,85)$ como itens de sintomas com significativo grau de gravidade. Os itens 9- Humor deprimido (11,55), 6- Ansiedade somática (11,18) e 16- Afeto embotado ou inapropriado $(10,86)$ também tiveram considerável pontuação quanto ao grau de gravidade dos sintomas. A auto-estima exagerada $(6,80)$ e retardo psicomotor $(6,58)$ foram os sintomas menos severos registrados nessa amostra.

A sobrecarga familiar foi avaliada no aspecto objetivo e subjetivo através da FBIS-BR. A Tabela 23 apresenta a descrição da sobrecarga objetiva dos cuidadores (familiares nesse caso), pela porcentagem de respostas 1 e 2 (que indicam baixa sobrecarga) e 4 e 5 (que indicam sobrecarga elevada no item) nas subescalas da FBIS$\mathrm{BR}$, relacionadas à análise de variância de postos.

A realização de tarefas na assistência cotidiana aos pacientes egressos de internação psiquiátrica causou significativa sobrecarga aos cuidadores.

Conforme pode ser observado na Tabela 23, preparar ou auxiliar os pacientes a preparar refeições $(6,60)$ foi a atividade que acarretou maior sobrecarga objetiva aos familiares (c2 = 35,213; $\mathrm{p} \leq 0,000$ - Teste de Friedman). A sobrecarga objetiva

Auxiliar os pacientes a administrar seus medicamentos (5,76), ajudá-los na administração do dinheiro (5,74), transportá-los (5,38), fazer compras para eles (4,93), pedir aos pacientes que ocupassem seu tempo $(4,83)$, auxiliá-los no cuidado e 
limpeza do quarto e roupas $(4,14)$, foram tarefas que também contribuíram para a sobrecarga objetiva destes familiares. Lembrar os pacientes de suas consultas médicas $(4,10)$ e assisti-lo quanto à higiene e cuidados pessoais $(3,52)$ foram as tarefas que menos contribuíram para a sobrecarga objetiva dos familiares.

Tabela 23 - Porcentagens de respostas dos familiares cuidadores às questões que avaliam a sobrecarga objetiva, em cada subescala A, B e D da FBIS-BR.

\begin{tabular}{|c|c|c|c|}
\hline Sub-escalas e questões & $\begin{array}{c}\text { Respostas } \\
1 \mathrm{e}^{\mathrm{a}}\end{array}$ & $\begin{array}{c}\text { Respostas } \\
4 \text { e } 5^{b}\end{array}$ & $\begin{array}{c}\text { Média de } \\
\text { postos }\end{array}$ \\
\hline \multicolumn{4}{|l|}{ Sub-escala A: Assistência ao paciente na vida cotidiana } \\
\hline A1 - Higiene e cuidados pessoais & $76,2 \%$ & $14,3 \%$ & 3,52 \\
\hline A2 - Administração dos medicamentos & $47,6 \%$ & $47,6 \%$ & 5,76 \\
\hline A3 - Cuidado e limpeza do quarto e roupas & $66,7 \%$ & $33,3 \%$ & 4,14 \\
\hline A4 - Compras diversas & $57,2 \%$ & $42,9 \%$ & 4,93 \\
\hline A5 - Preparo da alimentação & $28,6 \%$ & $71,4 \%$ & $6,60 * * *$ \\
\hline A6 - Transporte & $42,9 \%$ & $38,1 \%$ & 5,38 \\
\hline A7 - Administração do dinheiro & $42,9 \%$ & $57,1 \%$ & 5,74 \\
\hline A8 - Atividades e ocupação do tempo & $52,4 \%$ & $33,3 \%$ & 4,83 \\
\hline A9 - Freqüência às consultas médicas e atividades de tratamento & $66,7 \%$ & $19,0 \%$ & 4,10 \\
\hline \multicolumn{4}{|l|}{ Sub-escala B: Supervisão dos comportamentos problemáticos } \\
\hline B1 - Comportamentos problemáticos & $57,1 \%$ & $28,6 \%$ & $5,88^{* * * *}$ \\
\hline B2 - Demanda excessiva de atenção & $71,4 \%$ & $14,3 \%$ & 4,83 \\
\hline B3 - Perturbações durante a noite & $71,4 \%$ & $14,3 \%$ & 4,81 \\
\hline B4 - Agressividades verbal e física & $90,4 \%$ & $4,8 \%$ & 4,26 \\
\hline B5 - Tentativa ou ameaça de suicídio & $76,2 \%$ & $14,3 \%$ & 5,21 \\
\hline B6 - Bebidas alcoólicas* & $95,2 \%$ & $4,8 \%$ & 3,69 \\
\hline B7 - Excesso de alimentos, cigarros e líquidos. & $95,2 \%$ & $4,8 \%$ & 3,69 \\
\hline B8 - Abuso de drogas* & $95,2 \%$ & $4,8 \%$ & 3,62 \\
\hline \multicolumn{4}{|l|}{ Sub-escala D: Impacto na rotina* } \\
\hline D1a - Faltas, atrasos ou cancelamento de compromissos. & $52,4 \%$ & $19,0 \%$ & 2,15 \\
\hline D1b - Alteração nas atividades sociais e de lazer & $52,4 \%$ & $28,6 \%$ & 2,76 \\
\hline D1c - Perturbação nos serviços ou rotina da casa & $47,6 \%$ & $33,3 \%$ & 2,89 \\
\hline D1d - Alteração nos cuidados e atenção aos outros membros da família & $71,4 \%$ & $23,8 \%$ & 2,39 \\
\hline
\end{tabular}

Considerando a supervisão dos comportamentos problemáticos (subescala B), os resultados indicaram que supervisionar os comportamentos problemáticos dos pacientes $(5,88)$ foi a maior geradora de sobrecarga objetiva nos familiares $(\mathrm{c} 2=$ 33,298; p 50,000). A tentativa ou ameaça de suicídio $(5,21)$ foi a segunda maior questão relacionada à sobrecarga dos cuidadores. Os itens que contribuíram menos para 
a sobrecarga objetiva dos cuidadores nessa subescala foram supervisionar abuso de drogas $(3,62)$ de bebidas alcoólicas $(3,69)$ e de alimentos, cigarros e líquidos $(3,69)$.

Os resultados relativos aos itens da subescala D-Impacto na rotina, alterações diárias na vida por ser um cuidador, não indicaram nenhum item como gerador de sobrecarga objetiva nessa amostra de familiares cuidadores $(c 2=5,816 ; p=0,121)$.

A Tabela 24 apresenta a descrição da sobrecarga subjetiva dos cuidadores familiares pesquisados. A sobrecarga elevada é indicada pelas respostas 3 e 4 aos itens sobre o grau de incômodo na assistência cotidiana, supervisão dos comportamentos problemáticos e impacto na rotina do cuidador e por respostas 4 e 5 aos itens sobre a frequiência das preocupações com os pacientes.

A maioria dos familiares não manifestou elevada sobrecarga subjetiva por realizar tarefas cotidianas na assistência aos pacientes egressos, conforme se observa na Tabela 24, respostas 1 e 2 .

Pedir aos pacientes que ocupassem seu tempo $(5,79)$ foi a tarefa que mais causou incomodo entre os cuidadores $(\mathrm{c} 2=19,805 ; \mathrm{p} \leq 0,011)$. As tarefas que menos causaram incomodo na assistência ao paciente na vida cotidiana foram: Cuidado $\boldsymbol{e}$ limpeza do quarto e roupas $(4,05)$, Higiene e cuidados pessoais $(4,19)$

Em relação à supervisão aos comportamentos problemáticos dos pacientes, os resultados indicaram elevada sobrecarga subjetiva nos familiares $(5,90)$, item B1b $(39,286 ; \mathrm{p} \leq 0,000)$. O item Tentativa ou ameaça de suicídio $(5,38)$ também esteve relacionado à elevada da sobrecarga subjetiva. Os itens que geraram menor incômodo aos familiares foram Supervisionar os comportamentos de fumar ou ingerir bebidas não alcoólicas excessivamente $(5,55)$, supervisionar o uso de drogas $(3,44)$ e o de bebidas alcoólicas $(3,74)$. 
Tabela 24 - Porcentagens de respostas dos familiares cuidadores às questões que avaliam a sobrecarga subjetiva, em cada subescala A, B e D da FBIS-BR.

\begin{tabular}{|c|c|c|c|c|}
\hline Sub-escalas e questões & $\begin{array}{c}\text { Respostas } \\
1 \text { e } 2^{\mathrm{a}}\end{array}$ & $\left|\begin{array}{c}\text { Respostas } \\
3 \text { e } 4^{\mathbf{b}}\end{array}\right|$ & $\begin{array}{c}\text { Respostas } \\
4 \mathrm{e} 5^{\mathrm{b}}\end{array}$ & $\begin{array}{l}\text { Média } \\
\text { de } \\
\text { postos }\end{array}$ \\
\hline \multicolumn{5}{|l|}{ Sub-escala A: Assistência ao paciente na vida cotidiana } \\
\hline A1 - Higiene e cuidados pessoais & $20(95,2)$ & $1(4,8)$ & - & 4,19 \\
\hline A2 - Administração dos medicamentos & $20(95,2)$ & $1(4,8)$ & - & 5,76 \\
\hline A3 - Cuidado e limpeza do quarto e roupas & $21(100,0)$ & 0 & - & 4,05 \\
\hline A4 - Compras diversas & $20(95,2)$ & $1(4,8)$ & - & 4,43 \\
\hline A5 - Preparo da alimentação & $17(81,0)$ & $4(19,0)$ & - & 5,52 \\
\hline A6 - Transporte & $16(76,2)$ & $5(23,8)$ & - & 5,64 \\
\hline A7 - Administração do dinheiro & $18(85,7)$ & $3(14,3)$ & - & 4,90 \\
\hline A8 - Atividades e ocupação do tempo & $15(71,4)$ & $6(28,6)$ & - & $5,79^{* *}$ \\
\hline A9 - Freqüência às consultas médicas e atividades de tratamento & $17(81,0)$ & $4(19,0)$ & - & 4,71 \\
\hline \multicolumn{5}{|l|}{ Sub-escala B: Supervisão dos comportamentos problemáticos } \\
\hline B1 - Comportamentos problemáticos & $14(66,7)$ & $7(33,3)$ & - & 5,90 \\
\hline B2 - Demanda excessiva de atenção & $18(85,7)$ & $3(14,3)$ & - & 4,55 \\
\hline B3 - Perturbações durante a noite & $17(81,0)$ & $4(19,0)$ & - & 4,88 \\
\hline B4 - Agressividades verbal e física & $18(85,7)$ & $3(14,3)$ & - & 4,50 \\
\hline B5 - Tentativa ou ameaça de suicídio & $15(71,4)$ & $6(28,6)$ & - & 5,38 \\
\hline B6 - Bebidas alcoólicas* & $20(95,2)$ & $1(4,8)$ & - & 3,67 \\
\hline B7 - Excesso de alimentos, cigarros e líquidos. & $20(95,2)$ & $1(4,8)$ & - & 3,67 \\
\hline B8 - Abuso de drogas* & $21(100,0)$ & 0 & - & 3,45 \\
\hline \multicolumn{5}{|l|}{ Sub-escala E: Preocupações com o paciente } \\
\hline E1 - Segurança física do paciente & $2(9,5)$ & - & $17(80,9)$ & 5,05 \\
\hline E2 - Adequação do tratamento médico fornecido ao paciente & $13(61,9)$ & - & $5(23,8)$ & 2,83 \\
\hline E3 - Vida social do paciente & $4(19,0)$ & - & $10(47,6)$ & 4,17 \\
\hline E4 - Saúde física do paciente & $6(28,6)$ & - & $11(52,4)$ & 4,07 \\
\hline E5 - Condições de moradia para o paciente & $16(76,2)$ & - & $4(19,0)$ & 2,24 \\
\hline E6 - Sobrevivência financeira do paciente na ausência do cuidador & $8(38,1)$ & - & $11(52,4)$ & 3,86 \\
\hline E7 - Futuro do paciente & $1(4,8)$ & - & $18(85,7)$ & 5,79 \\
\hline
\end{tabular}

** $\mathrm{p}<, 01 ; * * * \mathrm{p}<, 000 ;{ }^{\mathrm{a}} 1=$ Nem um pouco ou nunca; $2=$ muito pouco ou raramente; ${ }^{\mathrm{b}} 3=$ um pouco ou as vezes; $4=$ muito ou freqüientemente e 5 =sempre ou quase sempre. ( $\mathrm{N}=21$, sendo $\mathrm{N}=$ número absoluto dos cuidadores pesquisados). Ribeirão Preto-SP, 2008.

Entre as preocupações com os pacientes, subescala E, os aspectos que geraram maior preocupação para os familiares, segundo o teste de Friedman $(\mathrm{c} 2=48,186$; $\mathrm{p}$ $\leq 0,000)$, referiram-se às preocupações com o futuro $(5,79)$ e com a segurança física dos pacientes $(5,05)$. Os itens com menor freqüência nessa subescala foram: condições de moradia dos pacientes $(2,24)$ e a qualidade do tratamento $(2,83)$. 


\subsection{Os pacientes egressos de internação psiquiátrica}

O presente trabalho identificou que os egressos de internação psiquiátrica nessa amostra são em sua maioria mulheres (62,5\%), residem com familiares $(93,8 \%)$, com casa própria $(70,8 \%)$, onde coabitam três ou quatro pessoas $(58,4)$. A renda individual não ultrapassou um salário de 380,00 reais para $66,7 \%$ dos pacientes, observando que $54,2 \%$ possuem até o primeiro grau completo de escolaridade e apenas 14,6 deles exercem algum tipo de trabalho regularmente. Esses achados são semelhantes a outros estudos realizados com pacientes assistidos por serviços de atendimento comunitário ${ }^{(\mathbf{7 0 -}}$ 72).

Nesse e em outros trabalhos verifica-se que a baixa escolaridade e baixo nível socioeconômico afetam a vidas de muitos pacientes psiquiátricos. Sabe-se que entre as dez principais condições de saúde, físicas e mentais, que provocam incapacidade, cinco são relacionadas a transtornos mentais, destacando: depressão, alcoolismo, transtorno afetivo bipolar, esquizofrenia e distúrbio obsessivo compulsivo ${ }^{(\mathbf{7 3})}$.

Verificou-se na presente pesquisa que esses transtornos estiveram presentes na amostra sendo mais prevalente os diagnósticos classificados no grupo da Esquizofrenia, transtornos esquizotípicos, transtornos delirantes e no grupo dos Transtornos de Humor (f20-F29; F31 a 33 do Cid 10), dados que remetem a amostra de diversos trabalhos na área ${ }^{(74,75)}$.

Trata-se de doenças severas, muitas vezes com manifestações de sintomas que limitam a atividade laboral, social e de lazer dos doentes. Além disso, desencadeiam também a discriminação e estigmatização ${ }^{(\mathbf{7 3 , 7 6})}$. Considerando esse aspecto, a baixa 
escolaridade e nível socioeconômico podem estar relacionados à severidade dos sintomas manifestados nessas doenças. A constante manifestação dos sintomas e os efeitos adversos do tratamento medicamentoso dificultam as relações do doente mental com sua família e meio social ${ }^{(77)}$. Nesse trabalho a ocorrência de efeitos adversos foi tão severa a um paciente que chegou a ser motivo para mais uma internação.

Considerado tamanho prejuízo, verifica-se a necessidade de uma adequada manutenção do tratamento dos pacientes não hospitalizados que são assistidos pelos serviços de atendimento comunitário. Com isso, a prevenção de recaídas pode minimizar danos e favorecer as relações sociais dos pacientes, o que torna a atuação dos serviços, enfermeiros e demais profissionais de saúde imprescindíveis nesse cotidiano.

A comorbidade psiquiátrica esteve presente em quatorze pacientes $(29,2 \%$ da amostra). Destaca-se que em seis deles um dos diagnósticos era relacionado a uso ou abuso de drogas. Este resultado foi um achado inesperado uma vez que na rotina do serviço em que realizamos essa pesquisa, pacientes com dependência química são encaminhados a serviços especializados.

A comorbidade psiquiátrica é um desafio aos serviços e profissionais da área, pois se apresenta uma clientela diferenciada e com necessidades específicas. Estudos evidenciam que a presença de co-morbidade com uso/abuso de álcool/drogas aumenta o risco de comportamentos violentos ${ }^{(\mathbf{7 8 )}}$. Sabe-se que a adicção as drogas muitas vezes está ligada a manifestação de doenças mentais e é atualmente um problema de saúde pública.

Neste trabalho os sintomas psiquiátricos, verificados através da BPRS, se manifestaram nos menores níveis de severidade. Apesar disso verificamos que a manifestação de alguns desses sintomas tiveram comprovada correlação com a 
ocorrência de reinternação e baixa adesão ao tratamento, que são ocorrências freqüentes no tratamento dos transtornos mentais e causam inúmeros prejuízos, não apenas para os doentes.

Por ter sido realizado em um serviço de atendimento comunitário e com uma amostra recentemente atendida em regime de internação, acreditamos que nos pacientes dessa pesquisa os sintomas psicopatológicos estavam mais controlados, embora presentes. Quando estão em regime de internação, esses pacientes têm o tratamento psicofarmacológico diariamente assessorado pela equipe de enfermagem.

Essa ocorrência evidencia que a finalidade terapêutica da internação ao minimizar a gravidade dos sintomas manifestados, porém a extinção dos sintomas não foi atingida. Considerando o comportamento de baixo grau de adesão manifestado pela amostra estudada verificamos que intervenções são necessárias para a manutenção do tratamento extra-hospitalar desses pacientes.

Os profissionais de saúde precisam desenvolver e utilizar, em sua prática, instrumentos capazes de evidenciar a manifestação dos sintomas psicopatológicos que são sinais claros de recaída. Além disso, intervenções educativas podem trabalhar as dificuldades dos pacientes e cuidadores na manutenção do tratamento.

A escala BPRS e o Teste de Morisky e Green utilizados nessa pesquisa demonstraram considerável capacidade de evidenciar fatores de risco para recaída como a baixa adesão ao tratamento e a exacerbação de alguns sintomas (hostilidade, retraimento emocional, agitação psicomotora). Acreditamos que a sistematização do cuidado oferecido nos serviços ambulatoriais de saúde mental pode contribuir para a manutenção do tratamento psicofarmacológico. 
A finalidade das internações em estabilizar o paciente (minimizando riscos, levantando necessidades psicossociais, ajustando o tratamento psicofarmacológico e a reinserção social do paciente) precisa ser trabalhada nos serviços extra-hospitalares, sendo a sistematização da assistência uma estratégia bastante correlacionada.

Sintomas como a ansiedade psíquica, a hostilidade e o retraimento emocional foram sintomas com significativo grau de severidade entre os egressos (c2 $=183,712$; $\mathrm{p}<0,000$ - Teste de Friedman). Estes sintomas estiveram inclusive relacionados à internação recente. Os principais motivos de internação foram justamente a hostilidade (agressividade, irritabilidade, agitação psicomotora), ideação suicida ou tentativa de suicídio e os sintomas psicóticos (delírios, alucinações, mania).

Os motivos descritos acima estão adequados ao preconizado na Lei no 10.216 de 04 de junho de $2001^{(79)}$. Atualmente, a internação psiquiátrica é indicada para casos graves em que as abordagens nos serviços extra-hospitalares não foram suficientes, ou seja, quando foram esgotados os recursos extra-hospitalares para o tratamento ou manejo do problema. É proibida a internação de pessoas em instituições com características asilares. São considerados casos graves situações em que há presença de transtorno mental com no mínimo, uma das seguintes condições: risco de auto-agressão, risco de heteroagressão, risco de agressão à ordem pública, risco de exposição social, incapacidade grave de auto-cuidados ${ }^{(79)}$.

Apesar de grande parte da amostra, ter apresentado diagnóstico e tratamento recente (menos de um ano), 56\% não souberam dizer o nome da doença mental que os acometia e que por ela estavam em seguimento no serviço de saúde mental. e 56,2\% não sabiam ou sabiam parcialmente obre os medicamentos a eles prescritos. Os pacientes egressos de internação apresentaram baixo conhecimento quanto ao nome de sua doença mental e seu tratamento psicofarmacológico. 
Estudos descrevem os primeiros anos de doença como um período em que doentes e familiares apresentam grande necessidade de atenção orientação sobre a doença mental e seu tratamento ${ }^{(\mathbf{8 0 , 8 1 )}}$. Trata-se de um período de grandes conflitos de entendimento e aceitação da doença frente ao desconhecimento, preconceito e estigmas que cercam os transtornos mentais. Estes trabalhos demonstram a importância de uma atuação de enfermagem mais próxima ao cotidiano de seus pacientes tendo a sistematização da assistência como recurso para levantar as necessidades dessa clientela. O desenvolvimento de protocolos para identificação de sinais de recaída podem colaborar na manutenção dos tratamentos psiquiátricos.

Outro resultado importante foi que embora não soubessem ou soubessem parcialmente dizer o nome dos medicamentos prescritos, quando questionados acerca da importância da manutenção do tratamento psicofarmacológico, 81,2\% dos pacientes consideraram que o tratamento através de medicamentos é importante. Porém, essa opinião parece não ter influência prática sobre a adesão uma vez que 70,8\% deles foram classificados com baixa adesão ao tratamento.

\subsection{A adesão do paciente egresso de internação ao tratamento psicofarmacológico}

Como descrito anteriormente, a maioria dos pacientes egressos de internação psiquiátrica, nesse estudo, foi classificada com baixo grau de adesão ao tratamento psicofarmacológico. Este resultado é semelhante a outros que utilizaram o mesmo teste, porém em pacientes hipertensos ${ }^{(\mathbf{8 2}, \mathbf{8 3})}$.

Há uma vasta quantidade de estudos sobre o tema adesão ao tratamento, nas mais diversas áreas da saúde. Em geral, a não adesão atinge cerca de $50 \%$ dos 


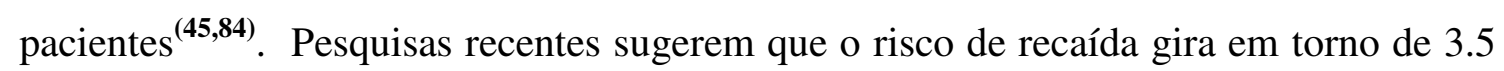
a $10 \%$ ao mês, aproximadamente ${ }^{(\mathbf{4 4 , 4 5 )}}$ e indicam a não adesão ao tratamento psicofarmacológico como a principal razão para ocorrência de recaída em pacientes não hospitalizados ${ }^{(47)}$. Entre pacientes tratados com antipsicóticos convencionais, $40 \%$ param de tomar sua medicação no primeiro ano de tratamento e $75 \%$ param de tomar esta medicação dentro de dois $\operatorname{anos}^{(\mathbf{8 5})}$.

Estudos que também utilizaram o teste de Morisky com o critério de classificar com baixo grau de adesão todos os sujeitos que respondam sim a pelo menos uma das quatro perguntas do teste descrevem que em torno de $50 \%$ a amostra de pacientes tem baixa adesão ao tratamento medicamentoso ${ }^{(\mathbf{8 3 , 8 6 - 9 0 )}}$.

Em relação ao tipo baixa adesão dos pacientes, observou-se que o comportamento misto entre intencional e não intencional foi predominante. Ou seja, os pacientes às vezes se esquecem de tomar o medicamento, são descuidados com o horário em que tomam suas medicações e também deixam de tomar o medicamento quando se sentem bem ou quando esse lhe faz mal. É importante observar que nas doenças psiquiátricas, a manifestação dos sintomas prejudica o senso critico dos pacientes, o que pode explicar a imprevisível postura dos pacientes quanto ao tipo de baixa adesão ao tratamento.

Todos os cuidadores entrevistados nesse trabalho afirmaram a importância do tratamento medicamentoso no tratamento dos doentes mentais e de seus entes. Porém, ter um cuidador não influenciou uma melhor adesão ao tratamento dos egressos de internação psiquiátrica. O fato de residirem com sua família $(93,8 \%)$ também demonstrou ser uma fator de proteção aos pacientes quanto a baixa adesão ao tratamento. O que se destaca é que os profissionais, pacientes e cuidadores apesar de 
terem consciência e discurso voltado á manutenção do tratamento ainda não conseguem atuar de forma eficaz a prevenir as recaídas e melhorar o prognósticos dos pacientes.

Ao pensar em adesão ao tratamento é necessário considerar o paciente sem seu contexto e momento de vida. A adesão é um importante aspecto na manutenção do tratamento do doente mental fora do regime de internação. Para alguns autores a adesão precisa ser compreendida não só no nível individual, mas também no meso e macro contexto, ou seja, nos níveis da comunidade e sociedade como um todo ${ }^{(91)}$.

Nesse trabalho nos limitamos a apenas identificar o comportamento de adesão ao tratamento considerando sua relevância e a complexidade em desenvolver estratégias de intervenção em sua manifestação. O teste utilizado é limitado à dicotomia das respostas sim e não o que não nos permitiu aprofundar questões relativas a dificuldades e entendimento dos pacientes a esse respeito. Estudos futuros posteriores serão desenvolvidos para aprofundar nosso conhecimento a esse respeito.

Entendemos a adesão ao tratamento psicofarmacológico como um comportamento a ser estimulado e compreendido no cotidiano da assistência através de consultas de enfermagem, supervisão do tratamento psicofarmacológicos e visitas domiciliares, e utilização de instrumentos que possam identificar sinais de risco e exacerbação dos sintomas. Consideramos que um atendimento mais humanizado e suportado por tecnologias adequadas pode contribuir ao desenvolvimento de uma melhor assistência e para o estabelecimento de confiança entre profissional, paciente e família. 


\subsection{Os cuidadores dos pacientes egressos de internação psiquiátrica}

A desinstitucionalização da assistência em saúde mental que conclama uma parceria direta entre profissionais de saúde, familiares e pacientes ainda não desenvolveu mecanismos para minimizar a sobrecarga que esse cuidado acarreta. Estudos demonstram que essas famílias sofrem significativas desorganizações em sua estrutura cotidiana ao ter que enfrentar as constantes alterações de humor e o comportamento dos doentes ${ }^{(\mathbf{9 2}-96)}$. Muitas vezes os familiares sentem dificuldade em compreender um comportamento diferente e tentam "normalizar" o estranho para mais próximo possível ao senso comum ${ }^{(\mathbf{9 6})}$.

É interessante observar que apesar de $93,8 \%$ dos pacientes ter afirmados residirem com seus familiares, apenas $43,7 \%$ deles afirmaram possuir um cuidador. Os outros pacientes negaram haver alguém que se preocupe e auxilie seu tratamento. Sabese que a família ao participar do cuidado de seus entes tem papel determinante no sucesso do tratamento ${ }^{(\mathbf{9 7})}$. O domicílio é um espaço em que pessoas portadoras de doenças crônicas e outras afecções podem viver com boa qualidade de vida e manter a estabilidade da doença ${ }^{(\mathbf{2 1 , 6 9 , 9 3 , 9 8 , 9 9 )}}$, desde que a família receba orientação e suporte dos serviços de saúde para isso. Os serviços de saúde mental precisar oferecer uma assistência á saúde que contemple cuidados para identificar e aliviar a sobrecarga dos cuidadores além de promover treinamento de habilidades que estimulem a autonomia e reabilitação psicossocial dos doentes mentais.

Nesse trabalho verificamos que todos os cuidadores possuíam algum tipo grau de parentesco com o egresso de internação e todos residiam com os pacientes sendo a figura feminina, materna, o destaque na amostra. Este acontecido pode estar relacionado à cultura brasileira que tem o acolhimento como uma postura agradável ${ }^{\left({ }^{(69)}\right.}$. 
A tarefa que acarretou maior incômodo aos familiares foi pedir aos pacientes continuamente para ocupar seu tempo, tarefa essa que também contribuiu para na sobrecarga objetiva dos familiares. Apesar de a realização ter tarefas, que geraram sobrecarga objetiva, terem sido identificadas nesse trabalho, essas atividades de assistência aos pacientes não geraram elevada sobrecarga subjetiva nos cuidadores. Ou seja, essas tarefas não causaram muito incomodo aos cuidadores e podem também não ter sido evidenciadas pelos pacientes.

A ociosidade dos pacientes demonstrou ser um comportamento que gera incomodo a seus familiares. O desenvolvimento de atividades ocupacionais, grupoterapia e atividades de orientação sobre o manejo dessa e de outras situações pode colaborar para que a sobrecarga cotidiana possa ser dividida entre o serviço e a família.

Salienta-se que, conviver com uma pessoa com transtorno mental acarreta um custo adicional que vai além das limitações em oportunidade de emprego, lazer e descanso aos cuidadores ${ }^{(\mathbf{9 9 , 1 0 0 )}}$. A necessidade de cuidados constantes gera também uma sobrecarga emocional aos cuidadores, o que é também demanda atenção dos profissionais de saúde mental. Atividades educativas e de reflexão podem colaborar para minimizar essa sobrecarga.

A efetividade do cuidado prestado pelos cuidadores, nesse caso familiares, não foi objetivo desta pesquisa. Porém consideramos toda sua relevância. Após a internação psiquiátrica o paciente egresso e sua família enfrentam o difícil processo de reintegração de suas relações sociais. É preciso identificar a demanda dessa clientela para que profissionais, pacientes e familiares executem a estruturação e manejo do cotidiano nas relações sociais, econômicas e culturais que giram em torno dela. 


\subsection{A sobrecarga Familiar - cuidadores}

Há estudos que afirmam uma relação direta entre o número de internações no curso da doença e a rejeição familiar ${ }^{(\mathbf{1 0 1})}$. Nesta pesquisa a rejeição não foi um aspecto considerado. Aos cuidadores, foi identificada a sobrecarga ocasionada pelo cuidado ao doente mental nos últimos trinta dias. Cabe ressaltar, em alguns casos nesse período o paciente estava internado o que pode ter influenciado nosso resultado. Porém, estudos indicam que a sobrecarga familiar é notória e pode ser manifestada mesmo quando o paciente responde positivamente a seu tratamento ${ }^{(\mathbf{1 0 0})}$.

A sobrecarga objetiva foi predominantemente maior entre os cuidadores de egressos de internação psiquiátrica recente e refere-se a conseqüências negativas concretas envolvidas no processo de cuidar. As atividades de preparo da alimentação, administração dos medicamentos, administração do dinheiro e supervisão de comportamentos problemáticos foram as que mais trouxeram sobrecarga a esses cuidadores.

Em relação à sobrecarga subjetiva as atividades que geraram maior grau de sobrecarga foram Pedir aos pacientes que ocupassem seu tempo e mais uma vez a supervisão aos comportamentos problemáticos dos pacientes.

Esse resultado é compatível com estudos internacionais e com uma recente pesquisa realizada no país ${ }^{(\mathbf{3 7 , 6 9 , 7 0 )}}$. Nessa pesquisa, 150 familiares foram entrevistados e a maioria dos cuidadores apresentou elevada sobrecarga objetiva relativa à alta freqüência de ajuda aos pacientes nas tarefas cotidianas e elevada sobrecarga subjetiva, referente às preocupações com os pacientes, ao elevado grau de incômodo ao supervisionar seus comportamentos problemáticos ${ }^{(\mathbf{6 9})}$. Nesse trabalho os 
comportamentos problemáticos referiam-se a agitação, agressividade verbal, fumar demais, falta de higiene, crises de nervo, fugir para a rua, pedir atenção demais, agressividade física, falar sozinho, quebrar objetos, recusar medicação, ficar sem roupa, problemas de sexualidade, drogadicção, pedir comida na rua e alcoolismo.

Sob o aspecto da sobrecarga subjetiva, as preocupações dos cuidadores em relação ao futuro do paciente e com sua segurança foram itens que geraram maior sobrecarga entre as preocupações. Essas preocupações também foram as principais geradoras de sobrecarga subjetivas em outras populações conforme descrito em vários trabalhos já publicados ${ }^{(36,69)}$. 
Um dos grandes desafios ao processo de desinstitucionalização da assistência à saúde mental é justamente o "desinstitucionalizar". A prática em saúde mental revela que a pessoa com uma doença mental, principalmente quando esta é grave, fica necessariamente ligada a uma instituição na busca da contenção da manifestação dos sintomas de sua patologia.

Considerando toda a evolução do paradigma de assistência à doença mental e toda sua complexidade frente à manifestação de sintomas, as limitações do tratamento psicofarmacológico, a sobrecarga familiar, os preconceitos sociais, a carência de serviços e profissionais este trabalho buscou caracterizar um momento na história de vida de pessoas com doenças mentais para refletir sobre uma atuação sistematizada de enfermagem em saúde mental.

No Brasil, o momento atual é de investimento em infra-estrutura de serviços e redefinições no campo da assistência à clientela na área da saúde mental ${ }^{(\mathbf{1 0 2})}$. A assistência psiquiátrica vem se modificando a algumas décadas tornando o cuidado na comunidade e a desinstitucionalização do paciente psiquiátrico o foco de sua atenção.

Contudo a OMS faz um alerta: enquanto se observe significativo investimento em saúde, com notável redução nas taxas de mortalidade, não houve significativa melhora em relação à saúde mental nos últimos 100 anos. Alguns autores atribuem essa defasagem a desinteresse político, falta de treinamento adequado das equipes de serviços comunitários e falta de recursos ${ }^{(\mathbf{8 0})}$. As diferentes modalidades terapêuticas desenvolvidas na atualidade já demonstraram que intervenções psicológicas, sociais ou psicossociais, são elementos importantes à manutenção do tratamento em saúde mental. 
Segundo o preconizado pelo Conselho Federal de Enfermagem (COFEN) sobre a Sistematização da Assistência de Enfermagem - SAE, resolução COFEN-272/2002, cabe como atividade privativa ao enfermeiro identificar situações de saúde/doença e através de métodos e estratégias de trabalho científico subsidiar ações de assistência de enfermagem que contribuam para a promoção, prevenção, recuperação e reabilitação da saúde do indivíduo, família e comunidade ${ }^{(\mathbf{1 0 3})}$. Ainda segundo essa resolução, a implementação da Sistematização da Assistência de Enfermagem - SAE - deve ocorrer em toda instituição da saúde, seja ela pública ou privada, adequando a assistência oferecida às necessidades da comunidade.

Porém a organização de trabalho e a rede de serviços de saúde que existe no Brasil, hoje, ainda não conseguem absorver as reais necessidades do paciente em seu contexto comunitário. Sob o paradigma da Reforma Psiquiátrica, os instrumentos materiais mais evidentes são os NAPS e CAPS (Núcleos e/ou Centros de Atendimento Psicossocial); hospitais-dia, enfermarias e ambulatórios em hospitais gerais ${ }^{(\mathbf{1 0 2})}$. Muitas vezes, a carência de recursos somada aos dispositivos legais que regulam a institucionalização do doente mental gera uma demanda que sobrecarrega os serviços e os profissionais neles inseridos.

Estudos que descrevem que o trabalho dos enfermeiros nesses serviços está centrado em atividades de gerenciamento intermediário na organização do trabalho da equipe. Assim, os enfermeiros são os que menos realizam atendimentos diretos à clientela quando comparados a outros profissionais envolvidos nessa modalidade de assistência $^{(104-106)}$.

Muitas vezes o discurso não se reflete na assistência oferecida. Em meio às limitações do serviço o que se encontra é um paradigma baseado em suas ações do modelo organicista de saúde. Na prática atividades de relacionamento interpessoal e 
reabilitação psicossocial dão lugar às práticas autoritárias que por serem ineficientes culminam no encaminhamento dos pacientes, em crise, para internação ${ }^{(\mathbf{1 0 4})}$.

Durante a coleta de dados para esta pesquisa verificamos que muitas vezes o enfermeiro do serviço realmente desenvolvia atividades de articulação entre os outros membros da equipe, atuando também em grande parte das atividades administrativas e de secretaria. Trata-se de um profissional experiente que na medida do possível exerce também atividades terapêuticas junto à clientela, como supervisão e orientação sobre a utilização de medicamentos, monitoramento do uso correto de medicamento de depósito, realização de visitas domiciliárias, consulta de enfermagem, suporte familiar. Embora elas sejam limitadas por outras atividades. Cabe ressaltar ainda, as dificuldades que esse, assim como outros serviços, enfrenta diariamente a citar algumas: limitada estrutura física, equipe reduzida, grande demanda populacional; descaso político.

Os dados obtidos demonstraram que em média treze pacientes ao mês recebem alta de internação psiquiátrica hospitalar e são atendidos no serviço. Observa-se que a manutenção do tratamento para pacientes "não institucionalizados", na maioria das vezes, é pautada na psicofarmacologia, sinais e sintomas, recorrendo à internação quando há aumento nos riscos à saúde ${ }^{(\mathbf{1 0 5})}$. Esse tipo de assistência deixa de absorver necessidades cotidianas e coletivas que também interferem na manutenção desses tratamentos e carecem de intervenções.

Sob a ótica de uma assistência parcial, o doente é fadado aguardar a consulta médica para garantir sua prescrição e buscar na medicação a contenção de sua doença. Assim, a instituição, com regime de internação ou regime ambulatorial, é o único recurso ao doente que ainda hoje carece de incentivo, educação e suporte para desenvolver sua reabilitação psicossocial de acordo com seus limites e capacidades. 
Muitas vezes, paciente e seus cuidadores não recebem suporte e preparo para lidarem com a doença, o que gera conflitos, culpa e stress a todos os envolvidos. O equilíbrio entre as possíveis intervenções terapêuticas no tratamento psiquiátrico ainda constitui um grande desafio. O que então resta aos profissionais hoje, para garantir o cuidado aos pacientes que recebem a alta hospitalar?

Buscamos no decorrer desse trabalho aprofundar nosso conhecimento sobre aqueles que utilizam a rede pública de serviços em saúde mental vigente e necessitaram de internação psiquiátrica durante seu tratamento. Tal conhecimento visa entre outras coisas, gerar reflexão e subsídios que colaborem na dinâmica entre o saber e o fazer em saúde mental. O comprometimento profissional com o saber em sua relação com a prática é uma importante fonte de evolução.

Este estudo teve também a finalidade de habilitar a pesquisadora quanto a instrumentos disponíveis no meio científico para identificar possíveis preditores de recaída e auxiliar os profissionais de saúde no desempenho de suas funções. Motivo esse que determinou a natureza desse estudo (exploratório).

O número limitado de sujeitos nessa amostra e a utilização de um único serviço como referência impossibilitou maiores análises e inferências sobre o tema estudado. A partir desse trabalho pretende-se aperfeiçoar os instrumentos de coleta de dados utilizados e desenvolver um estudo a longo prazo baseado na intervenção sistematizada de enfermagem junto a essa clientela. Com isso, espera-se que uma atuação de enfermagem que contemple a sistematização da assistência possa contribuir para a prevenção de recaídas, minimizar a necessidade de reinternações e melhorar as relações do paciente junto a seu meio social. 
As inovações geradas pela mudança de paradigmas na assistência psiquiátrica demandam mais estudos e adaptações dos profissionais e serviços de saúde para que possam atendam às demandas de seus paciente e cuidadores.

Com internações psiquiátricas criteriosas e marcadas por períodos mais curtos de institucionalização, pacientes e familiares se tornaram cada vez mais os principais provedores de cuidados em saúde mental. Nesse contexto a cronicidade dos transtornos mentais leva estas pessoas a conviverem com o processo de internação-reinternação, e suas as atividades cotidianas se organizam em torno das possibilidades de tratamento do transtorno mental.

Para tanto, conhecer quem são os egressos de internação psiquiátrica, hoje, possibilita identificar características que podem fomentar a determinação do melhor tratamento e suporte profissional aos pacientes e seus cuidadores. Os egressos pesquisados nesse trabalho representam a população assistida por um serviço público de saúde, e apresentaram importantes aspectos a serem considerados na manutenção do tratamento.

O baixo grau de adesão ao tratamento medicamentoso é fator relacionado à sobrecarga familiar, porém não é seu único determinante. Sabe-se que pacientes com boa adesão ao tratamento têm menos riscos à ocorrência de recaídas e reinternações, mas não estão livres de suas doenças e de todo fardo que essa acarreta em suas vidas. $\mathrm{O}$ baixo grau de adesão manifestado na maioria dos pacientes neste estudo reforça a importância do tema e a necessidade de abordagem profissional em relação a este comportamento a fim de melhorar a assistência oferecida nos serviços de saúde mental.

A presença de um familiar com transtorno mental sempre traz algum grau de sobrecarga a seus familiares e provoca a constante necessidade de adaptações na 
estrutura familiar ${ }^{(\mathbf{2 0 - 2 2})}$. Muitas vezes, o cuidado cotidiano precipita uma freqüente demanda de atenção do cuidador para com o doente que limita e prejudica as demais tarefas que este cuidador precisa desempenhar em seu loco social. Intervenções de manutenção ao tratamento, educação, ventilação e alívio de crises podem buscar atender a demanda de cuidado dessas pessoas, não se restringindo a apenas garantir adesão ao tratamento psicofarmacológico, mas também visando identificar e minimizar riscos, trabalhar carências e conflitos sociais, emocionais e financeiros gerados pela manifestação crônica da doença mental.

A identificação da sobrecarga familiar nesse trabalho pôde evidenciar um aspecto importante a ser considerado pelos serviços de saúde mental. A identificação das tarefas que mais acarretam sobrecarga pode possibilitar uma melhor elaboração de estratégias educativas que trabalhem junto aos pacientes e seus cuidadores as dificuldades cotidianas manifestadas perante a doença mental.

Os comportamentos problemáticos dos pacientes podem ser reflexo de sua baixa adesão ao tratamento. Esse é um problema que pode ser superado frente a uma atuação sistematizada do serviço, que seja capaz de identificar sinais de recaída psicótica. Os instrumentos utilizados nessa pesquisa mostraram ser sensíveis a alguns desses sinais e serão aprimorados para a realização de um estudo de intervenção a longo prazo nessa clientela.

Podemos buscar no egresso de internação psiquiátrica e sua família o estágio do adoecer em que se encontram esses sujeitos e então trabalhar os significados e enfrentamento a serem superados. $O$ processo de adoecer possui sete estágios: a conscientização; a ambivalência entre o desejo de buscar cuidado e de permanecer ignorante; a desorganização; fragilização, a identidade pessoal ameaçada; reorganização; encontro de novos significados frente à doença ${ }^{(\mathbf{1 0 7})}$. 
O desenvolvimento de novas habilidades práticas pelos profissionais de saúde mental pode colaborar para intervenções precoces no processo de adoecer que melhorem o prognostico de seus pacientes e ampliem a sua atuação para além da estrutura do serviço comunitário.

Sempre haverá novas possibilidades para assistência a pessoa que sofre devido a uma doença. A assistência à saúde mental nesse momento pede que os profissionais busquem entender o micro e o macro contexto cotidiano de sua clientela, o conhecimento integral do mundo do paciente, suas necessidades emocionais e questões de vida, atuando pontualmente ou não no incentivo ao desenvolvimento de habilidades psicossociais. Ao considerar tanto o que é objetivo quanto o que é subjetivo no curso de uma doença, a abordagem profissional se aproxima da real necessidade de sua clientela. 
1. Rodrigues LR. "Só quem sabe da doença dele é Deus" - o significado da doença mental no contexto cultural. [dissertação] Ribeirão Preto: Escola de Enfermagem de Ribeirão Preto/USP;2001.

2. Cury C.F.M.R., Galera, S.A.F. O programa saúde da família como ideal para a atenção às famílias de doentes mentais. Fam. Saúde Desenv. 2004 jan./abr;.6(1): 65-70.

3. Brasil. Ministério da Saúde. Secretaria de Atenção à Saúde. Departamento de Ações Programáticas Estratégicas. Saúde mental no SUS: os centros de atenção psicossocial / Ministério da Saúde, Secretaria de Atenção à Saúde, Departamento de Ações Programáticas Estratégicas. - Brasília: Ministério da Saúde, 2004. 86 p.: il. color. (Série F. Comunicação e Educação em Saúde) ISBN 85-334-0775-0. Disponível em: http://www.ccs.saude.gov.br/saude_mental/pdf/SM_Sus.pdf

4. World Health Organization The Tenth Revision of the International Classification of Diseases and Related Health Problems (ICD-10). 1992 Geneva: WHO.

5. Rodriguez A, Bravo MF. La Atención Integral en la Comunidad a las Personas con Transtorno Mental Grave. In Rehabilitación Psicosocial y Tratamiento Integral del Transtorno Mental Severo. 2003Asociación Espanola de Neuropsiquiatria.

6. Saraceno, B. Libertando identidades: da reabilitação psicossocial à cidadania possível. 2. ed. Rio de Janeiro: Te Corá; Instituto Franco Basaglia, 2001. 176p.

7. Brasil. Ministério da Saúde. Secretaria de Vigilância em Saúde. Departamento de Análise de Situação de Saúde. Saúde Brasil 2004 - uma análise da situação de saúde. Brasília: Ministério da Saúde, 2004b.

8. Rodrigues MR, Kirschbaum DR. Usuarios de un Centro de Atención Psicosocial: un estudio de sus representaciones sociales acerca del tratamiento psiquiatrico. Rev. Latino-Am. Enfermagem [periódico en la Internet]. 2003 Dic [citado 2007 Sep 17]; 11(6): 786-791. Disponible en: http://www.scielo.br/scielo.php?script=sci_arttext\&pid=S0104-11692003000600013\&lng=es\&nrm=iso.

9. Jorge Miguel R, França Josimar MF. A Associação Brasileira de Psiquiatria e a Reforma da Assistência Psiquiátrica no Brasil. Rev. Bras. Psiquiatr. 2007; 23(1):3-6.

10. Bandeira M. Desinstitucionalização ou transinstitucionalização: lições de alguns países. Psicologia: Teoria e Pesquisa. 19916 (2), 171-182.

11. Bandeira M, Dorvil H. Les Consultations a la salle $\mathrm{d}^{\prime}$ urgence psiquiatrique: comparaison entre des echantillons brésiliens et québecois. Le Médecin du Québec. 1996 31(8), 59-69.

12. Bechelli LPC. Antipsicóticos de ação prolongada no tratamento de manutenção da esquizofrenia. Parte I Fundamentos do seu desenvolvimento, benefícios e nível de aceitação em diferentes países e culturas. Rev. LatinoAm. Enf. 2003 .11(4):507-15.

13. Glazer WM, Kane JM. Depot neuroleptic therapy: na underrutilized treatment option. J. Clin. Psychiatry. 1992 (53): 426-33.

14. Shirakawa I. Aspectos gerais do manejo do tratamento de pacientes com esquizofrenia. Rev Bras Psiquiatr 2000;22(Supl I):56-8

15. Vermeire, E.; Hearnshaw, H.; Van Royen, P.; Denekens, J. Patient adherence to treatment: three decades of research. a comprehensive review. J. Clin. Pharm. Ther. 2001; 26:331-45. 
16. Leite SN, Vasconcellos MPC. Adherence to prescribed therapy: points for concepts and presuppositions discussion. Ciênc. saúde coletiva [serial on the Internet]. 2003 [cited 2007 Sep 18] ; 8(3): 775-782. Available from: http://www.scielo.br/scielo.php?script=sciarttext\&pid=S1413-81232003000300011\&lng=en\&nrm=iso.

17. Bandeira M, Barroso SM. Sobrecarga das famílias de pacientes psiquiátricos. .J. bras. psiquiatr. 2005 54(1):34-46.

18. Rose LE. Families of psychiatric patients: a critical review and future research directions. Arch Psychiatr Nurs, 1996 10(2): 67-76.

19. Gasque-Carter K. O, L.I.S.W., A.C.S.W. and Mary B. Curlee, L.M.S.W., A.C.S.W. The Educational Needs of Families of Mentally Ill Adults: The South Carolina Experience Psychiatr Serv 1999 50:520-524.

20. Martens L, Addington J. The psychological wellbeing of family members of individual with schizophrenia. Soc Psychiatry Psychiatr Epidemiol. 2001 36: 128-133.

21. Lauber C, Eichenberger A, Luginbühl P, Keller C, Rössler W. Determinants of burden in caregivers of patients with exacerbating schizophrenia. Eur Psychiatry. 2003 18: 285-9.

22. Jungbauer J, Wittmund B, Dietrich S, Angermeyer MC. Subjective burden over 12 months in parents of patients with schizophrenia. Arch Psychiatr Nurs 200317 (3): 126-34.

23. Dalla Vechia M, Martins STF. O cuidado de pessoas com transtornos mentais no cotidiano de seus familiares: investigando o papel da internação psiquiátrica. Estud. psicol. (Natal) [online]. 2006, vol. 11, no. 2 [citado 2008-04-18], pp. 159-168. Disponível em: <http://www.scielo.br/scielo.php?script=sci_arttext\&pid=S1413294X2006000200005\&lng=pt\&nrm=iso >. ISSN 1413-294X. doi: 10.1590/S1413-294X2006000200005

24. Saúde M. Portaria. Política Nacional de Saúde do Idoso. Diário Oficial da República Federativa do Brasil (Df) Dez 1999;(237-E) Seção 1:20. No.1395.

25. Rammohan A, Rao K, Subbakrishna DK. Religious coping and psychological well-being in carers of relatives with schizophrenia. Acta Psychiatr Scand. 2002;105: 356-62.

26. Pegoraro RF, Caldana RHL. Sobrecarga de familiares de usuários de um Centro de Atenção Psicossocial. Psicol. estud. 2006;11(3):569-577.

27. Mello, R. A construção do cuidado à família e a consolidação da reforma psiquiátrica / Building the family care and consolidating the psychiatric reforma . Rev. enfermagem UERJ. 2005;13(3):390-395.

28. Pedro KS, Marcon SS. Perfil e vivência dos cuidadores informais de doentes crônicos assistidos pelo NEPAAF - Núcleo de estudos, pesquisa, assistência e apoio à família. Online Brazilian Journal of Nursing. $2007 ; 6(0)$.

29. Hoenig J.; Hamilton MW. The Schizophrenic Patient in the Community and His Effect On the Household International Journal of Social Psychiatry, 1966, 12(3): 165-176.

30. Goldman, H. H. (1982). Mental illness and family burden: a public health perspective. A Journal of the American Psychiatry Association, 33 (7), 557-560.

31. Franco, R.F. - A família no contexto da reforma psiquiátrica: a experiência de familiares nos cuidados e na convivência com pacientes portadores de transtornos mentais [dissertação]. Universidade Federal de Minas Gerais, Belo Horizonte, 2002.

32. Greenberg, J.S.; Kim, H.W.; Greenley, J.R. - Factors associated with subjective burden in siblings of adults with severe metal illness. American Journal of Orthopsychiatry 67(2): 231-241, 1997. Arey \& Warheit, 1980; 
33. Koga, M.; Furegato, A.R. - Convivência com a pessoa esquizofrênica: sobrecarga familiar. Ciência, Cuidado e Saúde 1(1): 75-79, $2002 . \quad$ [ L Links ]

34. Lefley, H. P. Families, culture, and mental illness: constructing new realities.Psychiatry: Interpersonal and Biological Process, 1998. 61 (4), 335-355.

35. Maurin JT, Boyd CB. Burden of mental illness on the family: a critical review. Arch Psychiatr Nurs. 1990;4(2): 99-107.

36. Tessler RC, Gamache GM. Family Experiences with Mental lllness. Westport: Auburn House; 2000.

37. St. Onge M, Lavoie F. The experience of caregiving among mothers o adults suffering from psychoric disorders: factor associated to their psychological distress. Am J Community Psychol. 1997;25(1): 73-94.

38. Mueser K.T.;Glynn S.M. Behavioral family therapy for psichiatric disorders. Boston: Allyn and Bacon, 1995.

39. Mintz, L.I. et al. Expressed emotion: a call for partnership among relatives, patients, and professionas. Schizoph. Bull, Rockville.1987; 13:227-35.

40. Kuipers L, Bebbington P. Working in partnership: clinicians and carers in the management of longstanding mental illness. Oxford: Heinemann Medical Books; 1990.

41. Yacubian J., Neto FL. Psicoeducação familiar Fam. Saúde Desenv. Curitiba. 2001;.3(2):98-108.

42. Souza RC, Scatena MCM. Qualidade de vida de pessoas egressas de instituições psiquiátricas: caso de Ilhéus - BA. Saúde Deb. 2001;25(58):88-97.

43. Salles MM, Barros S.Reinternação em hospital psiquiátrico: a compreensão do processo saúde/doença na vivência do cotidiano Rev Esc Enferm USP. 2007; 41(1):73-81.

44. Csernansky JG, Schuchart EK. Relapse and rehospitalisation rates in patients with schizophrenia: effects of second generation antipsychotics. CNS Drugs. 2002;16(7):473-84.

45. Davis JM, Chen N. Choice of maintenance medication for schizophrenia. J Clin Psychiatry. 2003;64 Suppl $16: 24-33$

46. Yamada K, Watanabe K, Nemoto N, Fujita H, Chikaraishi C, Yamauchi K, Yagi G, Asai M, Kanba S. Prediction of medication noncompliance in outpatients with schizophrenia: 2-year follow-up study.Psychiatry Res. 2006 Jan 30;141(1):61-9. Epub 2005 Nov 28.

47. Hamann J, Cohen R, Leucht S, Busch R, Kissling W.Shared decision making and long-term outcome in schizophrenia treatment. J Clin Psychiatry. 2007 Jul;68(7):992-7.

48. Marder SR Facilitating compliance with antipsychotic medication. West Los Angeles Veterans Affairs Medical Center and The University of California at Los angeles School of Medicine, 90073, USA. J Clin Psychiatry. 1998; 59 Suppl 3:21-5.

49. Gray R, Wykes T, Gournay K. From compliance to concordance: a review of the literature on interventions to enhance compliance with antipschotic medication. J Psychiatr Ment Health Nurs. 2002 Jun; 9(3): 277-84.

50. Cardoso L, Galera, SAF. Perfil demográfico e clínico de pessoas que fazem uso de Decanoato de Haloperidol. Dissertação (mestrado) - Programa de Pós Graduação em Enfermagem Psiquiátrica - Escola de Enfermagem de Ribeirão Preto da Universidade de São Paulo. Ribeirão Preto, 2006. 78 f. 
51. Baldi, Vivian Melhado. A atuação do enfermeiro psiquiátrico em um macro-hospital estatal: análise de uma experiência de grupo. Ribeirão Preto. Apresentada a Universidade de São Paulo. Escola de Enfermagem de Ribeirão Preto para obtenção do grau de Mestre.s.n; 1992. $109 \mathrm{p}$.

52. OMS, Les soins infirmiers en action. Renforcer les soins infirmiers et l'obstétrique à l'appui de la Santé pour tous. Ed. J.Salvage. Copenhagen : Publications régionales de l’OMS, Série européenne, nº 48, p. 18, 1993.

53. Lucchese, Roselma. A enfermagem psiquiátrica e saúde mental: a necessária constituição de competências na formação e na prática do enfermeiro. Enfermagem (EE/EERP). Doutorado. 2005

54. Oliveira, Lilian Hortale; Miranda, Cristina Maria Loyola. A instituição psiquiátrica e o doente mental: a percepção de quem vivencia esse cotidiano.Esc. Anna Nery Rev. Enferm;4(1):95-104, abr. 2000.

55. Oliveira SL. Tratado de metodologia científica, projetos de pesquisa, TGI, TCC, monografia, dissertações e teses. São Paulo. Pioneira. 1997:320p

56. Campos, LFL. Métodos e técnicas de pesquisa em psicologia. Campinas 2aa.Ed. Alínea, 2001:158p.

57. Koizumi, MS. Fundamentos metodológicos da pesquisa em enfermagem. ver Esc Enf; 1992;(26): $\mathrm{n}^{\circ}$ especial.

58. Bech, P.; Kastrup, M. \& Rafaelsen, O.J. _ Mini-Compendium of Rating Scales for States of Anxiety, Depression, Mania, and Schizophrenia With Corresponding DSM-III Syndromes. Acta Psychiatrica Scandinavica Suppl 1986;326: 7-37.

59. Zuardi AW, Loreiro SR, Rodrigues CRS, Correa AJ, Glock SS. Estudo da estrutura fatorial, fidedignidade e validade da tradução e adaptação para o português da Escala de Avaliação Psiquiátrica Breve (BPRS) modificada. Rev ABP-APAL 1994; 16: 63-8.

60. Crippa JAS, Hallak JEC, Sanches RF, Loureiro SR, Zuardi A W. Roteiro de entrevista estruturada para a escala breve de avaliação psiquiátrica (SIG-BPRS). In: Gorestein C; Andrade LHSG, Zuardi A, ed. Escalas de avaliação clínica em psiquiatria e psicofarmacologia. São Paulo: Lemos Editorial, 2000, p.207-17.

61. Morisky, D.E.; Levine, M.; Green, L.W.; Smith, C.R. Health education program effects on the management of hypertension in the elderly. Arch. Intern. Med. 1982;142(10):1835-38.

62. Morisky, D.E.; Green, L.W.; Levine, D.M. Concurrent and predective validity of self-reported measure of medication adherence. Med. Care. 1986;24:67-74.

63. Ingaramo Roberto A, Nestor Vita, Mario Bendersky, Miguel Arnolt§,Claudio Bellido, Daniel Piskorz, Omar Lindstrom, Angel Garcia Piazza,Rafael Manzur, Emilio Marigliano, Sergio Hauad, Alfredo Donato,Mirta Santana. Estudio Nacional Sobre Adherencia al Tratamiento (ENSAT) Rev Fed Arg Cardiol 2005; 34: 104-111.

64. Strelec, Maria Aparecida Abdalla Moura . A influência do conhecimento sobre a doença e a atitude frente à tomada dos remédios no controle da hipertensão arterial. Säo Paulo; s.n; 2000. 109 p. ilus, tab, graf. Tese:Apresentada a Universidade de Säo Paulo. Escola de Enfermagem.

65. Pérez, A.M.G.; Fernández, F.L.; Crespo, F.M.; Ruiz, A.J.G.; Torres, P.D.; Alarcón, F.S.C. Como diagnosticar el cumplimiento terapêutico em atención primaria. Medicina da Família.2000;1:13-9.

66. Svarstad, B.L.; Chewning, B.A.; Sleath, B.L.; Claesson, C. The brief medication questionnaire: a tool for screening patient adherence and barriers to adherence. Patient Education and Counseling. 1999;37:113-24. 
67. Garcia, R.A.C. Os fatores de aderência ao tratamento farmacológico de hiperlipidemias em pacientes atendidos pela Secretaria Municipal de Saúde de Ribeirão Preto. 2003. 104f. Dissertação (Mestrado em Saúde na Comunidade) - Faculdade de Medicina de Ribeirão Preto da Universidade de São Paulo, Ribeirão Preto, SP, 2003

68. Teixeira, A.C.A. Adesão ao tratamento farmacológico da hipertensão arterial e seus determinantes em pacientes de ambulatório. 1998. 102f. Dissertação (Mestrado em Saúde Pública) - Faculdade de Medicina da Universidade Federal do Ceará, Fortaleza, CE, 1998.

69. Bandeira,M. ; Calzavara, M. G. P. ; Lucas Cordeiro de Freitas ; Barroso, S. M. . Family Burden Interview Scale for relatives of psychiatric patients(FBIS)BR): reabillity study of the Brazilian version. Revista Brasileira de Psiquiatria (São Paulo).2007;29:47-50.

70. Martínez, A.; Nadal, S.; Beperet, M.; Mendióroz, P. - Sobrecarga de los cuidadores familiares de pacientes con esquizofrenia: factores determinantes. ANALES Sis San Navarra 23(1): 101-110, 2000b. Martinez 2000

71. Bulger, M.W.; Wandersman, A.; Goldman, C.R. - Burdens and gratifications of caregiving: appraisal parental care of adults with schizophrenia. American Journal of Orthopsychiatry 63: 255-265, 1993.

72. Doornbos,M.M. -The problem and coping methods of caregivers of young a dults with mental illness. Journal of Psychosocial Nursing 35(9m): 22-26, 1997.

73. Organizações Mundiais de Saúde, 2001. Relatório sobre a Saúde no Mundo - Saúde Mental: Nova Concepção, Nova Esperança. 2001.

74. Coutinho ESF, Gomes MPC, Couto MCV et al. Censo de pacientes internados em uma instituição asilar no estado do Rio de Janeiro: dados preliminares. Cadernos de Saúde Pública, 2002;18:1803-7.

75. Coutinho, ESF ; Almeida Filho, N. ; Mari, JJ. Fatores de risco para morbidade psiquiátrica menor: resultados de um estudo transversal em três áreas urbanas no Brasil. Revista de Psiquiatria Clínica, São Paulo, 1999:V. 26, N. 5, P. 246-256.

76. Carvalho RJL. Utilização de recursos e custos diretos da esquizofrenia para o setor público do estado de São Paulo [dissertação de mestrado]. São Paulo: UNIFESP - Escola Paulista de Medicina; 2000.

77. Bechelli, Luiz Paulo de C.Impacto e evoluçäo do emprego dos neuropépticos no tratamento da esquizofrenia / Impact and evolution of the use of antipsychotic agents the tratment of schizophrenia. J. bras. psiquiatr;49(5):131-47, maio 2000. ilus, tab.

78. Josef, F, Silva, JAR. Doença mental e comportamento violento: novas evidências da pesquisa. J. bras. psiquiatr;52(2):127-135, mar.-abr. 2003.

79. Brasil. Leis; Decretos.Lei 10.216 de 6 de abril de 2001. In: Brasil. Ministério da Saúde. Secretaria de Atenção à Saúde. Legislação em Saúde Mental:1990-2004. 5a ed. Brasília: 2004. p. 243- 51.

80. Newstead L, Kelly M. Early intervention in psychosis: who wins, who loses, who pay the price? Journal of Psychiatric and Mental Health Nursing, 2003, 10, 83-88.

81. Van Meijel B, Van Der Gaag M, Kahn RS, Grypdonck. The practice of early recognition ao early intervention to prevent psychotic relapse in patientes with schizophrenia: na exploratory stud. Part 1. 2002 Journal of Psychiatric an Mental Health Nursing 9: 347-55.

82. Medeiros ARC. Adesão ao tratamento anti-hipertensivo em unidade de saúde da família de João Pessoa PB. Dissertação [Mestrado]. João Pessoa: Centro de Ciências da Saúde da Universidade Federal da Paraíba João Pessoa; 2006. 
83. Strelec MAAM, Pierin AMG, Mion JD. A influência dos conhecimentos sobre a doença e a atitude frente à tomada dos remédios no controle da hipertensão. Arq Bras Cardiol, v. 81, n. 4, p. 343-8, 2003.

84. Ostenberg L, Blaschke T. Adherence to medication. N. Engl. J. Med., v. 353, p 487-497, 2005.

85. Perkins DO. Adherence to antipsychotic medications. J Clin Psychiatry 1999; 60 Suppl 21: 25-30.

86. Krapek K, King K., Warren SS., George KG, Caputo DA, Mihelich K, Holst EM, Nichol MB, SHI SG, Livengood,KB; Walden S., Lubowski T J. Medication adherence and associated hemoglobin A1c in type 2 diabetes. Ann. Pharmacother., 2004v. 38, p.1357-62.

87. Davis NJ., Billett HH, Cohen HW., Arnsten JH. Impact of adherence, knowledge, and quality of live on anticoagulation control. Ann. Pharmacother., v. 39, p. 632-636, 2005.

88. Garcia RAC. Os fatores de aderência ao tratamento farmacológico de hiperlipidemias em pacientes atendidos pela Secretaria Municipal de Saúde de Ribeirão Preto. Ribeirão Preto, 2003. 104 p. [Dissertação de Mestrado. Faculdade de Medicina de Ribeiro Preto, Universidade de São Paulo].

89. Piñero F., GIL V., Donis M. Validez de 6 métodos indirectos para valorar el cumplimiento del tratamiento farmacológico en la hipertensión arterial. Aten Primaria, Miércoles, v. 19, n. 7, p. 372-5, Abr. 1997.

90. Garcia Pérez AM., Leiva Fernandez F.; Martos Crespo, F. Como diagnosticar el cumplimiento terapéutico en atención primaria? Medicina de Família2000, v. 1, n. 1

91. Kidd KE \& Altman DG. Adherence in social context. Controlled Clinical Trials 200021:184-87S.

92. Marsh, D. T. (1992). Families and mental illness: new directions in professional practice. New York: Praeger.

93. Melman, J. (2002). Família e doença mental: repensando a relação entre profissionais de saúde e familiares. São Paulo: Escrituras.

94. Ostman, M., Hansson, L. \& Anderson, C. (2000). Family burden, participation in care and mental health: an 11-year comparison of the situation of relatives to compulsory and voluntary admitted patients. International Journal of Social Psychiatry, 46 (3), 191-201.

95. Rose, L.E. - Families of psychiatric patients: a critical review and future research directions. Archives of Psychiatric Nursing 10(2): 67-76, 1996.

96. Spadini, LS; Bueno, SMV. Análise da conduta educativa do enfermeiro psiquiátrico e saúde mental e a educação problematizadora. Acta sci., Health sci; 2005, 27(1):1-7.

97. Oliveira LH, Miranda CML. A instituição Psiquiátrica e o doente mental: a percepção de quem vivencia esse cotidiano. Esc Anna Nery Rev Enferm. 2000;4(1):95-103.

98. Cattani RB, Girardon-Perlini NMO. Cuidar do idoso doente na voz de cuidadores domiciliares. Rev Eletrônica Enferm 2004; 6(2):254 - 71.

99. Soares, C. \& Menezes, P. R. (2000). Impacto econômico em famílias de pessoas com transtornos mentais graves e com transtornos devido ao uso de substâncias psicoativas. Revista de Psiquiatria Clínica, 27 (4), 31-39

100. Campos, Pedro Humberto Faria; Soares, Carlene Borges.Representação da sobrecarga familiar e adesão aos serviços alternativos em saúde mental / Social representations of family burden and adhesion to mental health alternative services Psicol. rev. (Belo Horizonte);11(18):219-237, dez. 2005. tab, ilus. 
101. Alonso SG. Falando sobre reinternação psiquiátrica: a voz das pacientes. [dissertação] São Paulo: Escola de Enfermagem, Universidade de São Paulo; 2000.

102. Brasil. Ministério da Saúde. Secretaria Executiva. Legislação em saúde mantal. 1990-2002. $3^{\text {a }}$ ed.rev. Brasília;2002.

103. SAE- cofen Resolução 272/2004 Dispõe sobre a Sistematização da Assistência de Enfermagem - SAE - nas instituições de saúde brasileiras.

104. Oliveira Alice G. Bottaro de, Alessi Neiry Primo. Mental health nursing work: contradictions and current potentialities. Rev. Latino-Am. Enfermagem [serial on the Internet]. 2003 June [cited 2008 Apr 23] ; 11(3): 333340. Available from: http://www.scielo.br/scielo.php?script=sci_arttext\&pid=S010411692003000300011\&lng=en\&nrm=iso. doi: 10.1590/S0104-11692003000300011

105. Bertoncello NMF. O processo de trabalho em ambulatório de saúde mental: a prática da enfermeira. [Dissertação]. Ribeirão Preto (SP): Escola de Enfermagem/USP; 1997.

106. Mello R. A questão da interdisciplinaridade no dia-a-dia da enfermeira que atua em Centros de Atenção Diária de saúde mental. Rev Bras Enfermagem 1998 janeiro/março; 51(1):19-34.

107. Stewart M, Brown J B, Donner A, McWhinney I R, Oates J, ; Weston W W, Jordan J The Impact of Patient-Centered Care on Outcomes. J Fam Pract 2000; 49:796-804 


\section{Pesquisa: "RECAÍDAS EM PACIENTES EGRESSOS DE INTERNAÇÃO PSIQUIÁTRICA- - um olhar sobre o paciente e sua família". \\ QUESTIONÁRIO \\ (OBS: Para todas as questões $9=$ Informação ignorada)}

Nome do paciente:

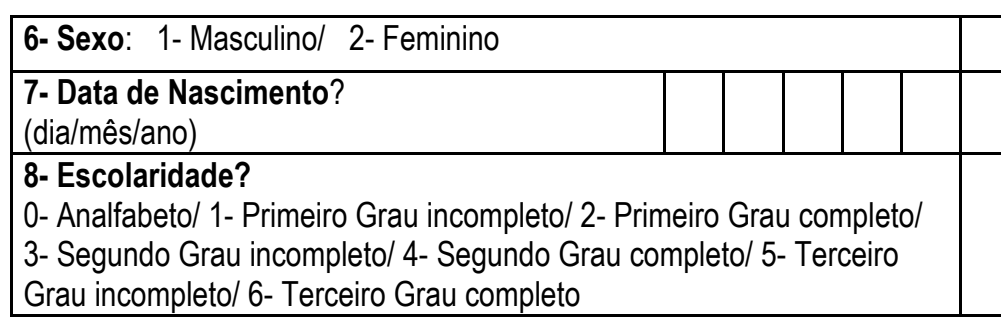

1. $N^{\circ}$ sujeito banco:

2. $\mathrm{N}^{\circ}(\mathrm{HYGIA})$ do paciente

3. Data coleta (dia/mês/ano)

4. Número da coleta

5- Local da entrevista: 1-NSM 2- Casa do paciente

\begin{tabular}{|c|c|}
\hline $\begin{array}{l}\text { 11- Você trabalha ou já trabalhou? } \\
\text { 0- Nunca trabalhou/ 1- Desempregado/ 2-Faz trabalhos eventuais } \\
\text { (“bicos”)/ 3-Trabalho regular (informal) / 4-Trabalho regular (registrado)/ } \\
\text { 5- Afastado do trabalho / 6- Aposentado INSS/ 7- Outra (........................... }\end{array}$ & 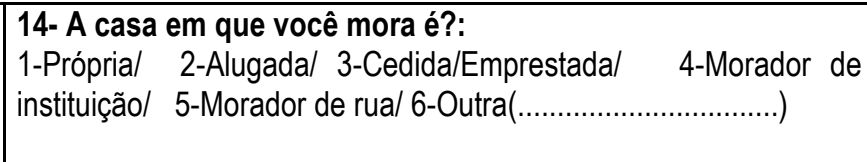 \\
\hline $\begin{array}{l}\text { 12- Quanto você ganha por mês? 0-Não tem renda/ 1-Até um salário } \\
\text { mínimo }(R \$ 380,00) / 2 \text { 2-Até dois salários mínimos }(\mathrm{R} \$ 760,00) / \text { 3-Até três } \\
\text { salários mínimos }(\mathrm{R} \$ 1140,00) / 4 \text {-Mais de três salários. }\end{array}$ & $\begin{array}{l}\text { 15- Com quantas pessoas você Paciente mora? (que } \\
\text { coabitam na mesma residência): }\end{array}$ \\
\hline $\begin{array}{l}\text { 13- Com quem você Paciente mora? 0-Mora sozinho/ 1-Com } \\
\text { familiares/ 2-Com amigos/colegas/ 3-Asilo/ 4-Casa Assistida } \\
\text { (comunidade terapêutica)/ 5-Outra (.........................................) }\end{array}$ & $\begin{array}{l}\text { 16- Qual é a Renda Total da sua família? 0-Não tem/ 1-Até um } \\
\text { salário mínimo( } R \$ 380,00) / \text { 2-Até dois salários mínimos ( } R \$ \\
760,00) / \text { 3-Até três salários mínimos }(\mathrm{R} \$ 1140,00) / 4-\text { Mais de três } \\
\text { salários mínimos/ 5-não sabe dizer }\end{array}$ \\
\hline
\end{tabular}

\begin{tabular}{|c|c|c|c|c|c|}
\hline \multirow{4}{*}{$\begin{array}{l}\text { 17-Diagnóstico psiquiátrico do } \\
\text { prontuário } \\
\text { (colocar código CID 10; em ordem } \\
\text { crescente): }\end{array}$} & 17.1 Diagnostico 1 & & \multirow{5}{*}{$\begin{array}{l}\text { 22- Classe de } \\
\text { Psicofármacos } \\
\text { prescritos: } \\
1 \text { - Não } \\
2-\operatorname{Sim}\end{array}$} & 28.1 Ansiolíticos e Hipnóticos & \\
\hline & 17.2 Diagnostico 2 & & & 28.2 Antidepressivos tricíclicos & \\
\hline & \begin{tabular}{|l|}
17.3 Diagnostico 3 \\
\end{tabular} & & & 28.3 Antidepressivos ISRS & \\
\hline & 17.4 Diagnostico 4 & & & 28.4 Antidepressivos mistos & \\
\hline \multicolumn{3}{|c|}{$\begin{array}{l}\text { 18- Você sabe dizer qual é o nome da doença psiquiátrical mental que } \\
\text { você tem? } 1 \text { - Não / } 2 \text { - Sim }\end{array}$} & & 28.5 Antipsicóticos Tipicos & \\
\hline \multirow{4}{*}{\multicolumn{3}{|c|}{$\begin{array}{l}\text { 19- Você sabe dizer há quanto tempo você tem essa doença? (em anos } \\
\text { completos) 0-Um ano/ 1-Dois anos/ 2-Três anos/ 3-Quatro anos/ 4-Cinco } \\
\text { anos ou mais/ 5- não sabe dizer }\end{array}$}} & \multirow{4}{*}{$\begin{array}{l}\text { "Verificar a prescrição } \\
\text { médica atual" }\end{array}$} & 28.6 Antipsicóticos Atipicos & \\
\hline & & & & 28.7 Estabilizadores do Humor & \\
\hline & & & & 28.8 Anticonvulsivantes & \\
\hline & & & & 28.9 Antiparkinsonianos & \\
\hline \multirow{2}{*}{\multicolumn{3}{|c|}{$\begin{array}{l}\text { 20-Você acha o tratamento com remédios importante para melhorar } \\
\text { sua saúde? } 1 \text { - Não / } 2 \text { - Sim } \\
\text { 21- Você sabe dizer quais são os remédios que você está tomando } \\
\text { atualmente (agora depois da internação)? 1-Não / 2-Parcialmente } \\
\text { (alguns)/ 3- Sim (todos) }\end{array}$}} & \multirow{2}{*}{\multicolumn{2}{|c|}{ OBS: }} & \\
\hline & & & & & \\
\hline
\end{tabular}

\begin{tabular}{|c|c|c|}
\hline \multicolumn{3}{|c|}{ 23- Você já teve internação psiquiátrica? 1 - Não / 2 - Sim } \\
\hline \multicolumn{2}{|l|}{ 24- Quantas vezes internado? } & \\
\hline \multicolumn{3}{|c|}{$\begin{array}{l}\text { 25- TEVE INTERNAÇÃO PSIQUIÁTRICA NO ULTIMO MÉS? } \\
1 \text { - Não(se não ir para questão 31) } / 2-\text { Sim }\end{array}$} \\
\hline \multicolumn{2}{|c|}{$\begin{array}{l}\text { 26- Data da última internação psiquiátrica } \\
0=\text { não teve }\end{array}$} & \\
\hline \multicolumn{2}{|c|}{$\begin{array}{l}\text { 27- Local } 0=\text { não teve 1-HCFMRP- Campus, 2-H Sta Terersa, 3- } \\
\text { HCFMRP-UE, 4-Outro (.............................................. }\end{array}$} & \\
\hline
\end{tabular}

9- Estado civil? 0 -Nunca se casou/amasiou / 1-Separado (a) / 2-Casado ou Amasiado (a) / 3-Viúvo (a)/ 4- Divorciado (a)

10- Quantos filhos você (Paciente) tem?

0-Não tem/ 1-Um filho/ 2-Dois filhos/ 3-Três filhos ou mais salário mínimo( $R \$ 380,00) / 2$-Até dois salários mínimos $(R \$$ $760,00) / 3-A t e ́$ três salários mínimos ( $\mathrm{R} \$ 1140,00) / 4$-Mais de três ários mínimos/5-não sabe dizer

29- Duração da última internação (dias): 0=não teve 30- Intervalo em dias entre a data de alta hospitalar e a ida do paciente ao serviço comunitário: $0=$ não teve 31- Precisou ir a um serviço de urgência/emergência psiquiátrica no ultimo mês? 1-Não 2-Sim OBS:
32- Você alguma vez esquece de tomar seu(s) remédio(s)? 1 Não / 2 - Sim

33- Você, as vezes, é descuidado com os horários de tomar seu remédio? 1 - Não / 2 - Sim
34- Quando você se sente bem, alguma vez, deixa de tomar seu remédio? 1 - Não / 2 - Sim

35- Quando você se sente mal, com o remédio, você as vezes deixa de tomar ele? 1 - Não / 2 - Sim 
BPRS (questões de 36 a 54) (escore de 0 a 4 )

\begin{tabular}{|l|l|l|l|l|l|l|}
\hline 1-PS & 2-AP & 3-RE & 4-DC & 5-AC & 6-AS & 7-DM \\
\hline
\end{tabular}

8-AEE 9 9-HD

\begin{tabular}{|c|c|c|c|}
\hline $10-H$ & $11-D$ & $12-A l$ & $13-R P$ \\
\hline
\end{tabular}

14-FC

\begin{tabular}{|c|c|}
\hline $4-F C$ & $15-P I$ \\
\hline
\end{tabular}

16-AE $17-\mathrm{AP}$

18-DC TOTAL

55- 0 paciente possui um cuidador responsável? 1-Não/ 2-Sim (se sim preencher dados do cuidador e escala FBIS-BR)

\begin{tabular}{|l|l|l|}
\hline Contatos & & \\
\hline Data retorno médico & & \\
\hline Data retorno pesquisa & & \\
\hline
\end{tabular}




\begin{tabular}{|l|}
\hline $\begin{array}{c}\text { Pesquisa: "RECAÍDAS EM PACIENTES EGRESSOS DE INTERNAÇÃO } \\
\text { PSIQUIÁTRICA- - um olhar sobre o paciente e sua família". } \\
\text { Cuidador }\end{array}$ \\
\hline Nome do paciente: \\
\hline Nome do cuidador:
\end{tabular}

1. Nº sujeito banco:
\begin{tabular}{ll|l|l|l|l|l|l|} 
2. No $(H Y G I A)$ do paciente & & & & & & & \\
\hline 3. Data coleta (dia/mês/ano) & & & & & & \\
4. Número da coleta \\
5- Local da entrevista: 1-NSM 2- Casa do paciente & \\
\hline
\end{tabular}

\begin{tabular}{|l|l|}
\hline 56- IDADE do cuidador: (anos completos) & \\
\hline $\begin{array}{l}\text { 57- Qual é vínculo familiar do cuidador com o paciente? 0-Não possui/ 1- } \\
\text { Mãe/ 2-Pai/ 3-Irmão(a)/ 4-Esposo(a)/ 5-Filho(a)/ 6-Avó(ô)/ 7- Tio(a)/ 8- outro }\end{array}$ & \\
\hline $\begin{array}{l}\text { 58- Grau de escolaridade do cuidador: } \\
\text { 0-Analfabeto/ 1-Primeiro Grau incompleto/ 2-Primeiro Grau completo/ 3-Segundo } \\
\text { incompleto/ 4-Segundo completo/ 5-Terceiro incompleto/ 6-Terceiro completo }\end{array}$ & \\
\cline { 1 - 2 }
\end{tabular}

59- Estado civil do cuidador 0 -Nunca se casoul 1-Separado(a) / 2Casado ou Amasiado(a)/ 3- Viúvo(a)/ 4- Divorciadoa)

60- Número de filhos do cuidador:

0-Não tem/ 1-Um filho/ 2-Dois filhos/ 3-Três filhos ou mais

61- Situação atual do cuidador quanto ao trabalho:

0 -Recebe pelo cuidado prestado/ 1-Nunca trabalhou/ 2-Desempregado/ 3-Faz trabalhos eventuais ("bicos")/ 4-Trabalho regular (informal) / 5-Trabalho regular (registrado)/6- Afastado do trabalho / 7- Aposentado INSS 8- outra

62- 0 cuidador acha o tratamento com remédios importante para melhorara saúde do(a) (nome paciente) ? 1-Não / 2 - Sim
PARTE A: ASSISTÊNCIA NA VIDA COTIDIANA : Geralmente as pessoas que têm doenças mentais precisam de ajuda ou precisam ser lembradas de fazer as coisas comuns do dia-a-dia. As perguntas que vou fazer agora são sobre isso. Talvez, nem todas elas se apliquem a (.......Nome..........), mas tente respondê-las, por favor, com o conhecimento que você tem sobre ele(a).

De A1a até A9a alternativas:1-Nenhuma vez/ 2-menos que uma vez $\mathrm{p} /$ semana / 3-1 ou 2 vezes $\mathrm{p} /$ semana / 4- de 3 a 6 vezes p/semana / 5-Todos os dias

A1a. Nos últimos 30 dias, quantas vezes você ajudou (Nome) ou lembrou-lhe de fazer coisas como se pentear, tomar banho ou se vestir? Foram quantas vezes? 1-Nenhuma vez (PASSE PI A2a)

A2a. Nos últimos 30 dias, quantas vezes você ajudou, lembrou ou encorajou (Nome) a tomar os remédios dele(a) ou teve que dar o remédio pessoalmente ou às escondidas? Foram quantas vezes? 1-Nenhuma vez (PASSE PI A3a)

A3a.Nos últimos 30 dias, quantas vezes você ajudou (Nome) ou lembrou-lhe de fazer tarefas da casa (ex. arrumar a cama, limpar o quarto, lavar roupa, etc.) ou teve que fazer isto para ele(a)? Foram quantas vezes?

A4a. Nos últimos 30 dias, quantas vezes você ajudou (Nome) ou lembrou-lhe de fazer compras de alimentos, roupas ou outros objetos ou teve que fazer compras para ele(a)? Foram quantas vezes?

A5a. Nos últimos 30 dias, quantas vezes você cozinhou para (Nome) ou o (a) ajudou a preparar as refeições? Foram quantas vezes?

A6a. Nos últimos 30 dias, quantas vezes você ajudou a levar (Nome) a algum lugar, à pé, de carro, de ônibus ou por outros meios de transporte? Foram quantas vezes?

A7a. Nos últimos 30 dias, quantas vezes você ajudou (Nome) a cuidar do dinheiro dele(a) ou teve que fazer isso por ele/ela? Foram quantas vezes?

A8a. Nos últimos 30 dias, quantas vezes você ajudou, lembrou ou insistiu com (Nome) para ele(a) se ocupar com alguma coisa, não ficar à toa, usar o seu tempo para fazer alguma coisa, como ler revista, se divertir com alguma coisa, trabalhar, estudar ou visitar as pessoas, etc. ? Foram quantas vezes?

A9a. Nos últimos 30 dias, quantas vezes você lembrou, encorajou ou insistiu com (Nome) ou teve que levá-lo(a) para as suas consultas médicas ou atividades nos serviços de saúde mental ? Foram quantas vezes?
De $A 1 b$ até $A 9 b$ alternativas:.1-Nem um poucol

2-muito poucol 3-um pouco/ 4-muito

A1b. Quanto the incomodou ter que ajudar (Nome) ou lembrar-lhe de fazer essas coisas?

A2b. Quanto the incomodou ter que fazer alguma coisa para (Nome) tomar os remédios dele(a)?

A3b. Quanto the incomodou ter que ajudar, lembrar ou fazer essas coisas para ele(a)?

A4b.Quanto the incomodou ter que ajudar, lembrar ou fazer essas coisas para ele(a)?

A5b. Quanto the incomodou ter que cozinhar para (Nome) ou ajudá-lo(a) a preparar as refeições dele(a)?

A6b. Quanto lhe incomodou ter que ajudar a levar (Nome) a algum lugar?

A7b. Quanto the incomodou ter que ajudar (Nome) a cuidar do dinheiro dele(a) ou a fazer isto por ele(a)?

A8b. Quanto the incomodou ter que ajudar ou lembrar (Nome) a se ocupar com alguma coisa?

A9b. Quanto the incomodou ter que lembrar, encorajar ou levar (Nome) para as suas consultas médicas ou atividades nos serviços de saúde mental?

PARTE B: SUPERVISÃO AOS COMPORTAMENTOS PROBLEMÁTICOS: Algumas vezes, as pessoas com doenças mentais podem precisar de ajuda quando ocorrem alguns comportamentos problemáticos. As perguntas que vou fazer agora talvez não se apliquem a (Nome), mas tente respondê-las, por favor, com o conhecimento que você tem sobre ele (a).

De B1a até A8a alternativas: 1-Nenhuma vez/ 2-menos que uma vez $\mathrm{p} /$ semana / 3-1 ou 2 vezes $\mathrm{p} /$ semana / 4- de 3 a 6 vezes p/semana / 5-Todos os dias

B1a. Nos últimos 30 dias, quantas vezes você tentou evitar ou impedir (Nome) de apresentar algum comportamento que te deixasse envergonhado(a) ou incomodado(a) ou teve que lidar com estes comportamentos ou com suas conseqüências ? Foram quantas vezes? Nenhuma vez (PASSE PI B2a)

B2a. Nos últimos 30 dias, quantas vezes você tentou evitar ou impedir que (Nome) ficasse exigindo demais sua atenção ou você teve que lidar com este comportamento ou suas conseqüências ? Foram quantas vezes? (Nenhuma vez PASSE P/ B3a)

B3a. Nos últimos 30 dias, quantas vezes você tentou evitar ou impedir que (Nome) incomodasse as pessoas durante a noite ou teve que lidar com este comportamento ou com suas conseqüências ? Foram quantas vezes? (Nenhuma vez PASSE P/ B4a)

De B1b até B8b alternativas:.1-Nem um poucol 2-muito poucol 3-um pouco/ 4-muito B1b. Quanto lhe incomodou ter que lidar com este comportamento desconcertante de (Nome)?

B2b. Quanto lhe incomodou ter que lidar com o comportamento de (Nome) de exigir que você dê atenção a ele(a)?

B3b. Quanto Ihe incomodou ter que lidar com este comportamento perturbador de (Nome)? 
B4a. Nos últimos 30 dias, quantas vezes você tentou evitar ou impedir que

(Nome) insultasse alguém, ameaçasse ou machucasse alguém ou teve que lidar com este comportamento ou suas conseqüências? Foram quantas vezes? (Nenhuma vez PASSE P/ B5a)

B5a. Nos últimos 30 dias, quantas vezes você tentou evitar ou impedir (Nome) de falar em morrer, ou de falar em se matar, de ameaçar ou tentar se matar? Foram quantas vezes? (Nenhuma vez PASSE PI B6a)

B6a. Nos últimos 30 dias, quantas vezes você tentou evitar ou impedir que (Nome) bebesse demais (bebidas alcoólicas) ou teve que lidar com as conseqüências deste comportamento? Foram quantas vezes? (PASSE P/B7a)

B7a. Nos últimos 30 dias, quantas vezes você tentou evitar ou impedir que

(Nome) comesse ou bebesse demais (bebidas não alcoólicas, ex. café, xaropes, etc.) ou fumasse demais? Foram quantas vezes? (PASSE P/ B8a)

B8a. Nos últimos 30 dias, quantas vezes você tentou evitar ou impedir (Nome) de usar drogas (ilegais) ou teve

que lidar com as conseqüências deste comportamento? Foram quantas vezes? (PASSE P/ C1a)
B4b. Quanto Ihe incomodou ter que fazer isso?

B5b. Quanto the incomodou estas conversas, ameaças ou tentativas de (Nome) de se matar ou de falar em morrer?

B6b.Quanto the incomodou o fato de (Nome) beber?

B7b. Quanto the incomodou ter que lidar com este comportamento de (Nome)?

B8b. Quanto lhe incomodou o fato de ( Nome ) usar drogas (ilegais)?

\section{PARTE C: GASTOS FINANCEIROS}

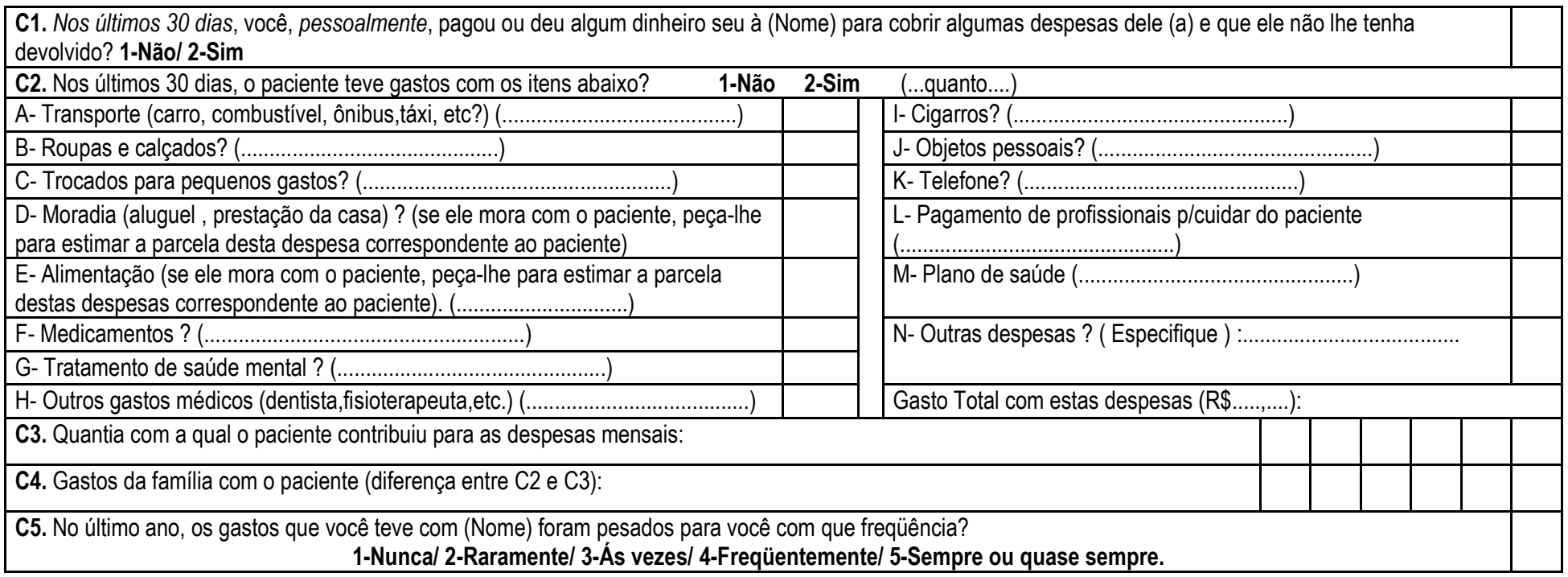

\section{PARTE D. IMPACTO NAS ROTINAS DIÁRIAS}

\section{1-Nenhuma vez 2-menos que uma vez p/semana $\quad$ 3-1 ou 2 vezes $\mathrm{p} / \mathrm{semana} \quad$ 4- 3 a 6 vezes $\mathrm{p} / \mathrm{semana} \quad$ 5- Todos os dias?}

D1a. Nos últimos 30 dias, quantas vezes você faltou, chegou atrasado ou cancelou algum compromisso, como no trabalho, na escola ou em outros lugares, porque teve que cuidar de (Nome)? Foram quantas vezes?

D1b. Nos últimos 30 dias, quantas vezes as suas atividades sociais e de lazer (ex. sair para descansar ou visitar alguém) foram alteradas ou perturbadas, porque você teve que cuidar de (Nome)? Foram quantas vezes?

D1c. Nos últimos 30 dias, quantas vezes os seus serviços de casa, ou a rotina da casa, foi alterada ou perturbada porque você teve que cuidar de (Nome)? Foram quantas vezes?

D1d. Nos últimos 30 dias, quantas vezes o fato de cuidar de (Nome) impediu de você dedicar aos outros membros da família a atenção e o tempo de que eles necessitavam? Foram quantas vezes?

D2. A doença de (Nome) provocou mudanças mais ou menos permanentes na sua rotina diária, no seu trabalho ou na sua vida social?

$$
\begin{array}{llll}
\text { 1- Nem um pouco } & \text { 2-muito pouco } & \text { 3- um pouco } & \text { 4-muito ? }
\end{array}
$$

D3. Questões de A - F: Por causa da doença de......................................... (Nome):

A- Você teve que trabalhar menos ou abandonar o seu emprego ou teve que trabalhar mais para cobrir os gastos?

B- Você teve que se aposentar mais cedo do que você planejava?

C- Você deixou de ter (ou tem menos) vida social (ex.deixou de passear, visitar pessoas, ir a festas, etc.)?

D- Você perdeu amizades?

E- Você deixou de tirar férias (ex. visitar parentes, viajar)?

F- Você deixou de receber (ou recebe menos) pessoas em casa (familiares e/ou amigos)? 
PARTE E: PREOCUPAÇÃO COM O PACIENTE: Mesmo quando as pessoas não se vêem por algum tempo, às vezes, mesmo assim elas se preocupam umas com as outras. Eu gostaria de perguntar-hhe sobre suas preocupações com $0(a)$. (Nome).

\section{1- Nunca, 2- Raramente, 3- Às vezes, 4- Frequentemente, 5- Sempre ou quase sempre}

E1. Você fica preocupado(a) com a segurança física de (Nome) (ex. que alguma coisa ruim aconteça com ele(a), que ele(a) sofra um acidente, entre em uma briga, que alguém se aproveite dele(a), que fuja, etc.):

E2. Você fica preocupado(a) com o tipo de ajuda e tratamento médico que (Nome) está recebendo ?(ex. com receio de que ele(a) não esteja sendo bem atendido(a), de que não esteja recebendo um bom tratamento para a doença dele(a), etc.?)

E3. Você fica preocupado(a) com a vida social de (Nome) (ex. preocupado se ele(a) não sai muito de casa, ou se sai demais ou se tem poucos amigos ou se sai com amigos que não lhe convém ?)

E4. Você fica preocupado(a) com a saúde física de (Nome)? (ex. dores, doenças, etc.)

E5. Você fica preocupado(a) com as condições de moradia atual de (Nome)?

E6.Você fica preocupado(a) ao pensar como (Nome) faria para sobreviver financeiramente se não houvesse você para ajudá-lo?

E7. Você fica preocupado(a) com o futuro de (Nome)? 


\section{TERMO DE CONSENTIMENTO LIVRE E ESCLARECIDO}

"Recaídas em pacientes egressos de internação psiquiátrica - um olhar sobre o paciente e sua família".

Pesquisa, nível Doutorado, vinculada ao Programa de Pós-Graduação Enfermagem Psiquiátrica - Escola de Enfermagem de Ribeirão Preto da Universidade de São Paulo. Inserido na linha de pesquisa: Enfermagem Psiquiátrica: o doente, a doença e as práticas terapêuticas.

Pesquisadora responsável: Lucilene Cardoso Orientadora: Prof ${ }^{\text {a }}$ Dr ${ }^{\text {a }}$ Sueli Aparecida Frari Galera

\section{ESCLARECIMENTO}

Nós profissionais da saúde estamos preocupados em melhorar nosso serviço para vocês e em entender como é para você e sua família o dia-a-dia com o tratamento da doença mental que você tem. Acreditamos que saber quais são as características do tratamento e como você e seu familiar se sentem é importante para isso. Na minha pesquisa quero acompanhar o tratamento de alguns pacientes como você e coletar informações sobre tudo o que acontecer com você durante 6 meses.

Para isso eu vou fazer perguntas para você e para uma pessoa da sua família. Serão encontros entre a gente uma vez por mês para acompanhar como está seu tratamento. Nesses encontros eu sempre vou fazer perguntas sobre como você está, como está seu tratamento e para o seu familiar vou perguntar também como ele está se sentindo.

Aí vou juntar tudo o que você e seu familiar me contar, com o que os outros pacientes me contarem, vou estudar tudo isso e fazer um trabalho final.

Se você e seu familiar concordarem em participar eu garanto que o nome de vocês não vai aparecer no meu trabalho em nenhum momento. Você não vai precisar pagar nada e também não vai receber dinheiro para participar. Sua participação não vai influenciar o seu atendimento aqui no Núcleo e você pode pedir para não participar quando você quiser, de acordo com a sua vontade. Eu prometo tirar qualquer dúvida que você tiver. Se você aceitar participar vou pedir que assine um documento que diz que você aceita e vou dar esta cópia para você guardar.

Em qualquer caso de dúvida você pode entrar em contato comigo no Núcleo (F: 3633-2829): 
$\mathrm{Eu}$, entendi e ouvi

da pesquisadora Lucilene Cardoso o que ela vai fazer na pesquisa: "Recaídas em pacientes egressos de internação psiquiátrica - um olhar sobre o paciente e sua família" e eu aceito participar dessa pesquisa.

Eu entendi que posso interromper ou parar a minha participação no estudo a qualquer hora que eu quiser, sem precisar explicar o porquê e que isso não vai atrapalhar o meu tratamento no Núcleo. Sei que meu nome não vai aparecer no trabalho final, que não vou ter gastos e que não vou receber dinheiro para participar do estudo.

Ribeirão Preto, de de 2008.

Assinatura do paciente (ou impressão digital)

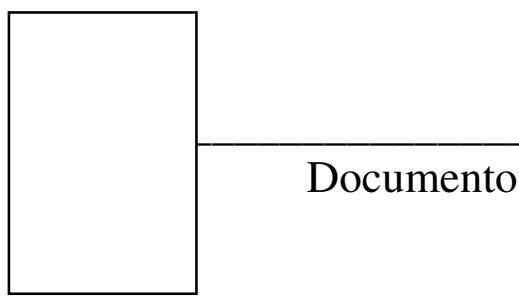

Assinatura do Responsável

(Ou impressão digital)

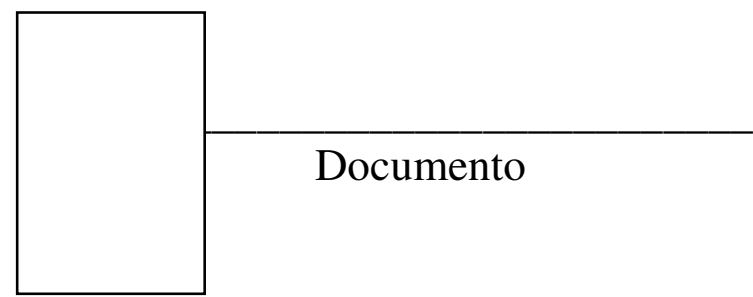

Assinatura do Pesquisador Responsável: Lucilene Cardoso

Em qualquer caso de dúvida você pode entrar em contato comigo no Núcleo (F: 3633-2829): 
$\mathrm{Eu}$,

Familiar (....grau de parentesco...) do paciente:

entendi e ouvi da pesquisadora Lucilene Cardoso o que ela vai fazer na pesquisa: "Recaídas em pacientes egressos de internação psiquiátrica - um olhar sobre o paciente e sua família" e eu aceito participar dessa pesquisa.

Eu entendi que posso interromper ou parar a minha participação no estudo a qualquer hora que eu quiser, sem precisar explicar o porquê e que isso não vai atrapalhar o tratamento de meu .(grau parentesco) no Núcleo. Sei que meu nome não vai aparecer no trabalho final, que não vou ter gastos e que não vou receber dinheiro para participar do estudo.

Ribeirão Preto, de de 2008 .

Assinatura do Familiar

Ou impressão digital

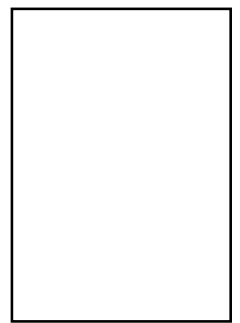

Documento

Assinatura do Pesquisador Responsável: Lucilene Cardoso

Em qualquer caso de dúvida você pode entrar em contato comigo no Núcleo (F: 3633-2829): 